IZA DP No. 5094

Youth Labour Markets in Europe and Central Asia

Niall O'Higgins

July 2010 


\title{
Youth Labour Markets in Europe and Central Asia
}

\author{
Niall O'Higgins \\ Università di Salerno \\ and IZA
}

\section{Discussion Paper No. 5094}

July 2010

IZA

P.O. Box 7240

53072 Bonn

Germany

Phone: +49-228-3894-0

Fax: +49-228-3894-180

E-mail: iza@iza.org

Any opinions expressed here are those of the author(s) and not those of IZA. Research published in this series may include views on policy, but the institute itself takes no institutional policy positions.

The Institute for the Study of Labor (IZA) in Bonn is a local and virtual international research center and a place of communication between science, politics and business. IZA is an independent nonprofit organization supported by Deutsche Post Foundation. The center is associated with the University of Bonn and offers a stimulating research environment through its international network, workshops and conferences, data service, project support, research visits and doctoral program. IZA engages in (i) original and internationally competitive research in all fields of labor economics, (ii) development of policy concepts, and (iii) dissemination of research results and concepts to the interested public.

IZA Discussion Papers often represent preliminary work and are circulated to encourage discussion. Citation of such a paper should account for its provisional character. A revised version may be available directly from the author. 
IZA Discussion Paper No. 5094

July 2010

ABSTRACT

\section{Youth Labour Markets in Europe and Central Asia}

Transition to the market economy in ECA opened up a range of potential opportunities for young people. It has also raised a series of challenges. Youth unemployment and joblessness have emerged as serious problems with the potentially very high costs. Formal Education and Training systems have been slow to adapt to the changing requirements placed upon them by the rapidly changing industrial structure arising from transition. The damage arising from on the one hand rising expectations and on the other the failure of systems to accommodate these is likely to have long-term consequences. It is important then that countries in ECA support young people in fulfilling their potential. This paper looks at developments in and around the transition of young people from education to work in the ECA region in recent years. The purpose of the paper is to aid understanding of the current situation and to suggest areas where action is most needed and is likely to be most effective. The first section considers developments in the general economic context of relevance to young people. Section 2 goes onto consider the current situation of (and trends in) factors affecting young people's entry into work. Section 3 assesses policies affecting youth employment and unemployment and section concludes identifying key issues and areas where action is needed and where it is likely to be effective.

JEL Classification: I28, J08, J13, J24

Keywords: $\quad$ youth labour markets, Europe and Central Asia, active labour market policies, vocational education and training, joblessness

Corresponding author:

Niall O'Higgins

DiSES

Università di Salerno

Via Ponte Don Melillo

84084 Fisciano (SA)

Italy

E-mail: nohiggins@unisa.it 


\section{LIST OF ACRONYMS}

$\begin{array}{ll}\text { ALMP } & \text { Active Labour Market Program } \\ \text { CoE } & \text { Council of Europe } \\ \text { CIS } & \text { Commonwealth of Independent States } \\ \text { ECA } & \text { Europe and Central Asia Region, World Bank } \\ \text { EPL } & \text { employment protection legislation } \\ \text { EU } & \text { European Union } \\ \text { EU-NMS } & \text { European Union New Member States (Bulgaria, Czech Republic, } \\ & \text { Estonia, Hungary, Latvia, Lithuania, Poland, Romania, Slovakia and } \\ & \text { Slovenia) } \\ \text { FSU } & \text { Former Soviet Union } \\ & \text { (FSU-Eur = Belarus, Moldova, Russia and the Ukraine; FSU-CCA = } \\ & \text { Armenia, Azerbaijan, Georgia, Kazakhstan, Kyrgyzstan, Tajikistan, } \\ & \text { Turkmenistan and Uzbekistan). } \\ \text { GDP } & \text { gross domestic product } \\ \text { ILO } & \text { International Labour Organization } \\ \text { IMF } & \text { International Monetary Fund } \\ \text { IOM } & \text { International Organization for Migration } \\ \text { KILM } & \text { Key Indicators of the Labour Market } \\ \text { MONEE } & \text { Monitoring the human impact of socio-economic change in CEE/CIS and the } \\ & \text { Baltics (UNICEF) } \\ \text { NGO } & \text { nongovernmental organization } \\ \text { OECD } & \text { Organisation for Economic Co-operation and Development } \\ \text { PES } & \text { Public Employment Services } \\ \text { SEE } & \text { South Eastern Europe (for the purposes of this report, Albania, Bosnia \& } \\ & \text { Herzegovina, Croatia, Macedonia, Serbia and Montenegro, Turkey) } \\ \text { UN } & \text { United Nations } \\ \text { UNDP } & \text { United Nations Development Programme } \\ \text { UNICEF } & \text { United Nations Children's Fund } \\ \text { VET } & \text { vocational education and training } \\ \text { WDR } & \text { World Development Report } \\ \text { WHO } & \text { World Health Organization } \\ & \\ & \end{array}$


Transition to the market economy in ECA opened up a range of potential opportunities for young people. It has also raised a series of challenges. Youth unemployment and joblessness have emerged as serious problems with the potentially very high costs. Formal Education and Training systems have been slow to adapt to the changing requirements placed upon them by the rapidly changing industrial structure arising from transition. The damage arising from on the one hand rising expectations and on the other the failure of systems to accommodate these is likely to have long-term consequences. It is important then that countries in ECA support young people in fulfilling their potential.

This paper looks at developments in and around the transition of young people from education to work in the ECA region in recent years. The purpose of the paper is to aid understanding of the current situation and to suggest areas where action is most needed and is likely to be most effective. The first section considers developments in the general economic context of relevance to young people. Section 2 goes onto consider the current situation of (and trends in) factors affecting young people's entry into work. Section 3 assesses policies affecting youth employment and unemployment and section concludes identifying key issues and areas where action is needed and where it is likely to be effective.

\section{General Economic Developments}

It is now firmly established that what happens in young people as they enter the labour market is very much dependent on what is going on in the economy as a whole'. In particular, youth unemployment rates are very closely related to aggregate labour demand. Moreover, labour market regulations and, in particular, labour taxes, minimum wages and employment protection legislation (or the lack thereof) are likely to affect the labour market prospects of young people disproportionately. These issues will be discussed further below, however, any discussion of youth labour markets clearly needs to be prefaced by a discussion of what is happening at the aggregate level. In this section, the general economic and employment situation in ECA is considered.

\subsection{Economic Growth}

Transition to the market brought with it pressures for substantial industrial restructuring which immediately caused recession followed by varying degrees of recovery. Figures 1a-1d report the growth performance in the region separately for the four sub-regions considered here ${ }^{2}$. For all the countries, save nontransition Turkey, the recession following transition and the subsequent recovery is evident. There are however, rather different patterns of recession and recovery across the region. In EU-NMS countries, recession was shorter and for the most part

\footnotetext{
${ }^{1}$ There are many many studies confirming this. For a recent discussion, see World Bank (2006).

${ }^{2}$ Specifically, EU-NMS comprises Bulgaria, Czech Republic, Estonia, Hungary, Latvia, Lithuania, Poland, Romania, Slovakia and Slovenia; SEE comprises Albania, Bosnia \& Herzegovina, Croatia, Macedonia, Serbia \& Montenegro and Turkey; FSU-Eur comprises Belarus, Moldova, Russia and the Ukraine; and, FSU-CCA comprises Armenia, Azerbaijan, Georgia, Kazakhstan, Kyrgyzstan, Tajikistan, Turkmenistan and Uzbekistan.
} 
shallower, so that by 2005, all countries had recovered their 1990 levels of GDP. SEE countries were largely slower to recover. Above-all Serbia and Montenegro ${ }^{3}$, but also Bosnia \& Herzegovina and Macedonia are all still suffering the effects of consequences of internal turmoil and conflict. In the FSU countries, recession was much longer and deeper and relatively few countries have yet recovered their 1990 levels of GDP, however, also here the signs of recovery are clearly visible.

Figures 1a-d - real gdp, 1990=100 - here

\subsection{Employment}

Although recession brought with it also reductions in employment, employment rates fell more gradually than GDP and the subsequent recovery of employment, if it happened at all, was much more modest (fig.s 2a-d). More differences emerge here also between countries and sub-regions. Much depended on the approach to the process of industrial restructuring which accompanied transition. As noted in the recent World Bank report (Rutkowski et al., 2005), the relatively slow decline in the employment rate in many CIS countries was by no means a positive sign in as much as it reflects the maintenance of low productivity jobs.

Figures 2a-d-employment rate trends - here

Compared to EU-15 countries, employment rates in the region are relatively low, despite the partial recovery in employment in some countries. However, there is much variation. Amongst EU-NMS countries, only Slovenia is above the EU-15 average of 65.2\%, although the Czech Republic and Estonia are also very close. At the other end of the scale, Bulgaria, Hungary, Slovakia and above all Poland have employment rates of under $60 \%$. Poland is over 12 percentage points below the EU-15 average and over 17 percentage points away from the Lisbon 2010 target of $70 \%$. It is only relatively recently, since around 2003, that it has started to reap the employment benefits of its strong economic growth performance since the mid 1990s. In SEE, the performance is even worse. The best performing country, Croatia, is still ten percentage points below the EU-15 average, and Macedonia has an employment rate which is little more than $30 \%{ }^{4}$. In the CIS countries, the picture is apparently somewhat better. In FSU-Eur, only Moldova - at $46 \%$ - is really struggling with its employment rate, however, since the situation in the FSU in part reflects low productivity employment rather than a buoyant labour market, the conclusions to be drawn from this are less than encouraging. In Russia and the Ukraine, there are some signs of recovering employment in the very recent period. In FSU-CCA, although employment rates tend to be relatively high, the trend is clearly downwards and reflects the still ongoing process of substantial industrial restructuring linked to

\footnotetext{
3 Although the two countries are now separate entities, until recently they composed a single administrative unit and so for the purposes of statistical reporting, information is generally presented for the two countries as a single entity.

${ }^{4}$ Although here too one might note that information for Macedonia is taken from the ILO's KILM database which reports for this and some of the other countries in the region, employment rates for the $15+$ population which would tend to underestimate slightly the rate in comparison with EU country data based on 15-64 year olds.
} 
transition itself. The exception here is Kazakhstan which, benefiting from oil revenues, has seen increasing employment rates in the new millennium ${ }^{5}$.

Figure 3 - employment rates 2005 - here

\subsection{Labour productivity}

The maintenance of employment levels despite recession in some countries reflects the tendency to keep people on in low productivity jobs: the other element in the employment picture. Whereas even the poorest performing EU-NMS countries have now more than recovered their pre-transition productivity levels (fig. 4a), countries of the former Soviet Union - with the exception of Belarus and Armenia clearly have not. This reflects the slower approach to reform adopted here which involved more maintenance of employment in low productivity employment (fig.s 4cd). SEE lies somewhere in between (fig. 4b). Croatia and particularly Albania have seen sustained productivity growth over the last decade or so, whereas Macedonia and Serbia \& Montenegro are still some way from recovering their pre-transition performance. Turkey displays a pattern more familiar outside the ECA region with a general upward trend in productivity and Bosnia \& Herzegovina's rather peculiar performance reflects the rather particular conditions in that country.

Figures 4a-d here - productivity trends, 1980-2004

As a consequence, the FSU countries lag well behind EU-NMS and some SEE countries in terms of productivity. This is illustrated in figure 5 which reports productivity in the region in 2003 relative to the regional average.

Figure 5 here - GDP per employee, 2003

\subsection{Summary}

The key points regarding aggregate economic performance in the ECA region emerging from this section are:

- Transition implied massive industrial restructuring which brought with it recession followed by recovery.

\footnotetext{
${ }^{5}$ At this point some data issues should be raised. As far as is possible, the attempt has been made to maintain data comparability across countries. However, this has a cost. The figures on trends in employment rates (figures $2 \mathrm{a}-\mathrm{d}$ ) are taken from the Transmonee 2007 database which defines the working age population as 15-59, and consequently reports employment rates for that age-group. The EU standard definition of the working age population (used to construct figure 3) is 15-64 which leads to a significant difference in the rates for 2005 reported in figures 2 and 3 respectively - in EU-NMS countries, for example, employment rates of 60-64 year olds are in the region of 10-20\%. One might also note that the substantial year-on-year variability in the employment rate particularly in some FSUCCA countries (figure $2 \mathrm{~d}$ ) may well be reflecting data reliability problems in addition to substantive trends. Further data issues in the construction of these and subsequent figures are taken up in the notes to the figures themselves.
} 
- Countries and, in particular, sub-regions are distinguished by their approach to transition. EU-NMS countries on the whole adopted a more radical approach to transition with labour shedding being followed by partial recovery in employment levels. FSU countries largely adopted a more protective approach leading to much slower employment losses but also the maintenance of much low productivity employment.

- Nowhere have employment rates regained their pre-transition levels and employment rate remain, for the most part, well below the level of EU15 countries. 


\section{From School to Work}

\subsection{Youth Population}

A large youth cohort represents both a potential problem - jobs have to be found to accommodate them - and a potential asset - a substantial youth population can make a significant contribution to the long-run growth performance of a country. The latter issue was emphasized in the most recent World Development Report (World Bank, 2006a), in its discussion of "windows of opportunity". Specifically, rising incomes are associated with greater longevity as well as falling birth rates. As a result there is a tendency in most parts of the world towards a rise in the average age of the population. This brings with it both potential opportunities and as potential problems. In particular, there is a period in which the overall dependency ratio ${ }^{6}$ tends to fall as large numbers of young people enter the labour market. This is followed by a period in which the dependency ratio is falling before the growing numbers of the elderly in the population cause the dependency ratio to rise once more. As the WDR points out, the period in which per capita labour supply is rising provides an opportunity for enhanced long-run growth. First because the greater (potential) labour supply increases potential output per capita. Second, because a rising share of the working-age population implies an increase in the savings (and consequently investment) rate leading to increased long-term growth. A third element in the equation regards levels of human capital. In an analogous way to investment in physical capital, appropriate investments in the human capital of young people through the education and training systems are likely also to lead to higher rates of long-run growth ${ }^{7}$.

All of these arguments relate to higher long-run growth potential. For the most part, in the short-run the effect of an increased youth population is generally thought to be negative. The larger the youth population the more difficulty labour markets have in accommodating the substantial flux of new entrants which a large youth cohort implies may lead to higher youth unemployment. However, in his analysis of the USA, Robert Shimer (2001) actually found a negative relationship between youth population size and youth unemployment rates. His explanation for this apparently counter-intuitive finding is that labour markets containing substantial numbers of young people are likely to be more flexible than those dominated by older workers and therefore in such markets employers are more willing to create jobs.

Peaking youth populations in several countries in the FSU, and particularly in Central Asia, mean that for them the 'window of opportunity' is currently open ${ }^{8}$. As can be observed from table 1 , the peak in the youth populations

\footnotetext{
${ }^{6}$ That is, the ratio of the non-productive population: the young and the old, to the overall population. How this is actually defined varies according to the definition of the working age population. See, the discussion above in note 2 .

${ }^{7}$ See, for example, Sianesi \& Van Reenen (2003) for a survey of the issue.

${ }^{8}$ Note however that, since dependency ratios depend not just on the size of youth populations but also, in particular, on the size of more elderly age groups, the relationship between the peak in youth relative populations and the 'window of opportunity' associated with falling dependency ratios is not a linear one. Although the peak in the youth population generally occurs during the period in which the dependency ratio is falling much depends also on what happens to older age groups.
} 
in ECA for the most part occurred in the last century. This is true for all EU and SEE countries except Turkey. In the FSU, and particularly in Central Asia, however, the peak in youth populations is occurring now or has occurred recently. It is precisely in the period following this peak that the window of opportunity occurs. It is not at all clear that these countries are in a position to take advantage of the potential that this window represents.

Table 1: Many countries in FSU are just reaching their peak in youth populations

\begin{tabular}{|c|c|c|c|}
\hline & \multirow{2}{*}{$\begin{array}{c}\text { Year of peak in } \\
\text { relative size of youth } \\
\text { population }\end{array}$} & \multicolumn{2}{|c|}{ Average annual growth rate $(\%)$} \\
\hline & & $2005-15$ & $2025-50$ \\
\hline \multicolumn{4}{|l|}{ EU-NMS } \\
\hline Bulgaria & 1970 & -3.6 & -1.4 \\
\hline Czech Republic & 1967 & -2.6 & -0.5 \\
\hline Estonia & 1988 & -3.7 & 0.2 \\
\hline Hungary & 1970 & -1.6 & -0.8 \\
\hline Latvia & 1979 & -4.0 & -0.2 \\
\hline Lithuania & 1983 & -2.7 & 0.1 \\
\hline Poland & 1973 & -3.3 & -0.3 \\
\hline Romania & 1991 & -3.4 & -1.1 \\
\hline Slovakia & 1997 & -2.8 & -0.5 \\
\hline Slovenia & 1994 & -2.9 & -0.7 \\
\hline \multicolumn{4}{|l|}{ SEE } \\
\hline Albania & 1989 & -0.5 & 0.1 \\
\hline Bosnia \& Herzegovina & 1978 & -1.8 & -0.7 \\
\hline Croatia & 1950 & -1.7 & -0.3 \\
\hline Macedonia & 1979 & -1.7 & -0.2 \\
\hline Serbia \& Montenegro & 1998 & -1.8 & -0.5 \\
\hline Turkey & 2020 & 0.4 & -0.3 \\
\hline \multicolumn{4}{|l|}{ FSU-Eur } \\
\hline Belarus & 1977 & -4.3 & -0.6 \\
\hline Moldova & 2002 & -3.6 & -0.3 \\
\hline Russia & 1975 & -4.4 & -0.5 \\
\hline Ukraine & 1976 & -4.0 & -0.9 \\
\hline \multicolumn{4}{|l|}{ FSU-CCA } \\
\hline Armenia & 1980 & -3.0 & 0.2 \\
\hline Azerbaijan & 2007 & -1.3 & 0.7 \\
\hline Georgia & 1977 & -2.6 & -1.0 \\
\hline Kazakhstan & 1977 & -2.5 & -0.2 \\
\hline Kyrgyzstan & 2008 & -0.1 & -0.5 \\
\hline Tajikistan & 2035 & 1.6 & 0.6 \\
\hline Turkmenistan & 2008 & -0.2 & 0.2 \\
\hline Uzbekistan & 2009 & 0.1 & 0.0 \\
\hline
\end{tabular}

Source: Extracted from Lam (2006, appendix B).

Note: Countries reported in blue are those who reached or are about to reach their youth population peaks between 2000 and 2010. Countries peaking after 2010 are reported in red. 
Even where the peak has already occurred, many countries are currently undergoing a relative boom in the numbers of young people in to the population? Figures 6a-d show estimates and projections of young people as a percentage of the total population for the countries in the region over the period 1980-2020. It will be observed that in several countries in EU-NMS and SEE although the highest peak may have been reached some years ago, many countries are currently undergoing, or have recently had, an expansion of the youth populations. As noted above, a substantial youth population represents a potential opportunity for countries to increase output, however this potential needs to be realized through appropriate action in terms of education, training, labour market and general economic development policies.

Figures 6a-d here -youth relative population trends, 1980-2020

In the short-run, there is little evidence to suggest that large youth cohorts cause significant unemployment problems for young people. The argument above largely concerns long-run growth whereas the impact in the short run is more often thought to be negative in that a larger youth labour force will put greater pressure on existing labour market institutions to accommodate them. Recently the impact of the relative size of the youth labour market has been estimated for a variety of countries. Korenman \& Neumark (2000) find an elasticity of the youth unemployment rate to the youth-to-adult population ratio of around 0.5 for OECD countries. O'Higgins (2003) finds elasticities of a similar magnitude for 32 developing and transition countries, however in both cases the size of the effect of the relative size of the youth population is much reduced and/or loses statistical significance when adult employment or unemployment rates are introduced to control for aggregate demand factors. In a recent paper prepared for the WDR2007, Fares et al. (2006) estimate similar models for a range of developing \& transition countries using a variety of specifications. Their main conclusion is that, "there is simply no evidence that large youth cohorts cause greater unemployment problems for the young." (Fares et al., 2006, p. 19). As noted above, Shimer (2001), in his analysis of regional labour markets in the USA, actually finds that the relative size of the youth leads to a fall in unemployment rates. Given that much is likely to depend on how countries handle large increases in new labour market entrants, it is perhaps fairest to say that, whilst concurring with the conclusions of Fares et al., the probable explanation of this finding lies in the variability of the effects of large youth cohorts across countries rather than there being no effect per se. This certainly would merit further investigation.

At the other end of the scale, in all countries in the region, the proportion of the population aged 65 and over is expected to increase significantly in the first quarter of the $21^{\text {st }}$ century ${ }^{10}$. In Bosnia \& Herzegovina the proportion of over- $65 \mathrm{~s}$ is expected to double, and in nine countries in the region - mainly concentrated amongst EU-NMS $^{11}$ - the proportion of over- $65 \mathrm{~s}$ is expected to comprise between one-fifth and one-quarter of the population by 2025 . This emphasizes the urgency of increasing

\footnotetext{
${ }^{9}$ One might speculate that this may be linked to 'optimism' related to the imminent arrival of transition in the late 1980s. Certainly the dates coincide.

${ }^{10}$ Chawla et al. (2007).

${ }^{11}$ Specifically, these are Bulgaria, Czech Republic, Latria, Poland and Slovenia (EU-NMS); Bosnia \& Herzegovina and Croatia (SEE); and, the Ukraine (FSU-Eur).
} 
the quantity and above-all the quality of human capital in the region in order to increase productivity and so overcome potential constraints to growth implied by the rapidly ageing populations in the region ${ }^{12}$.

\subsubsection{Youth Migration}

In the context of the emergence of significant problems for young people in finding employment which arose with the transition to the market, emigration became a fairly common coping strategy for young people. The extent to which this occurred, and is occurring, varied much across countries, but clearly youth migration and above-all emigration is a significant part of the picture of young people in the labour markets in ECA following transition. In Moldova for example, official estimates suggest 234,000 citizens are working abroad. However, unofficial estimates range from between 600,000 to $1,000,000$ or somewhere in the range of $15-30 \%$ of the population ${ }^{13}$. Emigration has positive and negative effects; however, inasmuch as long term emigration is largely associated with the more educated, with those with lower levels of education mainly being involved in short-term and/or seasonal migration, the phenomenon implies a significant brain drain effect. Moreover, it has also been suggested that even the positive effects of remittances on the sending country's populations whilst providing much needed income support does not promote the longrun growth prospects of the country.

\subsection{Labour Force Participation}

The labour force participation of young people has been falling throughout the region since transition. Figures 5a-d report labour force participation rates of 15-24 year olds before and after transition. It will be observed that in the EU countries, there was already a tendency towards lower labour force participation amongst young people during the 1980s. With some variation, this became a much steeper decline in the period immediately following the initiation of transition and has tended to level off in the new millennium. There is some significant variation in the pattern; Slovenia's fall in participation was particularly rapid presumably due to the war in Yugoslavia. On the other hand, the steep decline in labour force participation amongst Lithuanian youth did not occur until the second half of the 1990s and only since 2002 is it showing signs of leveling off. In SEE the pattern is slightly different. Bosnia \& Herzegovina and Serbia \& Montenegro had substantial drop in participation between 1990 and 1991, again attributable to the war, with a subsequent slight increase. In Bosnia' case the drop in participation followed a period of increasing participation during the 1980s. In the other countries, labour force participation rates had been more or less constant during the 1980s with a relatively gradual fall discernable after 1989. Macedonia's participation rates fell substantially in the second half of the 1990s and early 2000s. Turkey, as one might expect does not really fit any of these patterns, showing a variable but clear downward trend over the whole period.

\footnotetext{
${ }^{12}$ The centrality of productivity growth in raising per capita incomes in the context of ageing populations is also emphasised by World Bank (forthcoming).

${ }^{13}$ La Cava et al. (2005).
} 


\section{Figures 7a-d here - Labour force participation rates young people}

In the case of European CIS countries, falling youth labour force participation is discernable well before 1989. Indeed there were some signs of it leveling off following transition. In particular, in Moldova, the participation rate of young people fell hardly at all between 1991 and 2005. In Russia there a rapid decline between 1990 and 1992 and more gradual fall subsequently. In CCA, the pattern is somewhat varied. Across the region there was a fairly substantial drop in participation between 1990 and 1992. Two countries, Georgia and Tajikistan show a fairly constant decline over the 2 decades leading up to the new millennium. The other countries, with the exception of Armenia ${ }^{14}$, demonstrate very modest declines in participation over the quarter century.

The participation of rates of young women has fallen more than for young men since transition. The labour force participation rates by sex reported in figures $8 \mathrm{a}-\mathrm{d}$ and 9a-d suggest that although there are significant differences in the patterns observable across countries, one striking feature emerging is the overall similarity in general trends in the labour force participation of young men and young women. However, very clearly the variability and in particular the general reductions in participation rates are much more marked for young women than young men throughout the ECA region.

\section{Figures $8 a-d \&$ 9a-d here}

\subsection{Educational Participation \& Attainment}

Falling youth labour force participation may be attributed to two principal causes $^{15}$, one far more positive than the other. Young people may abstain from labour market participation either because they are participating in education or because they are in some sense 'discouraged' from participating. Although both may be related to lack of immediate labour market opportunities, clearly participation in education is likely to produce more longer run benefits both for young people and society as a whole than is non-participation in either education or the labour market. In the context of rapidly ageing populations such as are found throughout the ECA region, raising levels of human capital may be a key element in a strategy to combat in promoting income growth and combat poverty. A simple exercise taken from the ECA Chief Economist's report (World Bank, forthcoming) helps to make this clear. Elementary algebra tells us that:

$$
\frac{G D P}{P O P}=\left(\frac{G D P}{E M P}\right) \times\left(\frac{E M P}{\text { WorkingAgePOP }}\right) \times\left(\frac{\text { WorkingAgePOP }}{P O P}\right)
$$

\footnotetext{
${ }^{14}$ As noted in the notes to the figure, many observations in the figures are interpolated. This explains, in particular the rather odd picture emerging for Armenia which should be considered (relatively) reliable until after 1997 when labour force participation rates had become very low.

${ }^{15}$ There is a third affecting principally young women - withdrawal from the labour market due to maternity (or, in principal at least, paternity). This is unlikely to be a major factor here since the age of first birth has been rising across the ECA region.
} 
The first term is productivity, the second the employment rate and the third is the inverse of the dependency ratio. Clearly if the final term is falling, as is the case in most ECA countries, in order to maintain growth in per capita incomes, productivity and/or the employment rate must be raised. There are clear limits to the extent to, and speed at, which the employment rate can by increased, this is less the case with labour productivity. Improving the quantity, quality and relevance of human capital is thus a key means to promote the growth of per capita income and so combat poverty. As Chawla et al. (2007) note this should involve the development of lifelong learning, thusfar largely absent in the ECA region, but the mainspring must be the development of the human capital levels of young people.

Thus educational participation and, above-all, attainment are key areas of concern. This section looks at this issue, whilst the following section will raise issues to do with youth unemployment and joblessness.

In EU countries, the need to raise human capital levels amongst young people is well recognized and has been one of the central elements of the EU's European Employment Strategy. In practical terms this has meant inter alia establishing targets for the more or less universal completion of secondary education. Specifically, the Lisbon targets for education are that by 2010 at least $85 \%$ of 22 year olds should have completed upper secondary education ${ }^{16}$ and that by the same date, early school leaving, measured by the percentage of 18-24 years olds having achieved lower secondary education or less, should stand at no more than $\mathbf{1 0 \%}$. Figures 10 and 11 report information on these completion and dropout rates for a range of countries in the region.

\section{Figures 10 \& 11 here}

For the most part the EU-NMS countries compare favorably to the rest of the EU and several have already achieved the Lisbon targets. Even Romania, the poorest performer amongst EU-NMS countries is still above the average of EU-15 countries. A similar picture emerges for the FSU, although Moldova and Tajikistan are lagging behind the other countries. On the other hand, in SEE there are clearly serious problems of educational completion and dropout. With the exception of Croatia, which has already attained both targets, problems are evident in all countries. Particularly in Albania and Turkey, and to a lesser extent Macedonia, there is a huge gap between current educational attainment and the Lisbon target. In Albania and Turkey the majority of young people (18-24) have not completed secondary education.

Turning to educational attainment by gender (figure 12), one may observe that in most countries the educational attainment of young women is significantly better than that of young men. The exceptions to this occur largely in SEE. In Albania, Macedonia and Turkey, young women fare significantly, and in Bosnia \& Herzegovina slightly, worse than young men in terms of educational performance. To the extent that Albania, Macedonia and Turkey, as well as Tajikistan in the FSU, are the countries which have a lowest level of educational attainment overall, and the

\footnotetext{
${ }^{16}$ For practical purposes, the statistic which is reported by Eurostat inter alia is the percentage of 20-24 year olds who have completed secondary education.
} 
gender disparities are particularly worrying. That is, for the most part, the ECA region performs relatively well in terms of educational attainment overall as compared with the EU-15. The few countries which do not perform well overall, however, are also those where young women do poorly in terms of their educational attainment as compared to young men, thus compounding their disadvantage.

\section{Figure 12 here}

In contrast, if one looks at differences between urban and rural areas (figure 13), educational attainment is universally and often significantly worse in rural areas. There does not seem to be strong differences across regions, however, it does appear that again the countries which perform less well overall, are also those which have the highest urban-rural differentials in performance.

\section{Figure 13 here}

Participation in secondary education is on the increase throughout almost the entire ECA region with significantly higher participation rates in EU-NMS than in the rest of the region. Participation rates in most countries in other parts of the region are increasing although they are often not back to the 1989 rates, particularly in the FSU-CCA. Figures 14a-d report trends in gross secondary enrollment rates for the region. From these trends, it can be observed that, in the EUNMS, falling labour force participation occurred concurrently with a generally rising trend in participation in secondary education, although in some cases, there was a fairly significant fall between 1989 and 1992. In SEE, Croatia and Macedonia follow the generally rising trend in educational participation observed in the EU-NMS countries, whilst Albania had a fairly substantial fall in the first half of the 1990s but has been increasing since 1999. Bosnia \& Herzegovina and Serbia \& Montenegro show rather less encouraging trends. Although the data are rather patchy, there does appear to a downward trend in educational participation in these countries in the new millennium. With the exception of Moldova, the European CIS countries essentially show a small fall in secondary educational participation after 1989 with a gradual recovery since the early 1990 s so that by 2005 , the gross secondary enrollment rates were comparable to those of 1989. Moldova on the other hand had substantial falls particularly during early transition which were not recovered subsequently although one might wonder also here the extent to which this is due to unregistered emigration affecting the denominator ${ }^{17}$. In the non-European CIS countries, secondary education participation rates have been increasing since the beginning of the new millennium in all countries except Tajikistan and Turkmenistan. Despite the recent increases in participation in most of these countries, however, participation rates in this sub-region are not back to the 1989 levels.

Figures 14a-d here - gross enrollment rates, secondary education 1989-2005

\footnotetext{
${ }^{17}$ To be more explicit, in Albania and Moldova, there were fairly large movements out of the country particularly in the early 1990s which may not be fully recognized in the population estimates which act as the denominator of these enrolment rates. Figures for actual enrolment are, on the other hand, being based on school records, are likely to be more accurate.
} 
In contrast, enrollment rates in tertiary education have generally been increasing throughout the ECA region although at varying rates (fig.s 15a-d). With the exception of some countries in FSU-CCA, and most notably Turkmenistan where the gross tertiary participation rate has fallen from around $10 \%$ to less than $5 \%$ over the period, participation has increased in ECA, particularly since the second half of the 1990s. The increase was much more marked in EU-NMS countries which has actually meant that the gap between tertiary enrollment in EU-NMS countries and the rest of the ECA region has widened. In Slovenia, for example, enrollment in education is close to universal right through to the tertiary level ${ }^{18}$. At the other end of the scale, less than $10 \%$ of 18-24 year olds are enrolled in tertiary education in Turkmenistan and Uzbekistan.

\section{Figures 15a-d here - gross enrollment rates, tertiary education 1989-2005}

A further important and related issue regards the extent to which educational participation is converted into educational attainment and more precisely, the extent to which participation in education leads to the acquisition of useful skills: the quality and relevance of education. Many studies and results from international tests, such as TIMMS and PISA ${ }^{19}$, have highlighted concerns about the quality and relevance of education in ECA countries, including the quality of inputs as well as the quality of learning outcomes for students ${ }^{20}$.This is an issue of increasing concern for countries in the ECA region. The results of these studies over time are rather mixed for the countries in ECA. In terms of literacy skills, Russia seems to have seen a significant fall in the performance of students according to the PISA study between 2000 and 2003. Most of the other ECA countries included (save Latvia which has improved) have shown no significant difference between 2000 and 2003. The TIMSS study also shows a small fall in performance in mathematics of Russian students between 1995 and 2003. A similar fall is observable also in Slovakia, whilst other, mainly EU-NMS, countries show no significant difference in mean performance between 1995 and 2003.

Beyond the modest decline in FSU in terms of mean performance, analyses of the issue have emphasized the widening gaps in opportunities. La Cava \& Michael (2006) have reported widening gaps in different areas of the Russian Federation pinpointing problems of access to, and low standards and poor teacher quality in, education particularly in the poorer areas of the Northern Caucasus. Problems concerning educational quality have also been identified in South Eastern Europe ${ }^{21}$ which support the evidence presented in figures 10-13 above.

Although not of direct relevance to the 'youth' age-group it is worth noting that although primary school enrollment is nearly universal in most of the ECA region, there is an emerging problem of out of school children, particularly in the

\footnotetext{
${ }^{18}$ Although that it might be observed that this is not necessarily ideal. In Slovenia, tax incentives for student employment mean that many young Slovenians delay completion of their studies and remain in education well beyond 25 in order to take advantage of these benefits.

${ }^{19}$ These studies measure literacy mathematics and science skills in $4^{\text {th }}$ and $8^{\text {th }}$ grade students (TIMSS) and in 15/16 year olds (PISA). Brown \& Micklewright (2004) discuss inter alia the extent to which these surveys are comparable.

${ }^{20}$ See, in particular, Alam et al. (2005) for a good discussion of the declining quality of education in ECA. Also see TIMMS and PISA web sites for results from these international tests.

${ }^{21}$ La Cava et al. (2005).
} 
FSU. In Uzbekistan and Tajikistan around one in five children of primary age are not in school. In Bosnia \& Herzegovina there is also a significant problem with nearly $14 \%$ of primary age children not attending school ${ }^{22}$. In Turkey, primary school enrollment has increased significantly since the 1997 reforms but 10 percent of school-age children are still not enrolled in primary school. Clearly this is storing up problems for the future youth of these countries.

Returns to education have also increased throughout the region since transition began although they remain low compared to EU-15 countries. The increase in returns is largely a fairly natural consequence of the move to market-based economies and reflects differing skills premiums. Returns to education also seem to have grown faster in countries which reformed their economies more quickly ${ }^{23}$. In the current context, however, the widening gaps between those with more and less education reinforcing the picture of emerging structural inequalities in the education system.

\subsection{Youth Unemployment \& Joblessness}

Whilst youth unemployment is strongly influenced by aggregate economic factors, there is significant room to affect youth labour market problems more directly with youth-oriented policies. This section throws some light on this by looking specifically at indicators of the youth labour market situation

\subsubsection{Youth unemployment Rates}

The principal (and most widely available) indicator of difficulties young people face in the labour market is the youth unemployment rate. Figures 14a-d report youth unemployment rates for separately for the four sub-regions considered here. Several observations are in order:

- Youth unemployment rates are very high in the region - amongst EU countries, although falling in both countries, Poland has a youth unemployment rate of close to $40 \%$ whilst in Slovakia the rate remains a little under $30 \%$. As a whole, the ten new EU member states of the EU in 2005 had an average youth unemployment rate of $30.4 \%$ which is almost twice that of the EU-15 average of $16.7 \%^{24}$. In SEE, Macedonia and Serbia \& Montenegro have youth unemployment rates which have oscillated in recent times between $60 \%$ and $70 \%$. In the European CIS countries, youth unemployment rates are significantly lower. In 2005 these varied between $15 \%$ in Ukraine and $18.8 \%$ in Moldova. In the CCA countries, there is substantial variation in rates with Armenia hovering around a rate of $60 \%{ }^{25}$.

\footnotetext{
${ }^{22}$ UNESCO (2005).

${ }^{23}$ Yemtsov et al. (2006).

${ }^{24}$ European Commission (2006).

${ }^{25}$ There is also, despite attempts to maintain comparability, variation in the definitions and reliability of the figures. This particularly affects the figures form Armenia.
} 
- Youth unemployment rates closely mirror adult unemployment rates $^{26}$ and, inversely, aggregate employment rates (see figures 2a-d). The relationship to GDP growth is also evident albeit less obvious. The EU-NMS countries which returned to the pre-transition level of GDP most quickly, Poland and Slovakia, also have the highest youth unemployment rates. This is due largely to the nature of the transition process in the EU-NMS in general, but which was most marked in these two countries. Economic restructuring meant that the economic recovery during the 1990s translated into increased productivity and falling aggregate employment. However, since 2000 in Slovakia and 2002 in Poland when economic growth accelerated, youth unemployment rates have also started to fall significantly. Moreover, the countries with the best recent growth record, along with Slovenia which has maintained consistent rates of economic growth since 1994, are the countries with the lowest rates of youth unemployment.

- (relatively) low youth unemployment rates in European (and some nonEuropean) CIS countries reflect the different approach in CIS to the negative labour demand shock in the early 1990s. Specifically, in CIS countries, the primary response was through wage not employment adjustment (Boeri \& Terrell, 2002, Rutkowski, 2006). Particularly, but not only, in these countries youth unemployment rates are a rather limited indicator of youth labour market difficulties.

Figures 16a-d here - youth unemployment rates, 1992-2005

\subsubsection{Ratio of Youth - to - Adult Unemployment Rates}

An indicator of the relative difficulties that young people face in the labour market is provided by the ratio of unemployment rates of young people $\boldsymbol{v} \boldsymbol{v}$ - $\grave{a}$-vis those of adults. Taking as given that youth unemployment closely mirrors that of adults, this indicator illustrates differences across countries (and, in principal, across time) in the relative position of young people. Figure 15 reports this ratio for a range of countries in the region. Again several observations are in order:

- there is much variability across countries in the region, but in general, the ratio of youth to adult unemployment rates is significantly higher in EU and SEE than it is in CIS countries. Amongst the new EU member states, the average in 2005 was 2.5 compared to 2.3 for EU-15 countries $^{27}$. With the exception of Moldova, CIS countries (for which data is available) all have a youth-adult ratio which is at or below the EU-15 average.

- The ratio bears no relation to the youth unemployment rate per se. Hungary and Romania, with their relatively low rates of youth unemployment have the highest youth-adult ratio amongst the EU countries. At the other end of the spectrum as regards the youth-adult ratio, Latvia also has a relatively low rate of youth unemployment. Similarly, in SEE, the lowest youth-adult

\footnotetext{
${ }^{26}$ For comparable figures on aggregate unemployment rates see, for example, Rutkowski (2006).

${ }^{27}$ Author's calculations based on European Commission (2006).
} 
ratios are to be found in the countries with the lowest (Albania) and the highest (Macedonia) youth unemployment rates.

- From figure 18 one can see that in many countries the situation of youth vis-àvis adults is getting worse - particularly in FSU countries. Also in several EUNMS countries, young people seem to face greater difficulties now than they did in the mid 1990s, above-all in Estonia and Hungary.

Figure 17 \& 18 here -youth (15-24) and adult (25-54) unemployment rates and ratio of youth (15-24) to adult (25-54) unemployment rates over time

This supports the idea that although youth unemployment is influenced by aggregate economic factors, there is significant room to affect youth labour market problems more directly with youth-oriented policies.

\subsubsection{Youth Joblessness}

The extent to which the youth unemployment rate is an adequate indicator of youth labour market problems has increasingly been questioned over the last decade or $\mathbf{s o}^{28}$. Specifically, attention has begun to focus on discouraged young workers who are excluded from youth unemployment statistics. That is, young people who are neither in education or employment and who are not actively searching for work. How this group is defined varies - although it might be argued that it should include only those who are not searching for work because they know or believe that acceptable employment is not available, leading to the 'broad' or 'relaxed' ILO unemployment rate - in practice, it more usually includes all those who are not in education or employment ${ }^{29}$. In other words young people who are not engaged in a 'useful' or 'productive' activity ${ }^{30}$, the jobless youth. In order to facilitate the discussion below the it is worth stating the simple formulas for the youth unemployment and jobless rates explicitly:

YouthUnemployment Rate $\equiv \frac{\text { no.of young people who are unemployed }}{\text { no.of young people in thelabor market }}$

Youth Jobless Rate $\equiv \frac{\text { no.of young people who not employed or in education }}{\text { no.of young people }}$

\footnotetext{
${ }^{28}$ See, for example, Bowers et al. (1999), Fares et al. (2006), ILO (2006), Kolev \& Saget (2005), O'Higgins (1997, 2001 \& 2003), Ryan (2003) and World Bank (2006).

${ }^{29}$ In their exhaustive paper on youth labour market disadvantage in South East Europe, Kolev \& Saget (2005) report, in addition to the more standard indicators, both the broad ILO unemployment rate and the youth joblessness rate.

${ }^{30}$ For the purposes of this paper, I will sidestep the rather more difficult issue of whether teenage "home-making" and parenthood is a 'useful' activity by noting that throughout the region the age of both marriage and first pregnancy is on the increase throughout the ECA region.
} 
Clearly the difference in the indicators lies in the differences in both numerator and denominator of the expressions. Specifically, the numerator and denominator are both larger in the case of the jobless rate ${ }^{31}$; all those who are unemployed are by definition not in education or employment, but the latter also includes those not seeking work. Similarly not all young people participate in the labour market either because they participate in education or for some other reason do not actively search for work. The consequence is that the jobless rate may be bigger (or smaller) than the unemployment rate according to whether the proportion of the inactive population, as traditionally defined, which does not participate in education is greater (or less than) the proportion of the active population who are unemployed ${ }^{32}$. In other words, other things being equal, the higher the educational participation rate, the lower will be the jobless rate vis-à-vis the unemployment rate.

The jobless rate is a useful indicator because:

a)

it includes all those young people who are not in some sort of 'productive' or 'useful' activity - specifically it includes a potentially substantial group of people who are not actively seeking work but would do so if conditions in the labour market improved. Arguably it is precisely the discouraged young people who are most in need of intervention in terms of education, training and/or Active Labour Market Policies in order to prevent them from becoming entirely detached from the labour market; and,

b) it gives a sense of the size of youth labour market problems in relation to the youth population as a whole. It is perfectly possible for youth unemployment rates to be very high but, if labour force participation is very low, to affect only a very small proportion of the youth population. The youth jobless rate is an indicator of the incidence of youth labour market problems amongst young people as a whole ${ }^{33}$.

\footnotetext{
${ }^{31}$ Strictly speaking, the numerator and denominator respectively of the jobless rate are actually "greater than or equal to" those of the youth unemployment rate, however, for them to be equal, all those not in employment would have to actively seeking work and no young people would participate in education. Conditions which will never be satisfied in practice.

${ }^{32}$ It is a matter of elementary algebra that, $\left.\left.\frac{a+b}{c+d}\right\rangle \frac{a}{c} \Leftrightarrow \frac{b}{d}\right\rangle \frac{a}{c}$. If a stands for the unemployed, $\mathrm{b}$ the

number of those who are neither employed, (ILO) unemployed, or in education, $\mathrm{c}$ the size of the labour force, and d stands for the population not in the labour force, then we have the condition stated in the text.

${ }^{33}$ Thus, for example, if almost all young people continue in education until they are 24 , then even if the youth unemployment rate is very high, the youth jobless rate will be low. One might argue consequently that this is not strictly speaking an indicator of 'labour market' problems amongst young people. The debate is ongoing. I would argue that it is, at the very least, a useful additional indicator of youth labour market problems - or possibly more accurately school-to-work transition problems - for the reasons given above. Precisely this type of reasoning has lead the European Commission to include the youth unemployment ratio (i.e. youth unemployment narrowly defined as a percentage of the youth population) in addition to the youth unemployment rate amongst the standard indicators reported in its Employment in Europe annual reports.
} 
c) Comparison of youth jobless rates with youth unemployment rates also help in the interpretation of the employment adjustment process and consequently throw further light on cross-country differences in youth unemployment rates.

Information on the rate of youth joblessness is less widely reported than the youth unemployment rate although it is collected as a matter of course in labour force and/or household surveys. Figure 19 reports the youth unemployment and jobless rates across the region for the countries where data is available.

\section{Figure 19 here - youth unemployment and jobless rates}

Once more, comment is in order:

- The rate of youth joblessness is very high. Particularly in SEE, the rate of joblessness has reached worrying levels. In Albania, Bosnia \& Herzegovinia, Turkey, Ukraine, Armenia and Tajikistan, between one-in-two and one-inthree young people are neither in education or employment.

- Youth unemployment rates and youth jobless rates are fairly closely correlated, countries with high rates of youth unemployment tend to also have high rates of youth joblessness ${ }^{34}$. However there are some important differences which emerge from looking at the two indicators, and, in particular looking at countries where the two rates diverge strongly. In Poland, and to some extent in Bosnia \& Herzegovina, Serbia, Armenia and Croatia, youth unemployment rates are both very high and also significantly bigger than youth jobless rates. In Poland, although the youth unemployment rate is very high, given the relatively high level of educational participation, the proportion of young people who are neither in education nor employment is similar to other EU-NMS countries, such as Estonia, Hungary, Latvia and Lithuania which have youth unemployment rates which are around half the rate in Poland - youth unemployment is high in Poland but joblessness affects around the same proportion of young people as it does in neighboring countries.

- Youth joblessness is clearly related to poor educational attainment (figure 19), although the correlation is weaker (and somewhat different) in FSU-CCA countries $^{35}$. Moreover, countries which have a jobless rate which is much larger than the unemployment rate tend to be those which have low levels of educational participation and high levels of school dropout, for example, Albania, Turkey, Moldova and Tajikistan. In this context it might be observed that the relatively low rates of unemployment observable in Moldova and Ukraine are complemented by relatively high rates of youth joblessness. The implication is that in these countries, failure to find employment is accompanied by labour market withdrawal rather than by the active search for

\footnotetext{
${ }^{34}$ The simple correlation coefficient is .52-close but not that close.

${ }^{35}$ Here the simple correlation coefficient is .54 - roughly similar to the correlation between youth joblessness and unemployment. However, if one excludes FSU-CCA countries, the correlation increases to $.66-$ a much closer relationship.
} 
work. One may also observe in figure 20 presented below that Ukraine and Moldova are two rather exceptional countries in that, in these countries, obtaining a secondary education does not appear to significantly improve the chances of finding employment.

\section{Figure 20 here - youth jobless and secondary non-completion rates}

- Youth joblessness appears also to be positively related to the size of the informal sector in a country. Figure 21 plots the rate of joblessness against the extent of the informal sector (measured by the share in GDP accounted for by the informal sector) in countries of ECA for which data is available. The relationship is clearly positive albeit not very strong. There are many reasons why one should interpret this figure with care ${ }^{36}$, however, it is suggestive and might be a fruitful area for further investigation ${ }^{37}$.

Figure 21 here - Jobless rates versus the informal sector

\subsubsection{The duration of the School to Work Transition}

The incidence of youth labour market problems, as measured by either the youth unemployment or jobless rates ${ }^{38}$ provides a somewhat incomplete picture. A second general issue concerns the length of time it takes to move from education to employment. A high incidence of youth joblessness tells us that a large proportion of young people are neither in education or employment, however, this could be the result of two rather different phenomena ${ }^{39}$. It could be that all young people face a relatively short period of joblessness on leaving education ${ }^{40}$ or alternatively a relatively small number of young people become jobless but those that do remain so for extended periods of time. Clearly the policy implications of the two phenomena are very different. In the first case, the situation may not be considered very serious and if policy intervention is felt to be necessary, it may well be sufficient to improve job-matching services - Job search assistance (JSA) as it is commonly called. In the latter more structural intervention seeking to alter the characteristics of either the demand for or supply of young people's labour (or both) may be called for.

Considerations of this sort have lead the OECD and, to some extent, other international agencies, to include measures of the duration of the 'transition from School-to-Work'. However, the measurement of this phenomenon is fraught with difficulty. The most common (and simplest to implement) measure uses cross-section

\footnotetext{
${ }^{36}$ There are a series of uncertainties regarding the data underlying the figure, the measurement of both joblessness and the informal sector are subject to error. Moreover, it does not demonstrate a causal relation between the two phenomena. Indeed it is rather more likely that other factors lead to both higher youth joblessness AND a larger informal sector.

${ }^{37}$ Especially when considered in conjunction with table 2 below which considers the relation between strictness of EPL, effectiveness of enforcement (as measured by the size of the informal sector), and youth unemployment and joblessness.

${ }^{38}$ Or indeed by other indicators such as the number of discouraged young workers.

${ }^{39}$ Very obviously these are not mutually exclusive. Their juxtaposition here as polar cases serves to make the basic point.

${ }^{40}$ Or alternatively a series of short periods of joblessness (and employment) as they search for a good match on the labour market.
} 
information such as that found in labour force (or household) surveys to estimate the median age of school-leaving and compare this with an estimate of the median age of entry into employment. O'Higgins (forthcoming) discusses this in some detail, however, for now it is sufficient to note that cross-section measures: a) inevitably overestimate the duration of the transition; and, b) the extent of the error varies with the characteristics of the process of labour market entry, whilst measures based on the duration of transition as actually reported by individuals: a) are subject to a downward bias because they are based on completed durations (at the time of the survey); b) given their retrospective nature, concern transitions undertaken over an extended period of time, not those taking place 'now'; and, c) are subject to bias due to recall error. The solution proposed in the cited paper essentially involves turning the provble on its head and looking at the percentage of young people who have completed the transition within a given time period - in a similar way in which discussions of the duration of unemployment are more usually based these days on discussion of the incidence of 'long-term' unemployment.

In any event, relatively little evidence exists on the duration of transition in ECA countries. However there are one or two exceptions. Recent studies of the School-to-Work Transition in Georgia (Rosati et al., 2006) and in Serbia and the Ukraine (ETF, forthcoming) both include measures of the duration of the transition. The Georgia study uses the OECD cross-section indicator based on the estimated median school-leaving and employment entry dates as well as slightly modified indicator developed in Guarcello et al. (2005) which estimates the mean schoolleaving and employment entry dates correcting for those who never enter the labour market ${ }^{41}$. Both of these produce estimates of duration which are very substantial according to the results reported it takes just under 4 years for young men and between 9 and 11 years for young women to complete the transition, however, the nature of the indicators used will overestimate both the duration of the transition and the relative difference in durations between young men and young women, given their differing degrees of attachment to the labour market ${ }^{42}$.

For Serbia and the Ukraine, information on actual durations is available which allows a more accurate indication of the time taken to find a job on leaving full-time education. The table distinguishes between time to first job and time to first significant job. The latter simply implies employment which lasts at least six months. It is very clear that the durations experienced in Serbia and Ukraine are much shorter than those measured in the alternative way in Georgia. The median duration to the first job is under six months for both young men and young women in Ukraine, under one year for young men in Serbia and just over one year for young women in that

\footnotetext{
${ }^{41}$ The characteristics of this indicator are also considered in O'Higgins (forthcoming). Essentially it produces very similar results to a 'OECD difference in medians' indicator adjusted for non-labour market entry.

${ }^{42}$ Essentially the difference between the sexes in the overestimate of the duration arises because of differences in the labour market attachment of young men and young women. Apart from being based on means (as opposed to medians), the more sophisticated indicator correcting for non-labour market entry still assumes that there is no exit from employment once obtained (as does the 'modified' OECD indicator considered by O'Higgins, forthcoming). So the longer duration observed for women is likely to be due in part to the greater overestimate of their duration due to the indictor used as well as to their greater effective difficulties in labour market entry. Unfortunately, although the results from Serbia and Ukraine are indicative, without further information, it is impossible to distinguish between the two effects.
} 
country. In both Serbia and Ukraine, the duration of the transition is longer for young women than young men, although the difference is much less pronounced than that found in Georgia (with the different indicator). Whether the shorter transition duration is a positive reflection on the Ukrainian youth labour market is a more complex issue. Social safety nets are better developed in Serbia than in the Ukraine and so the longer duration in Serbia is likely to reflect this. Whether this is a positive or negative reflection on the transition process is more complicated and will depend on the quality of the job match once found.

Overall one may conclude that in both countries the transition process does not take too long for most young people in either country. The main concern here should be with the minority who do not manage to effect the transition within a reasonable period of time. Over $30 \%$ of young people (and nearly $40 \%$ of young women) in Serbia and nearly one-fifth of young people (just over one-fifth of young women) in the Ukraine had not found any job within 2 years of leaving school. This certainly is cause for concern.

Table 2: Duration of the School-to-Work Transition in Serbia (2006) and The Ukraine (2007).

\begin{tabular}{|l|c|c|c|c|c|c|}
\hline & \multicolumn{3}{|c|}{ Serbia } & \multicolumn{3}{|c|}{ Ukraine } \\
\hline \% of young people who have found: & All & Men & Women & All & Men & Women \\
\hline Any job & & & & & & \\
\hline - within six months & 39.0 & 40.8 & 37.4 & 67.8 & 72.0 & 64.0 \\
\hline - within one year & 50.4 & 53.1 & 48.0 & 74.5 & 79.0 & 70.4 \\
\hline First significant job & & & & & & \\
\hline - within six months & 32.8 & 32.3 & 33.4 & 59.7 & 63.2 & 56.6 \\
\hline - within one year & 42.9 & 43.1 & 42.8 & 66.1 & 69.6 & 63.0 \\
\hline & & & & & & \\
\hline & & & & & & \\
\hline
\end{tabular}

Source: Calculated from ETF (forthcoming, tables 3.1 \& 3.2).

\subsubsection{Which young people are most affected? Who are the "disadvantaged youth"?}

Youth unemployment and more generally labour market difficulties are obviously not spread evenly amongst young people. Increasingly it is recognized that attention needs to be focused on young people who face the greatest difficulties in their labour market entry ${ }^{43}$. It is worth considering several characteristics which might be associated with labour market disadvantage:

- Young Women -Almost invariably, young women in the ECA region have jobless rates which are higher than young men's (figure 22). In some cases the difference is very substantial. In Turkey, young women are more than three times as likely to be jobless than young men; in Azerbaijan and Tajikistan they are about twice as likely. In several other countries, Hungary, Latvia, Albania

\footnotetext{
${ }^{43}$ See, for example, Bowers et al. (1999), Godfrey (2003), OECD (2003), O’Higgins (2001) and Quintini \& Martin (2006).
} 
and Kazakhstan, the jobless rate for young women is around $50 \%$ higher than for young men. Clearly in part, this reflects the lower labour force participation rates of young women particularly in countries with the lower levels of (above-all female) educational participation and attainment. It may be observed in passing that the ratio of female to male youth jobless rates bears no relation to the youth unemployment rate per se. Only in Serbia, Moldova and Russia are the jobless rates for young men higher than for young women.

\section{Figure 22 here-male and female youth jobless rates}

- Ethnic Minorities and other marginalized groups- data on the unemployment of minorities is fairly thin on the ground, however, Kolev \& Saget (2005) report that both youth unemployment and jobless rates are roughly twice as high for Roma - the most disadvantaged ethnic group in the region - than for young people as a whole in Bulgaria and Kosovo ${ }^{44}$. In Romania this is true for the jobless rate but not for open youth unemployment. La Cava \& Michael (2006) find a similar disadvantage for Muslim young people in the North Caucasus republics of the Russian federation. In Chechnya, young people are more than five times as likely to be jobless than in the Russian federation as a whole. In Ingushetia, the figure is seven times. Another dimension of disadvantage is observable regarding rural youth in some countries. The picture varies across the region, however, rural youth often face greater jobless rates than their urban counterparts. Figure 21 reports youth jobless rates by urban and rural areas. In most countries, the youth jobless rate is higher in rural than in urban areas. In some cases there is a substantial difference. In Bulgaria, Hungary and Russia, the rural youth jobless rate is nearly twice the urban rate. There are some exceptions, in particular in Serbia, Turkey and the Ukraine, as well as in Lithuania and Romania where however the difference is much less marked, the jobless rate amongst urban youth is higher than the rural rate. Inasmuch as one would expect the underemployment of young people (as with adults) to be higher in rural areas, if information on the underemployment of young people were systematically collected for young people in urban and rural areas, this would in all probability further reinforce the picture of disadvantaged rural youth. Kolev \& Saget (2005) also point to the additional labour market disadvantages faced by disabled young people.

\section{Figure 23 here - urban and rural youth jobless rates}

- Education \& Skills - low and/or inappropriate education and skills levels are the key characteristic determining the difference between success and failure of young people on the labour market. This will be returned to below, however, it is worth noting here the rising employment and wage

\footnotetext{
${ }^{44}$ Although it might be observed that here the disadvantage reflects more the general disadvantage of Roma as a whole rather than a specific disadvantage of Roma youth. Ivanov et al. (2006) show that whilst Roma as a whole have much higher unemployment rates (and much lower wages) than their majority counterparts, young Roma do not face significant additional disadvantages. The unemployment rates of young Roma are less than one and a half times those of adults - less even than Latvia considered above.
} 
differentials between more and less educated young people which have emerged across the region since the early 1990s. Returns to education have risen fairly rapidly particularly in early transition as have differences in the employment prospects of those with more or less education. This is particularly evident if one looks at jobless youth. Figure 23 documents this. The figure reports the jobless rates rates of young(ish) people by level of education. The age-group 25-34 is used as a proxy for young people because, in this context, reporting labour market outcomes for young people as traditionally defined (15-24) will produce a distorted picture essentially because many young people who will subsequently obtain secondary and most who will obtain tertiary qualifications will still be in education. Using the 2534 age-group removes this problem whilst still focusing on the young ${ }^{45}$. In any event, the inverse relationship between educational level and joblessness is extremely clear from the figure. With the exception of general and 'specialized' secondary education, which in any event essentially represent the same or similar levels of education, the jobless rate invariably falls as the level of education rises. It may also be observed that low levels of education are also associated with greater participation in the informal sector considered below. Furthermore, recent evidence for Serbia and the Ukraine ${ }^{46}$ suggests that the duration of the School-to-Work transition is much longer for those with lower levels of education particularly in the Ukraine. Nearly $50 \%$ of those who did not complete secondary education do not find any sort of employment within two years of leaving school. The comparable figure for University graduates is $10 \%$. Unemployment rates by education for the same age-group (figure 25) largely confirm this picture although there are some exceptions and also some rather odd looking patterns emerging particularly in the low income countries in the region.

\section{Figures $24 \& 25$ - jobless rates by education and unemployment rates by education here}

- Also at an individual level, joblessness appears to be closely related to low levels of education and more generally poverty amongst young people. Kolev \& Saget (2005) find that in Bulgaria, young people who had no more than primary education were more than four times more likely to be jobless than those who had obtained at least some post-secondary education ${ }^{47}$. They also find that youth joblessness is strongly correlated with poverty. Guarcello

\footnotetext{
45 This issue is discussed further in O'Higgins (2001). The problem is one of comparison groups. Implicit in any such comparison is the fact that the principal difference between the groups being compared lies in the variable of interest. That is, in this example, the level of education. However, very obviously, 15-24 year olds with different levels of education will necessarily be systematically different in several ways, not just in their level of education, which will also affect the outcome variable - here the jobless rate. Specifically, to take the extremes, 15-24 year olds who have completed tertiary education (and no longer study) will necessarily be concentrated amongst the older members of the group, they will also have completed their education more recently, on average, than those who have completed only primary and/or secondary education, and they will, in many countries, be only a small subset of those who will, in the end complete tertiary education. All these factors will of themselves affect the probability of joblessness and will so 'contaminate' any comparison made on this basis.

${ }^{46}$ ETF (forthcoming) discussed above.

${ }^{47}$ Although less marked in other countries, the Kolev \& Saget (2005) find a similar pattern also in other countries in South East Europe.
} 
et al. (2005) observe a similar pattern with regard to both education and poverty in Georgia suggesting that this is not limited to SEE.

\subsection{Job Quality issues}

Youth labour market problems do not just manifest themselves in terms of difficulties in obtaining employment per se, but also in terms of the quality of jobs that young people are able to access. Consequently, this section briefly considers issues to do with job quality and in particular, informal sector employment and underemployment.

\subsubsection{Informal Sector Employment}

The Informal sector in ECA is substantial and it is growing. Simply stated, informal sector employment refers to unregistered employment. Actually defining the informal sector in operational terms and even more so, identifying participants in it is rather more complicated ${ }^{48}$. Informal sector employment is by its nature difficult to measure, however, increasing efforts have been made in recent times ${ }^{49}$. Figure 26 reports estimates of the size of the informal sector as a percentage of National Income. These should probably be taken as conservative estimates. Even so, they suggest the existence of a substantial informal sector, particularly in CIS countries. By this reckoning, in Azerbaijan, Belarus, Georgia and Ukraine, the informal sector is larger than the formal sector and in a number of others - Armenia, Moldova and the Russian Federation - it is almost as large as the formal sector. Throughout the ECA region the informal sector is larger than the OECD average. Moreover, without exception, it is on the increase.

\section{Figure 26 here - Informal sector as a \% of GDP in ECA}

Although employment figures for the informal sector broken down by age are not generally available at an international level, such evidence as does exist universally suggests that the involvement of young people in the informal sector is disproportionately high. In Serbia, for example, the incidence of informal sector employment amongst young workers at $52.1 \%$ is around twice as high as for adults $(25.9 \%)^{50}$. Moreover, for young people with little or no education the incidence of informal sector employment is even higher (86.4\%), almost nine out of ten young people with low levels of education who manage to find work in Serbia do so in the informal sector. Similar results have been found for other countries. In Georgia, 76\% of young workers are employed in the informal sector as opposed to $57 \%$ of the employed as a whole ${ }^{51}$.

\footnotetext{
${ }^{48}$ See, for example, Henley et al. (2006) for a recent discussion. For a more complete conceptual and operational definitions the interested reader is referred also to ILO (1993).

${ }^{49}$ See, for example, ILO (2002a, 2002b) and the ILO-KILM database.

${ }^{50}$ World Bank (2006b).

${ }^{51}$ Bernabè (2002).
} 


\subsubsection{Underemployment}

Another important, albeit rather neglected area concerns underemployment. Difficulties of concept and measurement are even more pronounced for underemployment than they are for involvement in the informal sector ${ }^{52}$. Although information is collected on a rather ad hoc basis, such evidence as exists suggests that here again, young people are likely to be disproportionately represented also in this type of employment.

\subsection{Summary} following:

Amongst the main points emerging from the preceding discussion are the

- Many of the countries in the ECA region are close to an absolute or relative peak in the relative size of their youth populations. There is no strong evidence to support the idea that this is likely to lead to an increase in youth unemployment or joblessness, indeed, substantial youth populations represent a "window of opportunity" which however, needs to be exploited through appropriate education and training measures.

- The labour force participation rates of young people have fallen throughout the region following transition. In some countries this has largely been compensated by rapid rises in secondary and tertiary educational participation. Elsewhere it has not, leading to the emergence of substantial groups of jobless young people. In some countries as many as one out of every two young people is neither in employment nor education.

- Young people have been amongst the losers from transition. Youth unemployment and joblessness have emerged as significant problems in ECA countries since 1989. Although these increases are associated with general movements in labour demand, differences in the ratio of youth to adult unemployment across the region suggest that much can be done to facilitate youth entry to employment independently of the aggregate economic situation.

- Disadvantage amongst young people has several dimensions, however, it is evident that young people with low levels of education are those which face the greatest difficulties in finding productive employment. Young people with little education are more likely to be unemployed and above-all jobless. If they do find employment, it is far more likely to be low quality employment in the informal sector than for their more educated counterparts.

- Disadvantage in labour market outcomes are also observable for young women, particularly in countries characterized by low levels of educational attainment, young people living in rural areas, and albeit less well (statistically) documented, those from ethnic minorities.

\footnotetext{
${ }^{52}$ For a formal definition of underemployment see ILO (1998).
} 


\section{Policies to Facilitate the School-to-Work Transition}

In the light of the analysis presented above, four main areas where the employment prospects of young people can be improved will be discussed in turn ${ }^{53}$. The first two of these are concerned with essentially general job creation issues and have been discussed fairly exhaustively elsewhere and consequently will be dealt with relatively briefly.

\subsection{Macroeconomic Policy \& the Investment Climate}

It should be clear from the preceding discussion and indeed from previous analyses of the problems of youth unemployment and joblessness, that youth employment and unemployment or more generally youth joblessness are closely related to the macroeconomic environment. Although, in the context of the ECA region, the link between employment and growth may have been brought into question, the analysis of Rutkowski et al. (2005) amongst others, makes clear that this has much to do with the way unproductive employment was maintained, above-all in CIS countries, following transition in a largely futile attempt to obviate or at least alleviate problems associated with massive industrial restructuring. This had the effect of delaying change and to some extent at least obstructing the creation of new productive employment. In any event, any strategy to facilitate the entry of youth into productive employment must be centered around a strategy for growth and job creation as a whole. Precisely how this is to be done is beyond the scope of this short paper and has, in any event been extensively discussed elsewhere, in particular in the aforementioned report by Rutkowski at al. (2005). However, a few of their findings are relevant here:

- The main differences across countries in their employment performance since 1989 are observable in countries' ability to create jobs rather than in significant differences in job destruction. Countries which were slow to reform were able to contain job destruction initially, however, later on job destruction occurred at higher rates.

- During transition the creation of new jobs has largely been associated with the entry of new firms rather than the expansion of existing ones. The correlation between firm entry and job creation is much stronger in ECA than in the OECD. Conversely job destruction was driven principally by the contraction of employment in existing firms rather than by firm exit - much more so than in the OECD.

- Restructuring and 'creative destruction' are necessary for the reconciling of the apparently conflicting aims of promoting employment and productivity growth

\footnotetext{
${ }^{53}$ These are close to the MILES framework developed by the World Bank and used as a tool in their National Labour Market Assessments. The MILES framework, as the name suggests, encompasses five areas: Macroeconomic environment, Investment Climate, Labour Policies, Education and Social Protection.
} 
The main implication of this is that overall job creation, necessary also for the general improvement in youth employment prospects requires the creation of a conducive investment climate. Rutkowski et al. op. cit. find that differences in job creation across the region largely reflect differences in the investment climate. Moreover, they find that the main impediments to investment and consequently job creation are to be found in poor access to finance, excessive market regulations, administrative barriers and high rates of taxation, and not labour market regulation per se.

Amongst these factors, one might emphasize the role of taxation and in particular payroll taxes. Payroll taxes are likely to affect the investment climate in general and therefore employment as a whole, and so, indirectly, youth employment. However, they are also likely to impact youth employment disproportionately, particularly low skilled youth, using a similar line of reasoning to that used with regard to labour market regulations discussed below. Nickell \& Bell (1996) have argued persuasively in favor of lower payroll taxes for the low skilled, which would tend to impact young workers disproportionately ${ }^{54}$ and Bassanini \& Duval (2006) find a particularly strong and robust negative impact of payroll taxes on youth employment in the OECD.

\subsection{Labour market regulation}

Labour market regulation can mean many things. Here, it refers to minimum wages, and employment protection legislation. For fairly obvious reasons, both types of regulation are likely affect young people more than other groups. Since young people are usually, by virtue of their age, either new or recent labour market entrants, they are more likely to be affected by employment protection legislation in as much as this impedes new hires. Similarly, they will likely to be disproportionately represented amongst the low paid and so may well be more affected than other groups by minimum wage legislation.

\subsubsection{Employment Protection Legislation (EPL)}

Over the last fifteen years or so, employment protection legislation has been relaxed to varying degrees throughout the region. The traditionally paternalistic and protective systems including guaranteed employment have been more or less rapidly dismantled with the transition to the Market. Countries which were seeking (and subsequently obtained) entry into the EU were particularly aggressive in pursuing reforms. These reforms were largely concentrated on the liberalization of temporary contracts. In this, countries in the EU-NMS sub-region have largely taken their lead from the EU-15 countries. By the early years of the new millennium, in Bulgaria, Hungary, Lithuania, Slovakia and Slovenia over half of all employees had temporary contracts with a duration of six months or less ${ }^{55}$. Whilst these more flexible forms of employment may to some extent facilitated access by young people to some

\footnotetext{
${ }^{54}$ Indeed, their argument applies essentially to the low waged rather than the low skilled per se making it all the more applicable to young workers.

${ }^{55}$ European Commission (2003).
} 
kind of job, the question remains, however, as to the ease with which temporary forms of employment may be transformed into long-term good quality employment ${ }^{56}$.

The increased emphasis on labour market flexibility has not actually led to any marked reduction in job stability as measured by employment tenure and job separation rates in the EU-15 $5^{57}$. In contrast, transition to the market in ECA countries was accompanied by a rapid decline in job stability and labour turnover with its effects being felt most keenly by the youngest and oldest groups of workers. In EUNMS countries, the fall in the job tenure of young people has, however, done no more than bring these countries in line with the their Western counterparts. In 1999, the average job tenure of young people in EU-NMS was 2.2 years as opposed to an average of 2 years in the EU in 2000. Probably of more consequence, the rapid changes in employment protection in ECA countries coupled with economic instability have led to a rapid deterioration in perceptions of job security amongst workers which in turn, has produced a pro-cyclical pattern of job tenure and countercyclical pattern of labour turnover. Cazes \& Nesporova (2003) argue that, "fear of the fragile economic situation of many companies, weak protection of workers' rights and substantial income loss when falling into employment cause workers to feel reluctant about quitting their jobs and moving to new ones even during economic upswings, while during economic downswings labour flows increase as many people lose their jobs or are pushed to quit "voluntarily",58. In common with several previous studies of OECD countries ${ }^{59}$, these authors find no relationship between youth unemployment rates and the strictness of EPL.

But there is a further issue of relevance here: compliance with EPL. As well as in strictness, countries vary greatly across the region in the extent to which EPL is actually enforced. ${ }^{60}$. Table 3 reports average youth unemployment and jobless rates and the ratio of youth to adult unemployment rates for countries grouped according to the strictness of its EPL and the strength of its enforcement. The information presented in the table by no means demonstrates a causal relation, however, it is suggestive. The countries which are doing best, in terms of youth unemployment and joblessness are those with 'strong enforcement' or in other words, those with a relatively small informal sector ${ }^{61}$. This is irrespective of whether they have strict EPL or not. Indeed the best performing countries are those where restrictive employment protection legislation is combined with its strong enforcement - or rather where there is a (relatively) small informal sector. Also somewhat surprising is that, as shown also in figure 23 above, far from being associated with low open unemployment rates, the presence of a substantial informal sector is associated apparently with high (rather than low) levels of youth joblessness. Finally, one may observe that in countries with

\footnotetext{
${ }^{56}$ See, for example, OECD (2003).

${ }^{57}$ Although, where falls in job tenure have been observed, they have tended to be concentrated amongst young workers (Auer \& Cazes, 2003).

${ }^{58}$ Cazes \& Nesporova (2003, p. 138).

${ }^{59}$ See, in particular, Bertola, Boeri \& Cazes (1999) and OECD (1999). On the other hand, Bassanini \& Duval (2006) find a negative and statistically significant impact of EPL on young adult (20-24) employment although this remains less influential (and less statistically significant) than aggregate demand in its effects on young adult employment.

${ }^{60}$ This is based on a table prepared by Rutkowski et al.. (2005, table 6.1, p. 215) with the addition of youth jobless and unemployment rates and youth to adult unemployment ratios.

${ }^{61}$ In practice, the strength of enforcement is proxied by the size of the informal sector - the larger the informal sector, the weaker is enforcement.
} 
a relatively flexible labour market the ratio of youth to adult youth unemployment ratios are relatively high. This is in line with the situation in several EU-15 countries where the relaxation of restrictions on contract lengths for new entrants produced essentially a dual labour market with a strongly protected core of primarily prime age male adults and a periphery composed primarily of young and female workers with insecure and badly paid work.

Table 3: EPL strictness, enforcement and youth labour market indicators

\begin{tabular}{|c|c|c|c|}
\hline & Flexible EPL & Restrictive EPL & Very Rigid EPL \\
\hline $\begin{array}{l}\text { Weak } \\
\text { Enforcement }\end{array}$ & $\begin{array}{l}\text { Mean YJR=27.3 } \\
\text { Mean YUR=26.1 } \\
\text { Mean RYA=1.9 }\end{array}$ & $\begin{array}{c}\text { Armenia, Georgia, } \\
\text { Russia, Serbia \& } \\
\text { Montenegro, } \\
\text { Turkey } \\
\text { Mean YJR=29.5 } \\
\text { Mean YUR=36.4 } \\
\text { Mean RYA=2.5 }\end{array}$ & $\begin{array}{c}\text { Azerbaijan, } \\
\text { Belarus, Bosnia \& } \\
\text { Herzegovina, } \\
\text { Kyrgyzstan, } \\
\text { Moldova, Ukraine, } \\
\text { Uzbekistan } \\
\text { Mean YJR=30.7 } \\
\text { Mean YUR=28.8 } \\
\text { Mean RYA=2.3 }\end{array}$ \\
\hline $\begin{array}{l}\text { Intermediate } \\
\text { Enforcement }\end{array}$ & & $\begin{array}{c}\text { Bulgaria } \\
\text { Mean YJR=22.5 } \\
\text { Mean YUR=20.5 } \\
\text { Mean RYA=2.5 }\end{array}$ & $\begin{array}{c}\text { Croatia, } \\
\text { Macedonia, } \\
\text { Romania } \\
\text { Mean YJR=21.0 } \\
\text { Mean YUR=24.8 } \\
\text { Mean RYA=2.9 }\end{array}$ \\
\hline $\begin{array}{l}\text { Strong } \\
\text { Enforcement }\end{array}$ & $\begin{array}{c}\text { Czech Republic, } \\
\text { Estonia, Hungary, } \\
\text { Poland, Slovakia } \\
\text { Mean YJR=11.8 } \\
\text { Mean YUR=20.7 } \\
\text { Mean RYA=2.6 }\end{array}$ & $\begin{array}{c}\text { Latvia, Lithuania, } \\
\text { Slovenia } \\
\text { Mean YJR=9.7 } \\
\text { Mean YUR=14.3 } \\
\text { Mean RYA= 2.1 }\end{array}$ & \\
\hline
\end{tabular}

Sources: Country Classifications - Rutkowski et al. (2005, table 6.1, p. 215); youth jobless (YJR) and unemployment rates (YUR) and the ratio of youth to adult unemployment rates (RYA) Author calculations on the basis of WDR, WB-ECA data and Kolev \& Saget (2005) for youth joblessness, ILO-KILM, UNECE and Transmonee 2007 data for youth unemployment and ILO-KILM data for the youth-adult ratio.

Notes: In addition to the country classification, the table reports the mean youth jobless rate (YJR), mean youth unemployment rate (YUR) and the ratio of youth to adult unemployment rates for the countries in each cell using the most recent observation available.

\subsubsection{Minimum wages}

Minimum wage legislation is in place throughout the region however, it varies greatly in terms of levels. In the EU and SEE sub-regions minimum wages are relatively high, averaging close to $40 \%$ of the average wage. In CIS countries they are for the most part, very low, of the order of $20 \%$, and, in several countries less than $10 \%$ of the average wage. In Ukraine, the minimum wage is relatively high (over $40 \%$ of the average wage), however, there is evidence that it is not enforced (Rutkowski et al., 2005). 
Despite the apparent plausibility of the argument that high levels of minimum wages tend to discourage the employment of particularly young people, the evidence is somewhat mixed. The most recent review evidence presented by Neumark \& Wascher (2007) finds estimates of the teenage employment elasticity with respect to the minimum wage which range from below -1 to above 0 . The authors conclude overall that the existing evidence points towards negative employment effects of minimum wages for young people. Of 102 studies considered, nearly two-thirds found negative albeit often not statistically significant employment effects of minimum wages, whilst only eight found 'convincing' positive effects. However, an emphasis on demonstrating that the effects are generally negative rather than positive rather misses the central point which is that the effects of minimum wages in the vast majority of cases are found to be small. In this sense, these results are in line with the review of evidence presented in O'Higgins (2001, chapter 6) which found small or zero (i.e. not statistically significant) employment effects of minimum wages for young people ${ }^{62}$. In the present context, it might be added that:

a)

Neumark \& Wascher (2007) find that the effects of minimum wages vary considerably (from negative to positive) according to the presence of other labour market institutions (employment protection legislation, active labour market policies and so on) and, in particular, the negative effects are most pronounced in unregulated labour markets; and,

b) none of the studies included in their review cover transition countries in $\mathrm{ECA}^{63}$.

Given the lack of evidence for the region, the other possibly beneficial effects of the minimum wage, the general finding of smaller negative (or even positive) effects of minimum wages in the presence of regulated labour markets as well as the relatively low rates of statutory minimum wages in most of the region, there does not seem to be a strong case to be made for the introduction of sub-minimum wages for young people or the lowering of minimum wages overall as an effective way of promoting youth employment.

\subsection{Education \& Training}

Education and training systems play a central role in determining youth labour market outcomes. Higher levels of human capital both improve the short run job and wage prospects of their possessors ${ }^{64}$ as well as, through their impact on long-

\footnotetext{
${ }^{62}$ Similar findings are reported also be Kolev \& Saget (2005).

${ }^{63}$ In general, studies on the effects of minimum wages on employment are few and far between in transition economies. One exception is the analysis of Kertesi \& Köllö (2003) who looked at the effects of the substantial increase in the minimum wage in Hungary in 2001 where the minimum wage increased by about $57 \%$ bringing it to around $40 \%$ of the average wage. They found that aggregate employment fell by between $0.5 \%$ and $1.1 \%$ (implying an elasticity of the order of between -.01 and $.02)$. Again, a very modest effect.

${ }^{64}$ The classic example of a system which, through its education and training system effectively promotes youth employment is provided of course by Germany. There, the ratio of youth to adult unemployment rates is of the order of one-to-one - in contrast to most other countries in the EU-15 and ECA region where, as noted above, the youth unemployment rate stands at between two and three times the adult rate. However, in recent years problems have begun to emerge even there, particularly as regards the fate of young people once they leave the dual system and also as regards the system's
} 


\section{run growth prospects, promoting the general outlook for economic and therefore youth (and adult) employment growth.}

Rapid industrial restructuring in the ECA region accompanying transition led to the need for Education and Training systems to adapt to cope with rapidly changing skills requirements manifesting themselves in the labour market. This they have been very slow to do. The need for reform is felt at all levels of education including secondary education ${ }^{65}$ and the vocational education and training (VET) structures. A recent World Bank report ${ }^{66}$ has argued in favor of greater integration of general and vocational education as well as providing a series of suggestions as to how greater efficiency might be achieved in these systems.

Throughout the region, reform of VET still has a long way to go. There are a number of problems in VET, including :

- Early and rigid tracking of students into VET;

- The provision of VET is spread over different ministries creating parallel structures;

- VET systems are inflexible, still being based on long-run planning without mechanisms to incorporate assessment of labour market needs;

- Social Partner involvement is not yet institutionalized. For example, there is no involvement of Social Partners in the development of curricula ${ }^{67}$.

In general, VET reform thus far has tended to be undertaken within traditional models and there is a need for greater recognition for more fundamental reform. Systems need to be made more responsive to ongoing changes in the needs for skills, not just reformed in terms of which industry-specific skills provided in school. It has been argued elsewhere that an important element in this is the development of less formal and more general links between schools and labour market actors or stakeholders $^{68}$.

Throughout the region there concerns have been expressed regarding declining quality of education (Alam et al., 2005). The early transition years were accompanied by a rapid deterioration in educational infrastructure. For example, heating, electricity and water services became irregular in many countries. Given the increasingly poor pay and conditions there has been a rapid rise in the average age of teachers. As noted

adaptability in times of rapidly changing occupational and industrial structures. It is also costly. Moreover, there are many questions as to the transferability of the German type system to other countries with differing institutional bases. For example, the German system rests inter alia on the existence of substantial numbers of large firms. In post-socialist ECA, companies tend to be small. Notwithstanding this, the German system illustrates the importance of specific design features which could be exported. Perhaps the most important amongst these is the strong involvement of employers ion the provision of training which ensures the labour market relevance of training. It provides equitable access to places, and its high (and recognized) quality means that participation does not carry the negative stigma associated with vocational education in many countries (World Bank, 2006c).

${ }^{65}$ See World Bank (2005).

${ }^{66}$ World Bank (2006c).

${ }^{67}$ ETF (2003b).

${ }^{68}$ For example, in O'Higgins et al. (2001) on Bulgaria. 
above, educational participation and formal educational attainment is, for the most part, still relatively high in ECA. However, much of this is to do with pre- transition investments, whose impact is eroding rapidly. There are some disturbing trends concerning the growing inequality in outcomes. Alam et al. (2005) note that in between 1995 and 1999, two of best educational performers, Czech Republic and Slovenia increased the proportion of underperforming students by $200-300 \%$ and suggest that policy interventions which improve the quality of education services are essential in order to halt this decline ${ }^{69}$.

\subsection{Passive Labour market Policy: Unemployment Benefits}

In ECA, the immediate reaction to the transition-induced recessions was, almost universally, to introduce relatively generous unemployment benefits in order to mitigate the social costs of transition. In the second half of the 1990s there was an increasing trend to shift labour market policy from 'passive' to 'active'. That is away from income support towards employment and training programs. At the same time, many countries significantly reduced unemployment benefit entitlement both in terms of its level and its duration. Here, the findings in the literature are relatively clear. In most studies, the duration of unemployment is positively linked to the level and duration of unemployment benefits in CEE as is the case also in studies of Western Europe $^{70}$. However, several observations on this are necessary. First, the disincentive effects are generally small. Second, the finding regarding disincentive effects is not universal, Lubyova \& Van Ours (1999) find little evidence of disincentive effects in Slovakia and Earle \& Pauna (1998) clearly reject the idea of disincentive effects in Romania. Third, in several studies, whilst the exit from unemployment is clearly increased, much of this exit is to inactivity rather than employment ${ }^{71}$. Fourth, unemployment benefits played a fundamental role in reducing poverty during early transition $^{72}$. That is, they did what they were designed to do; play a redistributive role during transition. Finally, young people are less likely to be recipients of unemployment benefits since they are less likely to have been employed for sufficient time to have accumulated the necessary qualifying period of employment ${ }^{73}$. The benefit safety net in ECA countries was heavily oriented towards laid off workers from the State sector. Indeed, young people might even benefit from the reduced competition in the labour market ${ }^{74}$.

\footnotetext{
${ }^{69}$ See, for example, Canning et al. (1999) for Russia. La Cava et al. (2005) find a similar situation in SEE.

${ }^{70}$ See, in particular, Vodopivec et al. (2002) on CEE and Atkinson \& Micklewright (1991) and more recently Bassanini \& Duval (2006) on OECD countries.

${ }^{71}$ For example, Cazes \& Scarpetta (1998) on Poland and Micklewright \& Nagy (1998) on Hungary.

${ }^{72}$ Vodopivec et al. (2002).

${ }^{73}$ For example, Kolev \& Saget note that the incidence of unemployment benefit receipt amongst the ILO unemployed is much lower for young people than for adults in SEE (Kolev \& Saget, 2005, table 12).

${ }^{74}$ In their study of OECD countries, Bassanini \& Duval (2006) are in some difficulty in explaining the effects on young adults of unemployment benefits which they find to be of the same order as the effects for other groups. The difficulty arises because ceteris paribus one would expect a smaller effect for young adults in that generally they are much less likely to receive them than say prime age adults. They suggest that the result may depend on the addition of an indirect effect, working through the negative impact of unemployment benefits on unemployment as a whole discouraging young people from participating in the labour market. This is not entirely convincing in as much as there is already an overall output variable present in the equation. Certainly it would merit further study.
} 


\subsection{Active Labour Market Policies}

There is evidence to suggest that Active Labour Market Policies for young people have been more successful in ECA than in the USA and EU-15. Moreover, internationally, it would appear that the most successful programs are those that target specific groups of disadvantaged youth. On the other hand, ALMPs do not appear to be sufficient to overcome barriers posed by highly regulated internal labour markets (Betcherman et al., 2007).

Active Labour Market Policies largely fulfill a remedial role in correcting malfunctions in the education system and in labour markets. As such, they tend to be more expensive and less effective than, in principle, action taken within in the context of initial education. However, in ECA ALMPs have played a fundamental role in filling gaps left by the failure of initial education $\&$ training systems to adapt and are likely to continue doing so for some years to come.

However, there is a growing need for employment services to play a more complementary - not just remedial - role to educational services. For example, in Slovenia which, at 6\% in 2006, has one of the lowest aggregate unemployment rates in the EU, performs relatively poorly vis-à-vis its youth-to-adult unemployment ratio. This persistent problem which affects also more educated young people is associated with the difficulties faced by first-time job seekers and the European Commission ${ }^{75}$ has recommended the strengthening of employment services for this group in order to strengthen the link between education and the labour market.

Traditionally Public Employment Services in the region have been involved largely in the payment of income support to the unemployed and in the administration of labour market based employment and training programs. In recent times, however, they have become more pro-active in promoting the better functioning of labour markets through the provision of guidance and counseling and more generally jobmatching services.

\subsubsection{Wage Subsidies}

Wage subsidies, or more generally financial incentives to firms, are relatively frequent in the ECA region (box 1). In general the evaluation findings are positive and it appears that wage subsidies have been particularly successful in improving the employment rates of young people, especially young women and the poorlyeducated in $\mathbf{E C A}^{\mathbf{7 6}}$. There are two major caveats here. First the employment benefits do not extend to wages ${ }^{77}$. Second, impact evaluations consider the outcomes of participants compared to a control group of non-participants. They do not as a rule take into consideration deadweight, displacement and substitution effects of

\footnotetext{
${ }^{75}$ European Commission (2007, p. 54).

${ }^{76}$ Puerto (2007)

${ }^{77}$ Betcherman et al. (2007).
} 
programs ${ }^{78}$. Whilst these confounding effects may be present with all types of program, where analyses have been undertaken suggest that they are most marked in wage subsidy programs ${ }^{79}$.

\section{Box 1: ECA wage subsidies for young people}

Several countries in the region have operated wage subsidy programs targeted at young people. In Poland, the Intervention Works Program was initiated in 1995 for people up to the age of 30. The program is estimated to have increased reemployment by 15.6 per cent in non-subsidized jobs, and by 13.1 per cent in any kind of job (including subsidized) but with lower monthly earnings. Based on a scientific evaluation with cost analysis, this program was assessed to generate positive employment impacts in a cost-effective manner. In the Czech Republic, a wage subsidy program has been in operation since 1996, for the benefit of young people. It achieved a statistically significant increase in employment of 12 per cent for participants. Women and less-educated participants (a considerable proportion of all participants) gained most from the program. Again, however, monthly earnings were lower than pre-program levels.

In Bulgaria, a program for subsidized Employment in Public Administration of Young School Leavers has been in place since 2002. At the end of July 2004, 909 people were employed through the program, out of 1,090 young people so far included in the program. Monitoring and assessment of the program's implementation are carried out on a regular basis. This provides the possibility of correcting the scope and mechanisms of the program and adapting it to suit the conditions and needs of the labour market. In Slovakia, employers can receive a monthly contribution from government to cover the costs of employing unemployed school leavers (who also receive a grant to cover personal expenses) in a 'graduate practice' scheme. In 2004, 14,462 job seekers participated in the scheme, of whom 68 per cent were women and 83 per cent were from disadvantaged groups. No analysis of the net impact of the intervention is available. In Latvia, a pilot project of subsidized work experience during the summer holidays for students from secondary and secondary vocational schools and vocational training students was organized in 2004. The pilot project can be evaluated as successful, but there is also room for organizational improvements, with better targeting - for instance to students from large families. Contracts were signed with 448 employers (enterprises and organizations) nationwide and 3,191 subsidized jobs were offered. The employers who offered the majority of the jobs were retailers, food factories and farm enterprises, while some positions were also offered by a children's hospital. Some employers were highly satisfied with the employed students and asked them to continue the cooperation after the pilot project was finished. In Kyrgyzstan a Youth Job Vouchers scheme has operated since 1996. A survey found both employers and young people to be highly satisfied with the scheme, although employers claim that it would be possible to create even more jobs if they only had to commit themselves to the young people for one year. Vouchers opened the door to a career start for 180 young women and 80 young men; 75 per cent of the jobs were assessed to be genuine new jobs.

Source: Betcherman et al. (2007) based on O'Leary (1998), Fretwell et al. (1999), EU (2005 and 2006b) and BMZ (2006).

\footnotetext{
${ }^{78}$ Specifically, in designing wage subsidy programs, Care needs to be taken that the workers employed would not have been taken on by recipients of the subsidy even without the intervention (deadweight loss); that employers do not simply substitute one group of workers (eligible for subsidy) for another whom are not eligible (substitution effect); or, that the jobs created do not displace jobs in other firms which do not receive the subsidy and are therefore less able to compete in the product market with subsidy recipients (displacement effect). In each case, the key question is: does the subsidy create new jobs which would not have existed in its absence? For obvious reasons it is rather difficult to ensure this is so and such programs have often been criticized on the grounds that they are consequently a relatively costly way of increasing overall employment with a low level of net job creation. However, careful targeting of both direct recipients (firms) and the ultimate beneficiaries (new employees) can mitigate this problem.

${ }^{79}$ See, for example, O'Higgins (2001, pp. 110-111) for a more detailed discussion of this issue.
} 


\subsubsection{Labour Market Training}

Labour market based training is the most common form of ALMP for young people in the ECA region ${ }^{80}$. In practice employment services have been called upon to remediate the failure of VET systems in the region to provide labour market relevant skills in the context of the rapidly changing industrial structure. To an extent this is natural. Employment Services feel the effects of the failure to reform training systems directly in terms of a greater draw on the resources devoted to passive labour market policies. Educational institutions are at one remove from this and so do not feel the pressure so acutely. Perhaps then, it is not surprising that they have been much slower to react.

Labour market training is often combined with some form of wage subsidy and it has been argued that this is indeed the most effective form of intervention for young people ${ }^{81}$. On the one hand, the training component remedies the lack of employable skills of school leavers while on the other, the work experience component provides above-all direct links with employers and the world of work.

In general, youth training programs whether part of a more comprehensive package or not have been relatively successful in ECA. Indeed significantly more successful in this region than in the rest of the world ${ }^{82}$.

\subsubsection{Self-employment and small business support}

Although self-employment increased rapidly over transition, this was in part a survival strategy adopted by individuals (Rutkowski, 2006). Programs promoting business start-up for young people are relatively few and far between in the ECA region. However, the broader analysis of Betcherman et al. (2007) finds highly positive effects for such programs although the number of such interventions is small impeding the drawing of general conclusions. The only such program in ECA which has been subject to an impact evaluation, the Bulgarian Self-Employment Program, did show significant short-term gains in employment for participants particularly for young females, although the cost-effectiveness and long term effects are more doubtful. Certainly, costs per placement exceed those of training and subsidized employment programs. On the other hand, policies aimed at overcoming the additional barriers that young people face in establishing their own businesses appear to be popular with the young people themselves (La Cava et al., 2005).

\subsubsection{Public Works and Direct Job Creation Programmes}

In many countries in the region, the initial response to the collapse in labour demand was first the rapid expansion of passive labour market policy (income support) followed by the introduction of substantial public works programs. In essence, these types of programs are intended to provide some income support to the unemployed as well as maintaining, or, in the case of young people, developing the

\footnotetext{
${ }^{80}$ As indeed is true world wide (Betcherman et al., 2007).

${ }^{81}$ For example, O’Higgins (2001).

${ }^{82}$ Betcherman et al. (2004), Betcherman et al. (2007).
} 
labour market attachment of participants and to help mitigate some of the detrimental consequences of long-term unemployment. They can be used to produce goods of benefit to the community at large such as in the construction, and in South East Europe, postwar reconstruction of infrastructure. Indeed Betcherman et al. (2007) note that positive net benefits to society as a whole can be sometimes observed with these programs if the value of the goods and services produced by the program is included.

What they do not do very effectively is promote the long-term employment prospects of participants. These programs are generally temporary or short-term in nature, employing labour in relatively low skill work on specific projects. In some cases, the longer term, employment promotion role can be enhanced by the introduction of training elements. However, the overall finding of evaluation research on this subject, is that public works are not an effective means to integrate the unemployed into employment ${ }^{83}$. Such programs are best seen principally as income generating measures or means to promote work attachment amongst the longterm unemployed rather than as a means to promote the integration into long-term decent work of young people. However, one such program, the Temporary Employment Program in Bulgaria, was found to raise the post-program employment probability of participants by six percentage points. For the most part, however, such programs tend to have, at best no positive impact, and often a negative one.

\subsubsection{Guidance and Counselling}

Much of the recent work in the area of policies to promote youth employment has emphasized the importance of guidance and counseling, both before and after young people enter the labour market ${ }^{84}$. In many countries the information available to young people does not allow them to make realistic choices concerning the options available to them. Indeed, in recent times, Active Labour Market Policies have increasingly included a preliminary phase of orientation and guidance in which young people are made aware of the effectively available alternatives. This has proven to be a relatively cost effective form of intervention which often obviates the need for more expensive work oriented training ${ }^{85}$, although there is very little hard evidence, in terms of impact evaluation, on the effectiveness of such interventions specifically for young people.

Although guidance and counseling functions are relatively developed in richer countries, both within the educational system and also on the labour market through Public Employment Services, this is not true in others. One major obstacle faced by many countries is the basic lack of labour market information on which to base guidance and counseling or indeed the more general job matching function fulfilled by Public (and increasingly private) Employment Services.

\footnotetext{
${ }^{83}$ See, for example, the findings of Fretwell et al. (1999). However, more recent work has tended to put a somewhat more favorable light on the usefulness of public works programs in promoting the employment prospects of participants (Betcherman et al, 2004).

${ }^{84}$ See, for example, Fay (1996).

${ }^{85}$ See, for example, Betcherman et al. (2004) and/or OECD (2006).
} 


\section{Box 2: The New Deal for Young People}

In 1998 the British Government launched the New Deal for young people under the age of 25 .

The program is composed of several parts, with different options offered to different groups of the unemployed. The New Deal for young people is compulsory for all those aged 18-24 who have been receiving the Jobseekers allowance for more than six months. Initially, individuals enter a "Gateway" period, where they are assigned a personal adviser who gives them extensive assistance with job search. If the unemployed person is still on JSA at the end of the Gateway period (formally a period of 4 months), they are offered four options:

i) Entry into full-time education or training for up to 12 months for those without basic qualifications (without loss benefits);

ii) A job for six months with a voluntary sector employer (paid a wage or allowance at least equal to social assistance plus $£ 400$ spread over six months);

iii) A job on the Environmental Task Force (paid a wage or allowance at least equal to social assistance plus $£ 400$ spread over six months);

iv) A subsidy to a prospective employer for six months, with training for at least one day a week (£60 per week plus an additional $£ 750$ training subsidy spread over six months).

If an option is refused, the claimant is liable to suffer a benefits sanction. Initially, sanctions take the form of withdrawal of benefit for two weeks, and further refusal may result in repeated four-weekly withdrawals. Individuals returning to unemployment within thirteen weeks after leaving an option go onto the follow-through program of job assistance, which is essentially the same as Gateway.

Impact evaluations show that the programs have been effective between 1998 and Young unemployed men are about $20 \%$ more likely per period to gain jobs as a result of the New Deal. Part of this effect is due to subsidized jobs, part a pure "Gateway" element (enhanced job search), at least one fifth of the total effect. The cost benefit analysis suggests that the program is worth continuing. The job search assistance element of the New Deal element is more cost effective than the other ALMP options as there is no subsidy involved.

The New Deal stands as the least costly comprehensive intervention for youth in OECD countries. The cost per beneficiary served ranges from $£ 454$ to $£ 790$ (in $1999 £$ ). In addition, the cost per job created is under $£ 4,000$ (in $1999 £$ ), given an average placement rate of 17,250 participants per year (Van Reenen, 2003). Regarding its sustainability, the New Deal has received extensive political support and the government is placing greater emphasis on enhancing and scaling-up the assistance during the Gateway period.

Source: Puerto \& Rother (2007) based on O'Higgins (2001) and Van Reenen (2003)

\subsubsection{Comprehensive programs}

Comprehensive programs involve some combination of subsidized employment, training, self-employment support, guidance and counseling and so on. They are not very common in the ECA region but have a long history in OECD countries and above all in the US. One of the most cost-effective programs, the UK's new deal for young people is illustrated in box 2. All three of the comprehensive programs considered by Stavreska (2007) seem to have had positive impacts on the employment prospects of participants. 


\subsubsection{Job Matching Services}

In EU-15 countries, the job matching function fulfilled by public employment services is becoming ever more important. Indeed, more and more, ALMPs include an element of job search assistance. Thus, PES, beyond administering financial unemployment assistance, is taking a more active role in the promotion of employment through the implementation of ALMPs themselves but also through the role of matching job seekers to jobs. In many countries, the PES also organize job fairs which bring together prospective employers and young potential employees. However, although these no doubt play a useful informational role in terms of informing young people about the available opportunities and vice versa with firms, little actual recruitment actually takes place during these events.

In most ECA countries and particularly in the FSU, jobs are largely filled through informal contacts of relatives and friends or through direct recruitment by firms. This in itself is no bad thing as long as the system of informal networks works efficiently ${ }^{86}$. The large numbers of unsuccessful young job seekers however suggests that in many countries, this is not the case. Clearly, there is room for an increase in the active role played by the PES. One way in which this may be accomplished, particularly suitable to young people, is through the establishment of and access to Internet based job-seeking services. In Slovenia, for example, such services are relatively well developed. In less wealthy countries where access to computers and above all the Internet is less widespread, employment centers could, in principle, be a focal point for access to the Internet for job-seeking. Essentially what is required is for the centers to be seen as a useful source of information and access to jobs. The PES needs to make itself more attractive to young people by providing useful services.

\subsubsection{Factors influencing the success of ALMPs for young people}

The meta-analysis undertaken in Betcherman et al. (2007) suggests that it is certain specific program characteristics which are important in determining their effectiveness rather than the type of intervention per se. Encouraging amongst their results, the authors find that programs aimed at economically disadvantaged young people are more successful as are programs generally in transition (and developing) countries as opposed to industrialized ones. Less encouraging in the context of ECA, they find a negative impact of the strictness of EPL on outcomes, however, this is not supported by the specific albeit limited evidence presented for the ECA region (Stavreska, 2007, table 14, p. 27-28).

\subsubsection{Labour Market Information (LMI), Monitoring and Evaluation}

In ECA countries progress is being made in this area, particularly in the collection of appropriate labour market information through the implementation of regular labour force surveys which now take place in almost all the countries in the region. However, a key element in the design and subsequent modification of youth

\footnotetext{
${ }^{86}$ Although bribes also appear to be common in this area too (La Cava et al., 2006)
} 
(as indeed for adult) employment policies is the monitoring and evaluation stage. This relies on an established labour market information (LMI) collection system in order, for example, to identify the appropriate target group for intervention. Which of those amongst the general category of 'youth' are most in need of assistance and so forth.

Once programs are actually implemented, monitoring of the programs (sometimes referred to as process evaluation ${ }^{87}$ ) can be used to ensure that for example, the programs reach the designated target group, that program costs are kept within target limits, that a target proportion of the group complete programs, that a target proportion of participants find employment after the program and so on. Where these targets are not met, further consideration can be given to why this is so and corrective action adopted. The central elements here are on the one hand the establishment of targets. Targets which must be realistic and realizable given the resources allocated to the program. On the other hand, the collection of information is necessary in order to allow such process evaluation to take place. Both of these are very obvious albeit fundamental points, however, experience shows that the importance of their role is clearly underestimated in the implementation of youth labour market policies in many countries.

Perhaps of most importance, certainly in terms of its regular absence in ECA, is the post-program evaluation of program impact. This is beginning to be implemented in the EU-NMS countries in the region under the auspices of the European Employment Strategy which sees evaluation as key tool. Evaluation is at least as important as monitoring. It is through impact evaluation that one may gain an understanding of what the effects of the program actually are. Essentially, impact evaluation seeks to compare the experiences of participants on programs with what would have happened in the absence of the program ${ }^{88}$. This in itself is not an easy exercise and much ink and effort have been employed to develop and refine the methodology. However, the crucial element is that the experiences of program participants are compared with a like group of people ${ }^{89}$ who act as a proxy for the experiences of participants in the absence of the program. Betcherman et al. (2007) note that the overall evaluation situation is rather poor. Even including industrialized countries in the calculation, they found that only a quarter of programs in the youth inventory were subject to net impact evaluation and less than $10 \%$ including an assessment of impact and $\operatorname{cost}^{90}$.

\footnotetext{
${ }^{87}$ Auer \& Kruppe define monitoring as the "regularly conducted observation of statistical indicators of labour market policy input/output and performance (outcome) for the purpose of improving programme implementation and even programme design," (Auer \& Kruppe, 1996, p. 901).

${ }^{88}$ Here the review is limited to a schematic overview. More details can be found in O'Higgins (2001, chapter 5) and/or Grubb \& Ryan (1999). For a practical handbook on the implementation of impact evaluation, see also, Baker (2000).

${ }^{89}$ Typical examples are the program participants before participation or other young people who do not participate in the program. More recently, attention has turned to experimental methods involving the random selection of program participants from a larger group of eligible persons. Discussion of this goes beyond the scope of this paper. For more details see the above-cited works on evaluation.

${ }^{90}$ Knowles \& Behrman (2003) also note the difficulties in evaluating the economic returns to investing in young people arising from the lack of information on the effects of youth oriented interventions.
} 


\section{Key Issues and Areas for Action}

This final section brings together some of the implications of the previous discussion in order to suggest some priority areas for action. The main emphasis here is on Education \& Training systems and Active Labour Market Policies.

\section{General Issues/findings}

- Disadvantaged Youth: A theme running through this paper concerns the need to concentrate resources on disadvantaged young people. In a sense, young people were amongst the losers of transition, however, this is not accurate when applied to young people as a whole. The groups for whom transition has created acute difficulties varies across countries in the region, however, one unifying characteristic defining disadvantage concerns those with low levels (and/or inappropriate forms) of education and skills. Young people with low levels of education are both more likely to be jobless as well as being more likely to work in low wage and low quality informal sector jobs if they do succeed in finding employment. Lack of sufficient and/or appropriate education is a key problem in general, but also significant contributor to the problems faced by specific disadvantaged groups. For example, the problems faced by young women in some countries, specific ethnic groups such as the Roma or Muslim youth in the Caucasus, and rural youth universally are clearly exacerbated by difficulties in access to education. Moreover, the evidence suggests that interventions aimed at disadvantaged young people are likely to be more cost effective.

- Youth Unemployment and Joblessness: The paper has argued that in addition to the conventional indicator of youth labour market problems, the youth unemployment rate, should be added the rate of youth joblessness, a broader indicator of labour market problems covering also discouraged young people as well as giving an assessment of the incidence of youth labour market problems in the youth population a whole.

- Education and Training and ALMP: In general, Education and Training systems have been slow to adapt to the rapidly changing labour market requirements arising from the fundamental shifts in industrial structure which accompanied transition. ALMPs have to some extent filled this gap, however, they are largely remedial in nature providing second chances where the initial education systems have failed. Clearly both types of intervention are required. The fundamental reform of Education and Training systems which is needed in the region will take many years and should be seen as a long-term investment. Although ALMPs tend to be less cost-effective than appropriate investment in educational systems, above-all in the short run, ALMPs have a crucial role in supporting the labour market integration particularly of disadvantaged young people.

- Monitoring and Evaluation: In Education \& Training reforms and above-all in ALMPs greater emphasis needs to be placed on the evaluation of 
interventions. A key finding of World Bank work in this area concerns the general lack of systematic assessment of the cost-effectiveness of programs and policies. In order to better design interventions, better information is required on what works, where and why.

- Learning from the experiences of others: Reforms in Education and Training systems are more advanced, and ALMPs more developed, in EUNMS countries. Their experiences can provide a useful basis to aid SEE \& FSU countries in improving their own policies.

- Emphasis on SEE and FSU: Young people face significantly greater problems in effecting the transition from School-to-Work in SEE and FSU countries. Investment in the reform process here as well as in ALMPs is both more urgent as well as potentially at least being more cost-effective.

\section{Macroeconomic Environment, Investment Climate and Labour Market Regulation}

- In general, the labour market entry of young people will clearly be facilitated by a better general environment for job creation. More specifically, measures which promote and facilitate hiring are likely to disproportionately benefit young people. One such type of measure which worth consideration concerns the reduction of the burden of payroll taxes on the hiring of those with low levels of skills. In practice this may be, and indeed is, incorporated into ALMPs aimed at young people.

\section{Education \& Training}

- Out of school children \& youth: There is clearly an issue of out of school children in some countries as well as serious issues arising from the dropping out of young people from secondary and vocational education

- Fundamental reform: Systemic reform is still required throughout the ECA region to make education systems more responsive to the changed and changing requirements of the labour market.

- Educational Quality: Throughout the region there are concerns with the quality and relevance of education. There is some evidence of decreasing educational quality. In some countries, there appear to be significant problems arising from bribery and corruption which exacerbates problems of access and cost particularly for poorer students.

- Educational attainment: whilst overall the ECA region is characterized by a relatively high level of educational attainment as compared to, for example the EU15 countries, there is evidence of declining educational attainment in some countries and, moreover, poor educational attainment is a key contributor to the difficulties faced by ethnic minorities, rural youth and, in some countries, young women. 
- Involving stakeholders: the involvement of labour market actors in education and training systems is extremely limited in the region and where it does exist tends to be confined formal and centralized forms. A more fruitful approach would be to promote less formal and/ more decentralized links between educational institutions and the labour market through for example, work experience programs, internship, entrepreneurship training and mentoring and so on.

\section{Active Labour Market Policies}

- Correcting the failings of Educational systems: The paper has emphasized the important role played by ALMPs in correcting deficiencies in Education and Training.

- Policies for disadvantaged youth: A key finding in the recent literature is that polices aimed at disadvantaged young people are more likely to be cost effective. This further supports the idea that the emphasis should be placed on young people who fail to affect a successful labour market entry on the basis of schooling alone, particularly those leaving the educational system with few relevant skills.

- ALMPs are more cost-effective in ECA than in EU-15: ALMPs appear to be more cost- effective in ECA (as they are also in developing countries) than they are in EC-15 countries. As well as supporting the idea of an important role for ALMPs in the region this also raises the question as to why ALMPs are more effective in ECA. Seeking an answer to this question would clearly help in the design of better policies. More generally, in the implementation of program and policy evaluation greater emphasis might be placed on identifying why some interventions are more successful than others, not just which ones work. 


\section{References}

Alam, A., M. Murthi, R. Yemtsov, E. Murrugarra, N. Dudwick, E. Hamilton \& E. Tiongson - 2005 - Growth, Poverty, and Inequality: Eastern Europe and the Former Soviet Union, World Bank, Washington, D.C.

Atkinson, A.B. \& J. Micklewright - 1991 - "Unemployment Compensation and Labor Market transitions: A Critical Review," Journal of Economic Literature vol. 29, pp. 1679-1727.

Auer, P. \& S. Cazes - 2003 - "The Resilience of the Long-Term Employment Relationship," in P. Auer \& S. Cazes (ed.s), Employment Stability in an Age of Flexibility, ILO, Geneva.

Auer, P. \& T. Kruppe - 1996 - "Monitoring of Labour Market Policy in EU Member States,” in G. Schmid, J. O'Reilly \& K. Schömann (ed.s), International Handbook of Labour Market Policy and Evaluation, Edward Elgar, Cheltenham.

Baker, J. - 2000 - Evaluating the Impact of Development Projects on Poverty, World Bank, Washington, D.C..

Bassanini, A. \& R. Duval - 2006 - "Employment Patterns in OECD Countries: Reassessing the Role of Policies and Institutions," OECD Social, Employment and Migration Working papers no. 35, OECD, Paris.

Bernabè, S. - 2002 - “A Profile of Informal Employment: The Case of Georgia," ILO Employment Sector working paper no. 2002/9, ILO, Geneva.

Bertola, G., T. Boeri \& S. Cazes - 1999 - "Employment Protection and Labour Market Adjustment in OECD Countries: Evolving Institutions and Variable Enforcement," Employment and Training Papers no. 48, ILO, Geneva.

Betcherman, G., M. Godfrey, S. Puerto, F. Rother \& A. Stavreska - 2007 "Global Inventory of Interventions to support Young Workers: Synthesis Report," World Bank, Washington D.C..

Betcherman, G., K. Olivas \& A. Dar - 2004 - "Impacts of Active Labor Market programs: New Evidence from Evaluations with Particular Attention to Developing and Transition Countries," Social Protection Discussion Paper no. 0402, World Bank, Washington, D.C.

BMZ - 2006 - Cornerstones of Youth Employment Promotion in Development Cooperation, Federal Ministry for Economic Cooperation and Development, Division of Development Education and Information, Germany.

Boeri, T. \& K. Terrell - 2002 -“Institutional Determinants of Labor Reallocation in Transition," Journal of Economics Perspectives, vol. 16, no. 1, pp. 51-76. 
Bowers, N., A. Sonnet \& L. Bardone - 1999 - "Giving Young people a Good start: The experiences of OECD Countries," in OECD, The Transition from Education to the Labour Market, pp. 7-86.

Brown, G. \& J. Micklewright - 2004 - "Using International Surveys of Achievement and Literacy: A View from the Outside," UNESCO Institute for Statistics, Montreal.

Canning, M., P. Moock \& T. Heleniak - 1999 - Reforming Education in the Regions of Russia, World Bank, Washington D.C..

Cazes, S. \& A. Nesporova - 2003 - Balancing Flexibility and Security in Central and Eastern Europe, ILO, Geneva.

Cazes, S. \& S. Scarpetta - 1998 - "Labour Market Transitions and Unemployment Duration: Evidence from Bulgarian and Polish Micro-data," Economics of Transition, vol. 6, pp. 113-144.

Chawla, M., G. Betcherman, A. Benrji, A.M. Bakilana, Cs. Feher, M. Mertaugh, M.L. Sanchez Puerta, A. M. Schwartz, L. Sondegaard \& A. Burns - 2007 - From Red to Gray: The "Third Transition" of Ageing Populations in Eastern Europe and the former Soviet Union, World Bank,. Washington D.C..

Dell'Anno, R. \& M. Piirisild - 2004 - "Estimate of Non-Observed Economy in Bosnia and Herzegovina," paper prepared for USAID \& CBBH.

Earle, J. S. \& C. Pauna - 1998 - "Long-term Unemployment, Social Assistance and Labor Market Policies in Romania," Empirical Economics, Vol. 23, no.1/2, pp. 203-235

European Commission - 2003 - Employment in Europe 2003, EC, DG Employment, Social Affairs \& Equal Opportunities, Brussels.

European Commission - 2005 - European Employment Observatory, Review: Autumn 2004, Employment and European Social Fund, Brussels.

European Commission - 2006a - Indicators for Monitoring the Employment Guidelines including Indicators for Additional Employment Analysis: 2006 Compendium, EC, DG Employment, Social Affairs \& Equal Opportunities, Brussels.

European Commission - 2006b - European Employment Observatory, Review: Spring 2005, Directorate-General for Employment, Social Affairs and Equal Opportunities, Brussels.

European Commission - 2007a - "Youth Employment in the EU," Staff working document accompanying the Communication from the Commission on promoting young people's full participation in education, employment and society, Com(2007)498, Brussels. 
European Commission - 2007b - Indicators for monitoring the Employment Guidelines including indicators for additional employment analysis: 2007 compendium, DG Employment, Social Affairs \& Equal Opportunities, EC, Brussels.

Eurostat - 2007 - “Young Europeans Through Statistics," News Release 44/2007.

ETF - 2003a - Regional Paper on Acceding and Candidate Countries, ETF, Turin.

ETF - 2003b - Regional Paper on Eastern Europe and Central Asia, ETF, Turin.

ETF - 2005 - "Key indicators on Vocational Education, Training and Employment in South Eastern Europe," ETF Staff working document.

ETF - forthcoming - Transition from education to work in EU Neighbouring Countries, ETF, Turin.

Fares, J., C. E. Montenegro \& P. F. Orazem - 2006 - "How are Youth Faring in the Labor Market? Evidence from Around the World," World Bank Policy Research Working Paper no. 4071, Washington D.C..

Fay, R.G. - 1996 - "Enhancing the effectiveness of Active Labour Market Policies: Evidence from Programme Evaluations in OECD Countries", Labour market and Social Policy occasional papers no. 18, OECD, Paris.

Fetsi, A. - 2003 - "Vocational Education and Training Developments in South Eastern Europe," ETF working paper, Turin.

Fretwell, D.H., J. Benus \& C.J. O'Leary - 1999 - "Evaluating the Impact of Active Labor Market Programs: Results of Cross-Country Studies in Europe and Central Asia," World Bank, Washington D.C..

Godfrey, M. - 2003 - "Youth Employment Policy in Developing and Transition Countries: Prevention as well as Cure," Social Protection discussion paper series no. 0320, World Bank, Washington, D.C.

Godfrey, M. - 2005 - "Towards a National Action Plan for Youth Employment in the Azerbaijan Republic," Employment Strategy papers no. 2005/04, ILO, Geneva.

Grubb, W.N. \& P. Ryan - 1999 - The Roles of Evaluation for Vocational Education and Training: Plain Talk on the Field of Dreams, ILO, Geneva.

Guarcello, L. M. Manacorda, F. Rosati, J. Fares, S. Lyon \& C. Valdivia - 2005 "School-to-Work transiitons in Sub-Saharan Africa: An Overview," UCW research report.

Henley, A., G. R. Arabsheibani \& F. G. Carneiro - 2006 - "On Defining and Measuring the Informal Sector," World Bank Policy Research Working paper no. 3866, Washington, D.C.. 
Hoşgör, Ş. - 2004 - Status and Trends of Education in Turkey, 1970-2003, background paper, World Bank Review of Education in Turkey

ILO - 1993 - Resolution Concerning Statistics of Employment in the Informal Sector, adopted by the $15^{\text {th }}$ International Conference of Labour Statisticians, ILO, Geneva.

ILO - 1998 - Resolution Concerning the Measurement of Underemployment and Inadequate Employment Situations, adopted by the $16^{\text {th }}$ International Conference of Labour Statisticians, Geneva, ILO.

ILO - 2002a - Women and Men in the Informal Sector: A Statistical Picture, ILO, Geneva.

ILO - 2002b - Decent Work and the Informal Economy, Report VI, ILC 90th session, ILO, Geneva.

ILO - 2006 - Global Employment Trends for Youth, ILO, Geneva.

Ivanov, A., M. Collins, C. Grosu, J. Kling, S. Milcher, N. O'Higgins, B. Slay \& A. Zhelyazkova - 2006 - At Risk: Roma and the Displaced in Southeast Europe, UNDP-RBEC, Bratislava.

Kertesi, G. \& J. Köllő - 2003 - "Fighting "Low Equilibria" by Doubling the Minimum Wage? Hungary's Experiment," Discussion paper no. 970, IZA, Bonn.

Knowles, J.C. \& J.R. Behrman - 2003 - "Assessing the Economic Return to Investing in Youth in Developing Countries," HNP Discussion paper, World bank, Washington D.C..

Kolev, A. \& C. Saget - 2005 - "Towards a Better Understanding of the Nature, Causes and Consequences of Youth Labor Market Disadvantage: Evidence for South-East Europe," Social Protection Discussion Paper no. 0502, World Bank, Washington, D.C.

Korenman, S. \& D. Neumark. - 2000 - "Cohort Crowding and Youth Labor Markets: A cross-national analysis," in D. Blanchflower and R. B. Freeman (ed.s), Youth Employment and Joblessness in Advanced Countries (Chicago: University of Chicago Press, 2000).

La Cava, G. \& S. Michael - 2006 - "Youth in the Northern Caucasus: From Risk to Opportunity," mimeo, World Bank, Washington D.C..

La Cava, G., P. Lyttle \& A. Kolev - 2006 - Young People in South Eastern Europe: From Risk to Empowerment, World Bank, Washington D.C 
Lam, D. - 2006 - "The Demography of Youth in Developing Countries and its Economic Implications," World Bank Policy Research Working Paper no. 4022, Washington D.C..

Lubyova, M. \& J. Van Ours - 1999 - "Unemployment Duration of Job Losers in a Labour Market in Transition," Economics of Transition, Vol. 7, no. 3, pp. 66586.

Micklewright, J. \& Gy. Nagy - 1998 - "The Implications of Exhausting Unemployment Entitlement in Hungary," Budapest University of Economics Working Papers on the Labour Market no. 1998/2.

Neumark, D. \& W. Wascher - 2004 - "Minimum Wages, Labor Market Institutions, and Youth Employment: A Cross-National Analysis" Industrial and Labor Relations Review, Vol. 57, no. 2, pp. 223-248.

Nickell, S. \& B. Bell - 1996 - "Would Cutting Payroll taxes on the Unskilled have a Significant Impact on Unemployment?" Discussion Paper no. 276, CEPR, London.

O'Higgins, N. - 1997 - "The Challenge of Youth Unemployment," International Social Security Review, Vol. 50, no. 4, pp. 63-93, 1997, also available as, Employment and Training Papers no. 7, ILO, Geneva.

O'Higgins, N. - 2001 - Youth Unemployment and Employment Policy: A Global Perspective, ILO, Geneva.

O'Higgins, N. - 2003 - "Trends in the Youth Labor Market in Developing and Transition Countries," Social Protection Discussion Paper no. 0321, World Bank, Washington, D.C.

O'Higgins, N. \& A. Ivanov - 2006 - "Education and Employment Opportunities for the Roma," Comparative Economic Studies, Vol. 48, no. 1, pp. 6-19, 2006

O’Higgins, N., F. Pastore, I. Beleva \& A. Ivanov - 2001 - "Targeting Youth Employment Policy in Bulgaria," Economic and Business Review, Vol.3, no. 2, 2001, pp. 113-135.

O'Leary, C. J. - 1998 - "Evaluating the Effectiveness of Active Labor Programs in Poland," Upjohn Institute Technical Report No. 98-012.

OECD - 2003 - Employment Outlook, OECD, Paris.

OECD - 2006 - Employment Outlook, OECD, Paris.

Puerto, O. S. - 2007 - "International Experience on Youth Employment Interventions: The Youth Employment Inventory," World Bank, Washington D.C. 
Quintini, G. \& S. Martin - 2006 - "Starting Well or Losing Their Way? The Position of Youth in the Labour Market in OECD Countries," OECD Social, Employment and Migration Working papers no. 39, OECD, Paris.

Rosati, F., Z. Özbil \& D. Marginean - 2006 - "School to Work Transitions and Youth Inclusion in Georgia," IBRD, Washington D.C.

Rutkowski, J. - 2006 - "Labor Market Developments During Economic Transition," World Bank Policy Research Working Paper no. 3894, Washington D.C..

Rutkowski, J., S. Scarpetta, A. Banerji, P. O'Keefe, G. Pierre, \& M. Vodopivec 2005 - Enhancing Job Opportunities: Eastern Europe and the Former Soviet Union, World Bank, Washington D.C..

Ryan, P. - 2001 - "The School-to-Work Transition: A Cross-National Perspective," Journal of Economic Literature, Vol. 39, no. 1, pp. 34-92.

Schneider, F. - 2006 - "Shadow Economies and Corruption All Over the World: What Do We Really Know?” Discussion Paper no. 2315, IZA, Bonn.

Shimer, R. - 2001 - "The Impact of Young Workers on the Aggregate Labour Market," Quarterly Journal of Economics, Vol. 116, no. 3, pp. 969-1007.

Sianesi, B. \& J. Van Reenen - 2003 - "Returns to Education: Macroeconomics," Journal of Economic Surveys, Vol. 17, no. 2, pp. 157-200.

Stavreska, A. - 2007 - "Europe and Central Asia Youth Employment Inventory: Summary Report," World Bank, Washington D.C..

UNESCO - 2005 - Children Out of School: Measuring Exclusion from Primary Education, UNESCO, Institute for Statistics, Montreal.

Van Reenen, J. - 2003 - "Active Labour Market Policies and the British New Deal for the Young Unemployed in Context," NBER Working Paper no. 9576

Vodopivec, M., A. Wörgötter \& R. Dhushyanth - 2003 - "Unemployment Benefit Systems in Central and Eastern Europe: A Review of the 1990s," Social Protection discussion paper series no. 0310, World Bank, Washington, D.C.

World Bank - 2005 - Expanding Opportunities and Building Competencies for Young People: A New Agenda for Secondary Education, World Bank, Washington, D.C.

World Bank - 2006a - World Development Report 2007: Development and the Next Generation, World Bank, Washington D.C..

World Bank - 2006b - Serbia: Labor Market Assessment, World Bank, Washington, D.C. 
World Bank - 2006c - Fiscal Efficiency and Vocational Education in the EU8 Countries, World Bank, Washington, D.C.

World Bank - (forthcoming) - Productivity Growth, Job Creation, and Demographic Change in Eastern Europe and the Former Soviet Union, Office of the Chief Economist, ECA, World Bank, Washington.

Yemtsov, R. G., S. R. Cnobloch \& C. Mete - 2006 - "Evolution of the Predictors of earnings during Transition," mimeo, World Bank, Washington D.C. 
Figure 1: Throughout the region transition meant recession followed by recovery.
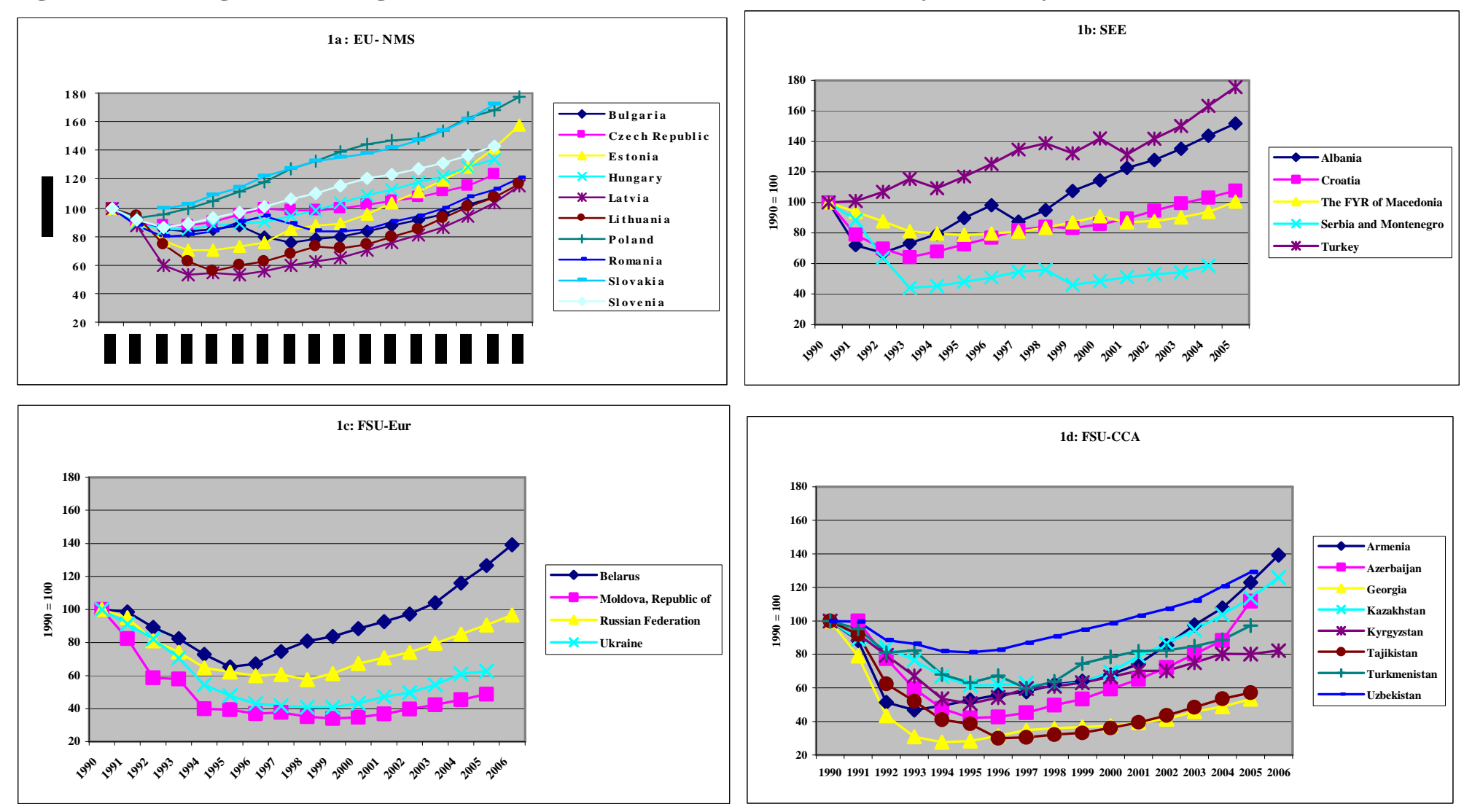

Source: Author calculations on the basis of UNECE database (http://www.unece.org/stats/data.htm).

Note: the figures report GDP growth in ECA 1990-2005, PPP in USD of 2000, 1990=100 (For Slovakia, 1992=100). 
Figure 2: But recovery did not mean returning to previous levels of employment
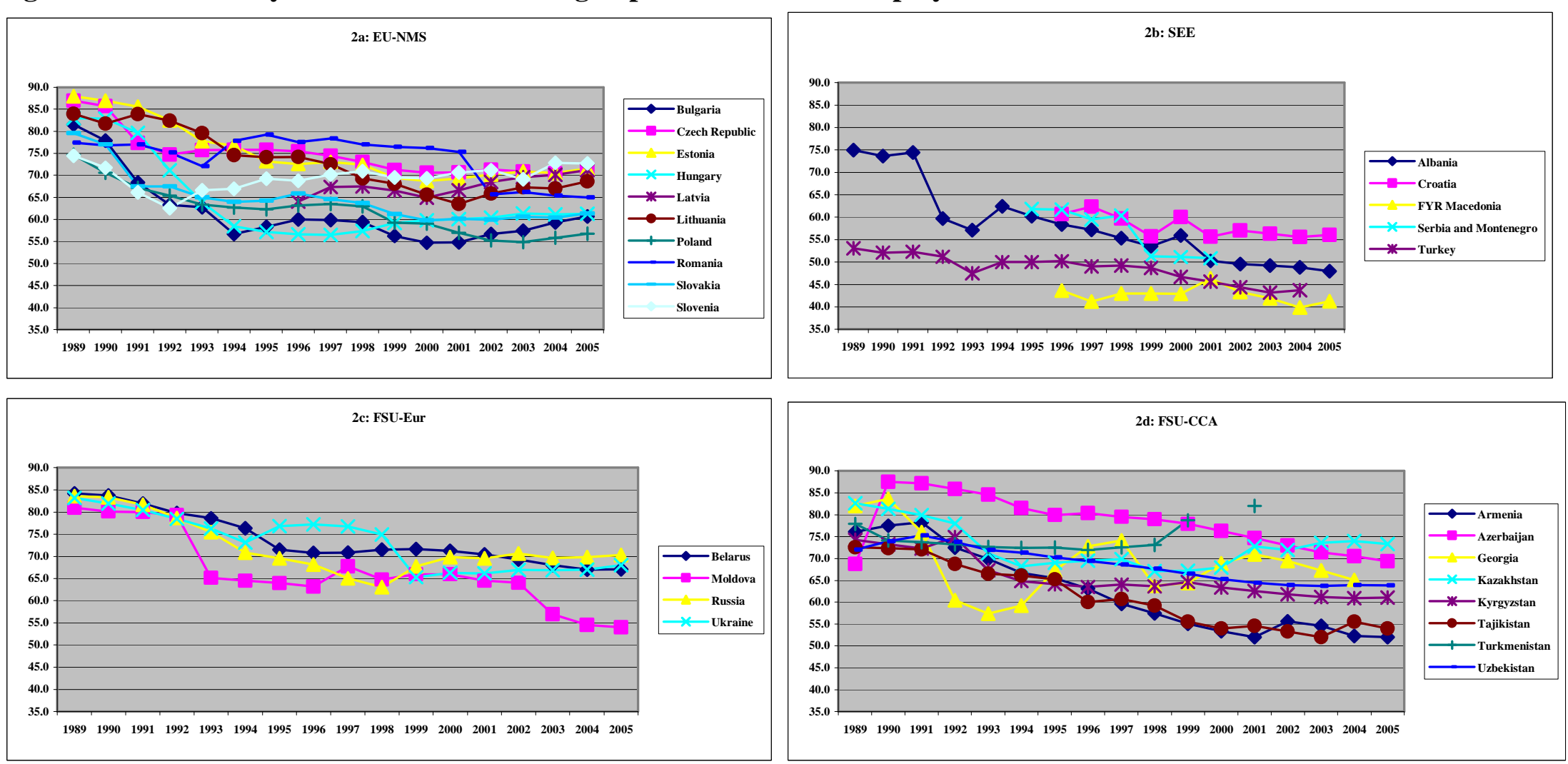

Source: Based on data from the Transmonee 2007 database, UNICEF IRC, Florence (http://www.unicef-icdc.org/resources/) except for Turkey taken from ILO-KILM database (http://www.ilo.org/public/english/employment/strat/kilm/index.htm).

Note: The figures report employment rates in ECA, for the working age population (15-59), 1989-2005, (Turkey = 15+ age-group). 
Figure 3: So employment rates in the region remain well below the EU-15 average and far from the Lisbon 2010 target of $70 \%$.

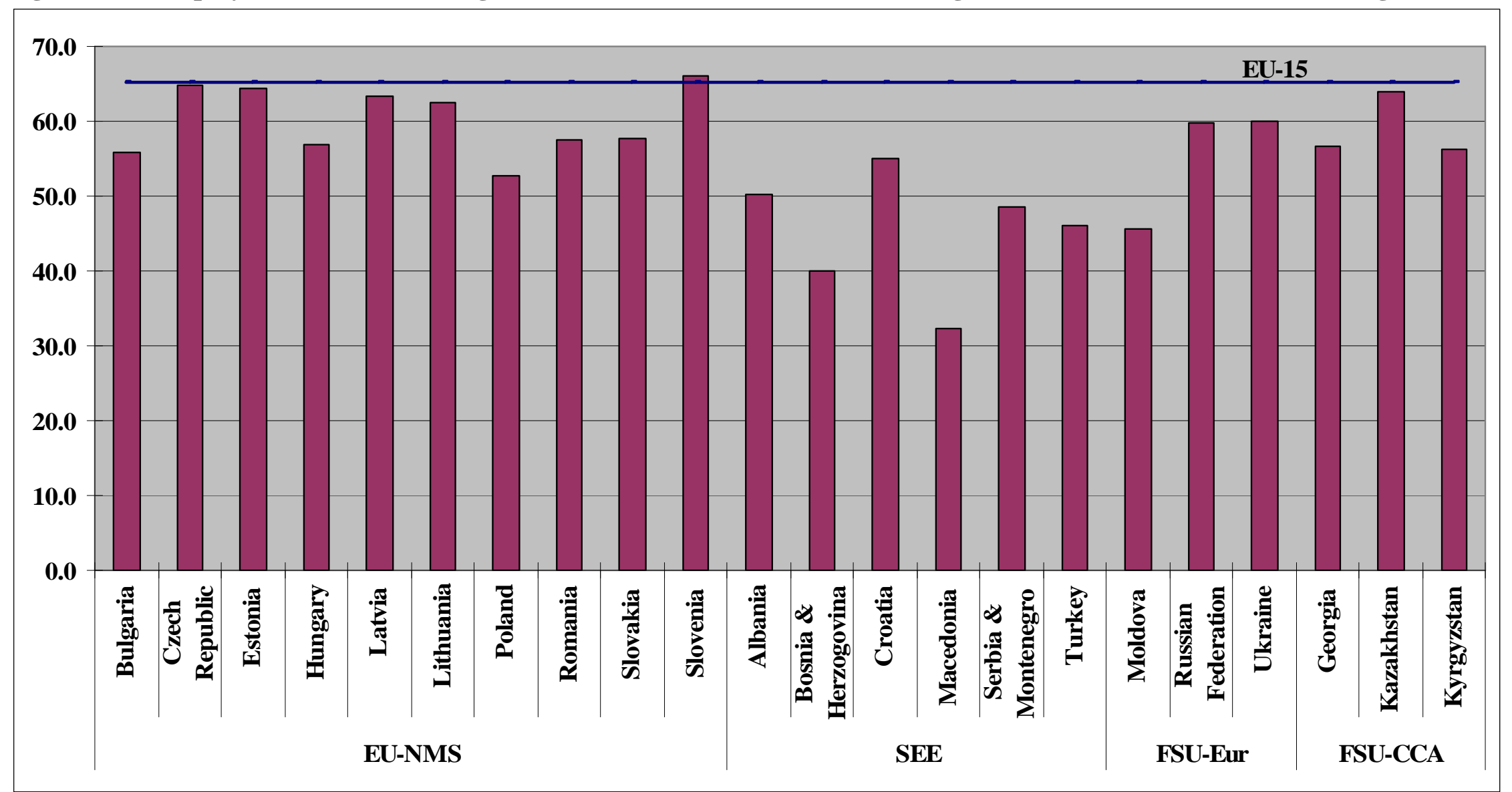

Source: European Commission (2006: EU-NMS, Croatia \& Turkey), ILO-KILM (Albania, Macedonia, Moldova, Russia, Georgia, Kazakhstan \& Kyrgyzstan), and Rutkowski (2006: Bosnia \& Herzegovina, Serbia \& Montenegro and Ukraine).

Note: The figure reports employment rates for $\mathbf{2 0 0 5}$ for 15-64 year olds except Albania, Macedonia, Moldova, Georgia \& Kazakhstan 2004 for the population over-14; Russia, 2004 for the population aged 15-72; Kyrgyzstan 2002 for the population over-14; and, Bosnia \& Herzegovina, Serbia \& Montenegro and Ukraine 2001. 
Figure 4: Productivity has recovered in EU-NMS and some SEE countries, but in FSU remains well below pre-transition levels.
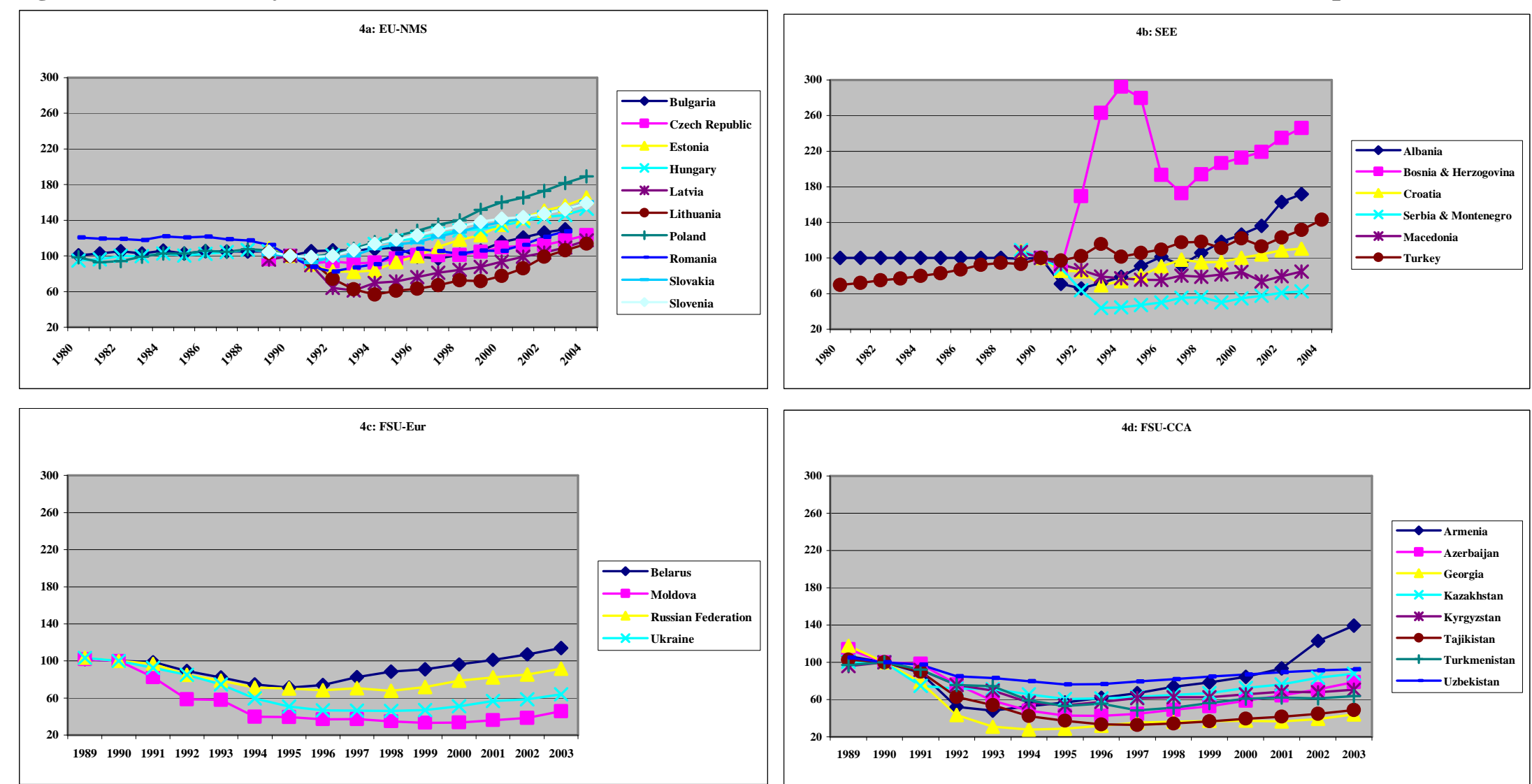

Source: Author calculations Based on ILO-KILM database (http://www.ilo.org/public/english/employment/strat/kilm/index.htm).

Note: The figures report indices of GDP per employee, 1980-2004 (according to availability), in ppp USD 1990 with $1990=100$. 
Figure 5: So that productivity in EU-NMS countries is well above productivity in the FSU.

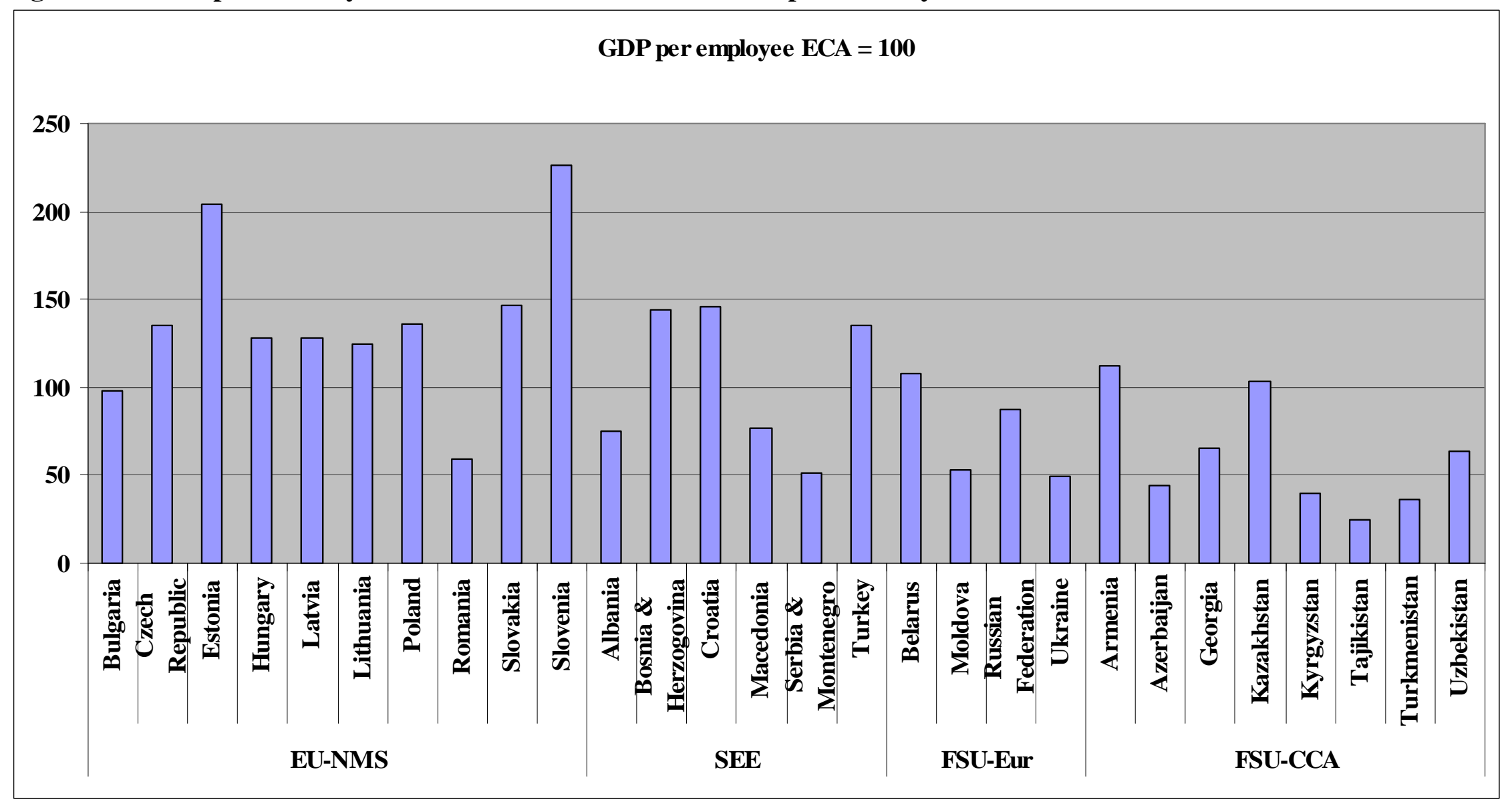

Source: Author calculations Based on ILO-KILM database (http://www.ilo.org/public/english/employment/strat/kilm/index.htm). Note: The figure reports GDP per employee, 2003 relative to the ECA average $(\mathrm{ECA}=100)$. 
Figure 6: Even in countries where the youth peak has already been reached, many countries are currently undergoing a relative boom in youth populations
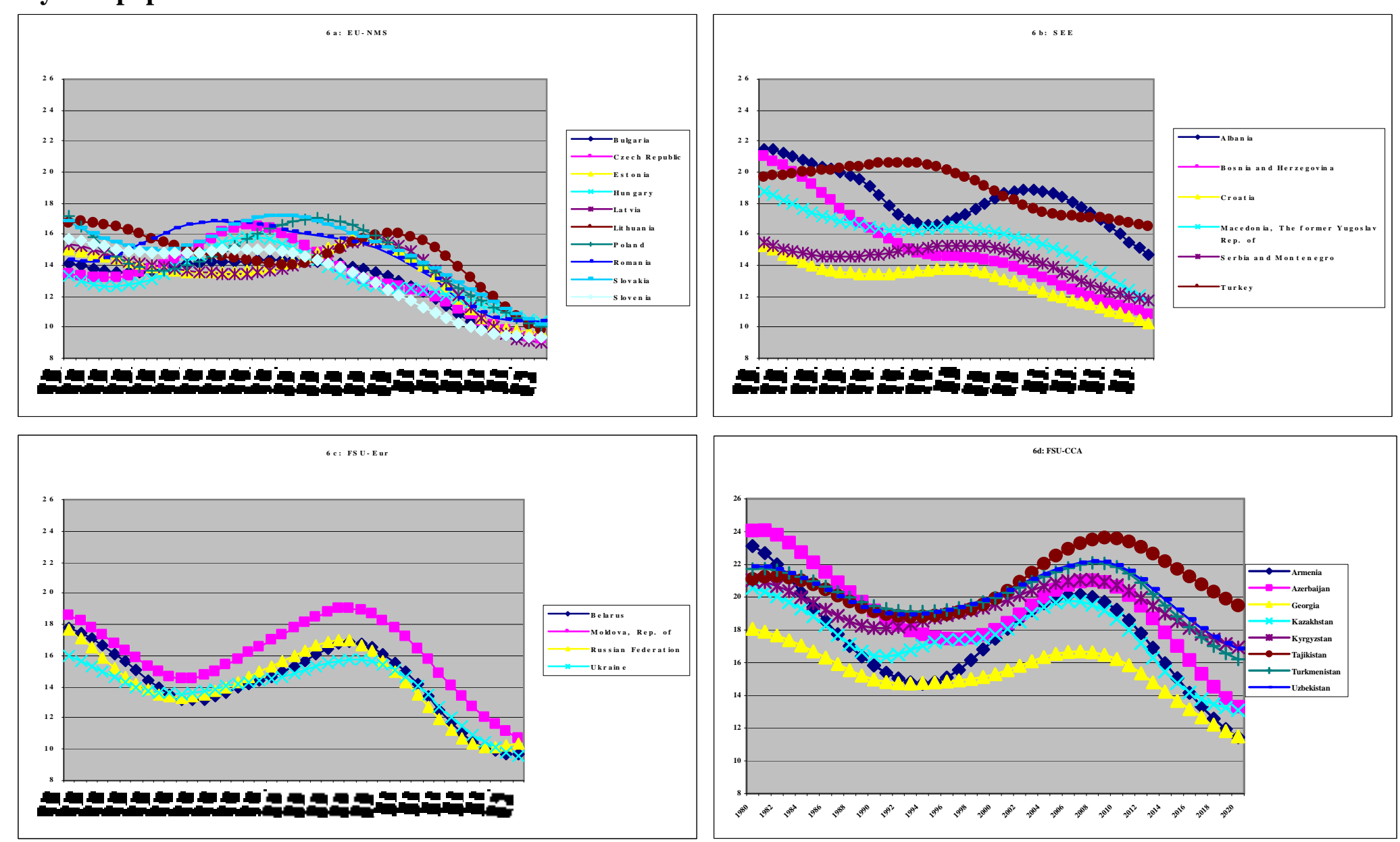

Source: Author calculations based on ILO - Economically Active Population, Estimates \& Projections 1980-2020, $\mathrm{V}^{\text {th }}$ edition, 2007.

Note: The figures report estimates (1980-2003) and projections (2004-2020) of the youth population as a \% of the total population in ECA countries. 
Figure 7: The Labour Force Participation Rates of Young People are falling throughout the region
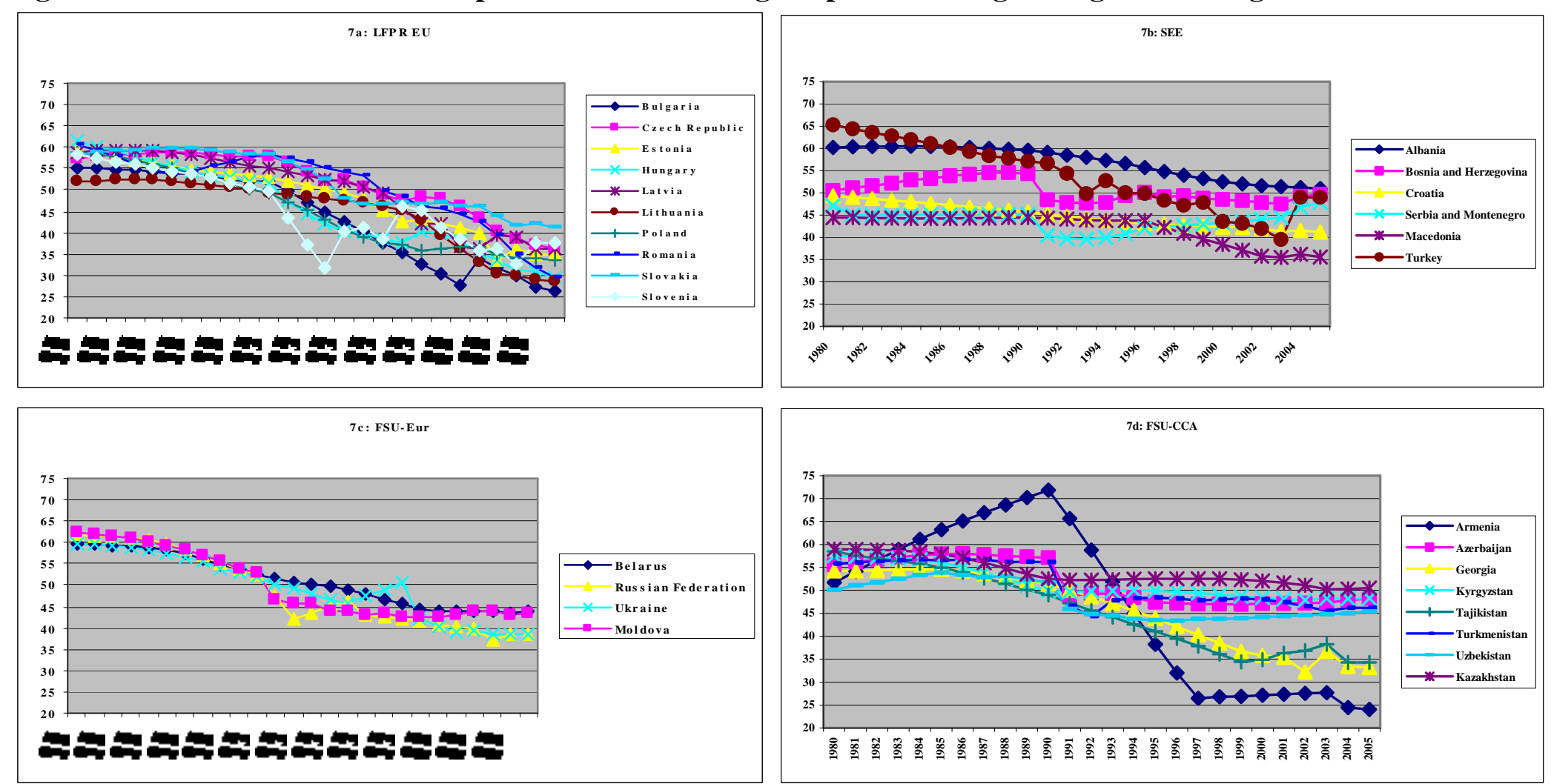

Source: Based on ILO-KILM database (http://www.ilo.org/public/english/employment/strat/kilm/index.htm).

Note: The figure reports labour market participation rates of young people (15-24), 1980-2005. Much of the data in these figures have been interpolated so not too much significance should be given to single observations, although, for the most part, the identified trends can be considered reliable. One exception is Armenia which is based on very few data points and should be considered relatively reliable only after 1997. 
Figure 8: Labour Force Participation Rates of Young Women (15-24) 1980-2005.
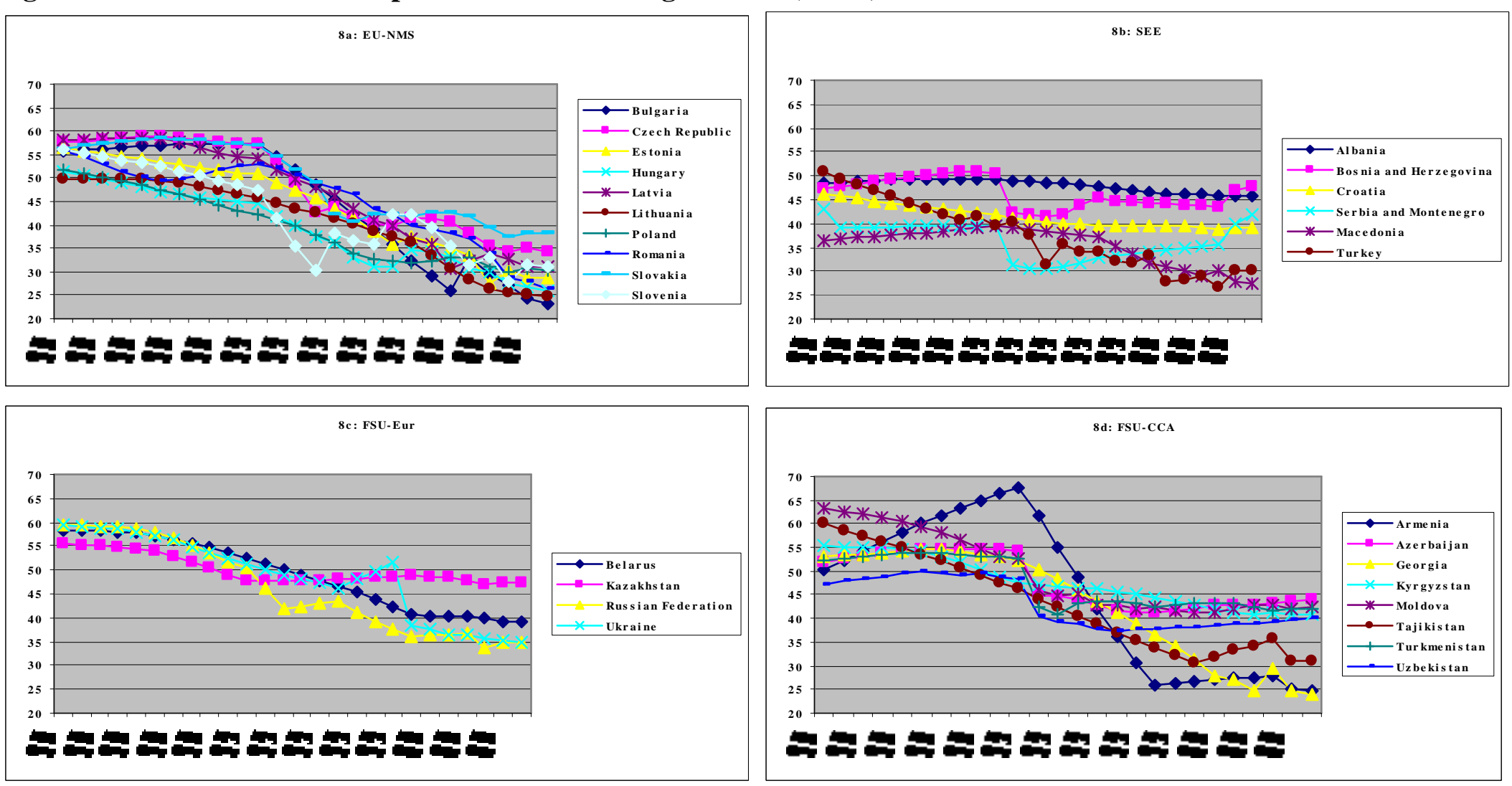

Source: Based on ILO-KILM database (http://www.ilo.org/public/english/employment/strat/kilm/index.htm). 
Figure 9: Labour Force Participation Rates of Young Men (15-24) 1980-2005.
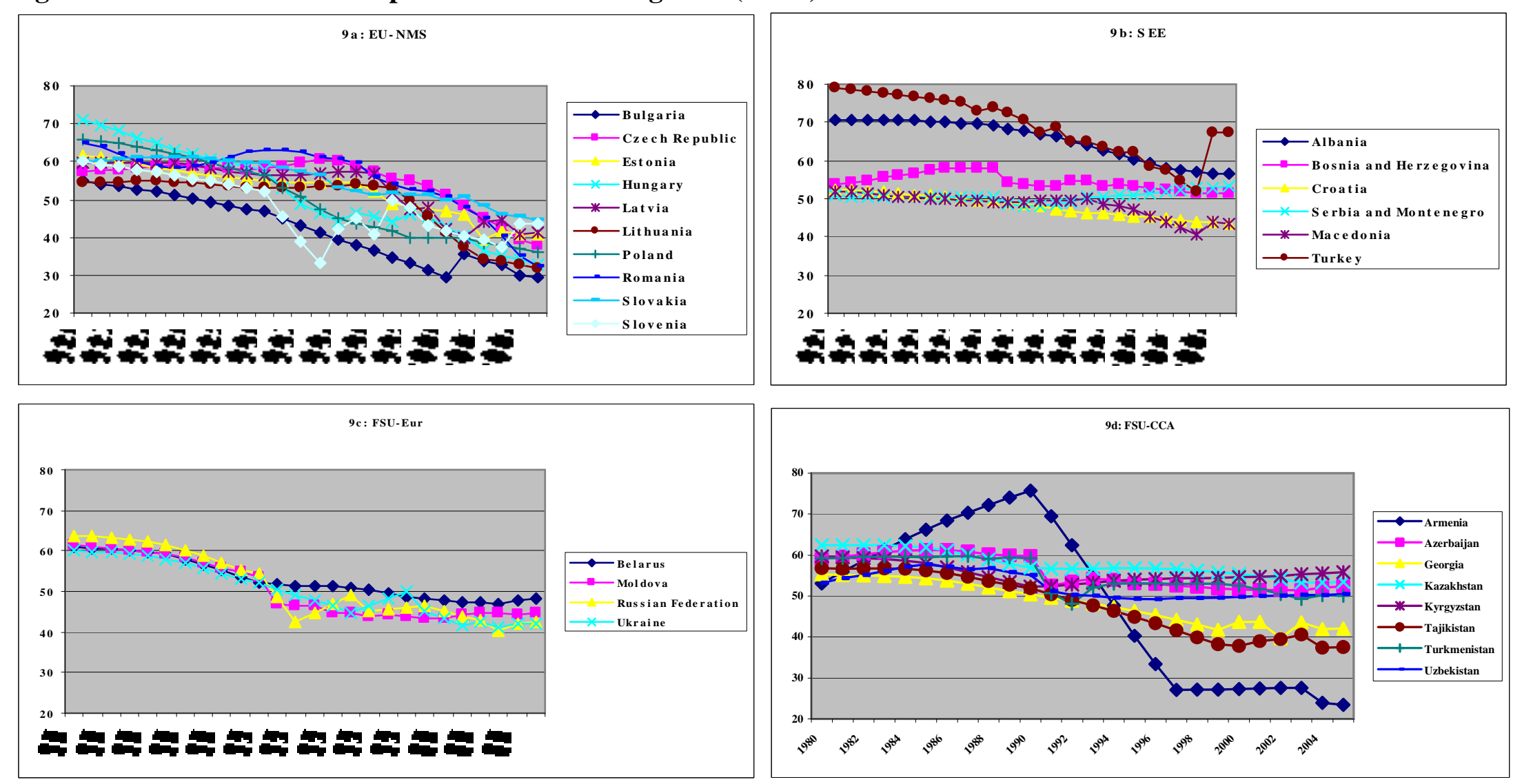

Source: Based on ILO-KILM database (http://www.ilo.org/public/english/employment/strat/kilm/index.htm). 
Figure 10: With some notable exceptions, most countries in the region compare favorably to the EU-15 and many have already reached the Lisbon target for the completion of secondary education.

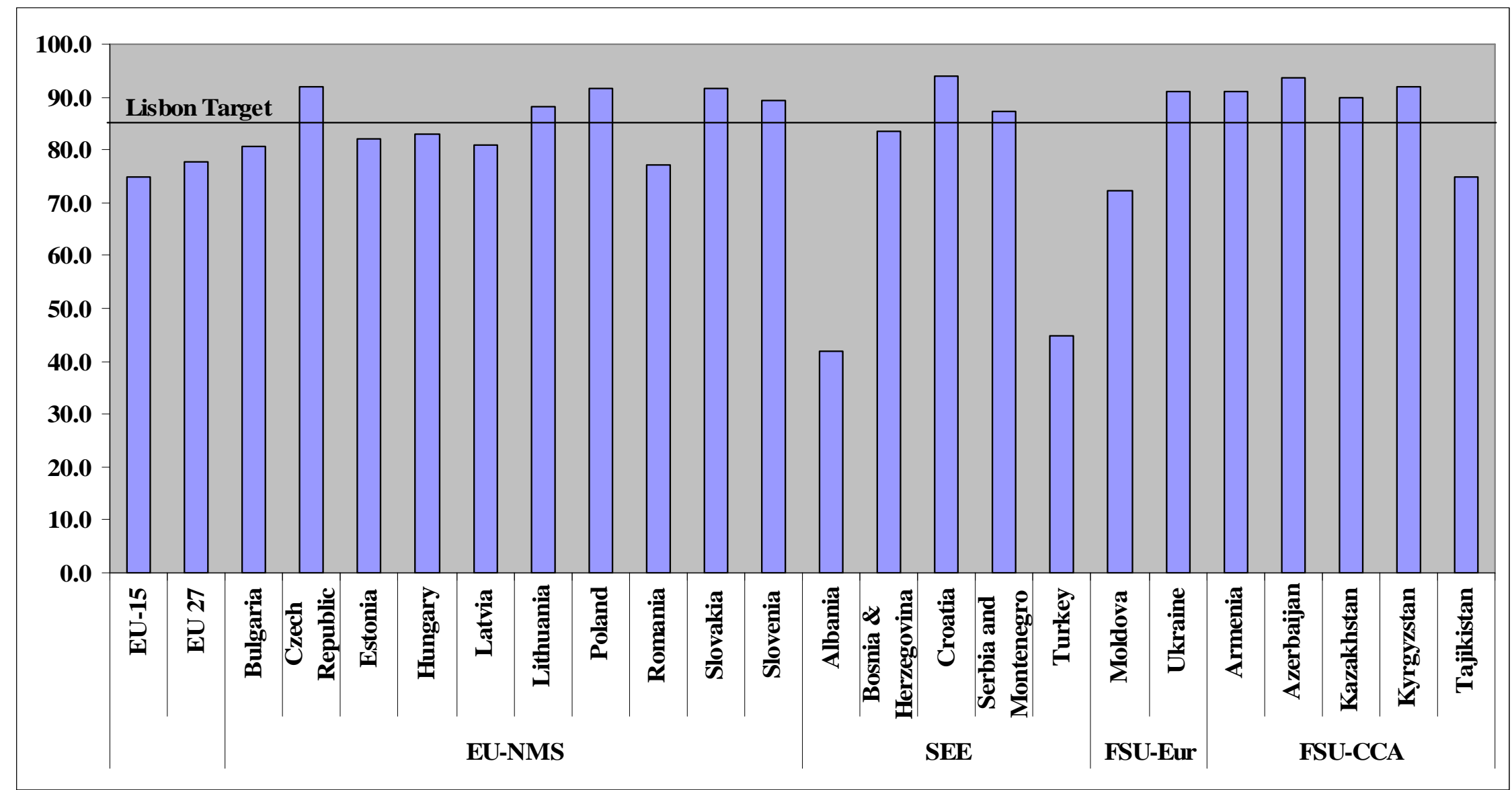

Source: Eurostat (http://epp.eurostat.ec.europa.eu) for EU-15, EU-27, EU-NMS, Croatia and Turkey; Bosnia \& Herzegovina, own calculations on the 2006 LFS; all other countries, own calculations on the World Bank database of household surveys.

Notes: The figure reports the \% of 20-24 year olds who have completed upper secondary education. Data are for 2006 except, Albania, Croatia and Serbia \& Montenegro (2005); Moldova and Tajikistan (2004); and, Armenia, Azerbaijan, Kazakhstan and Kyrgyzstan (2003). 
Figure 11: Those which don't also have problems with early school leaving

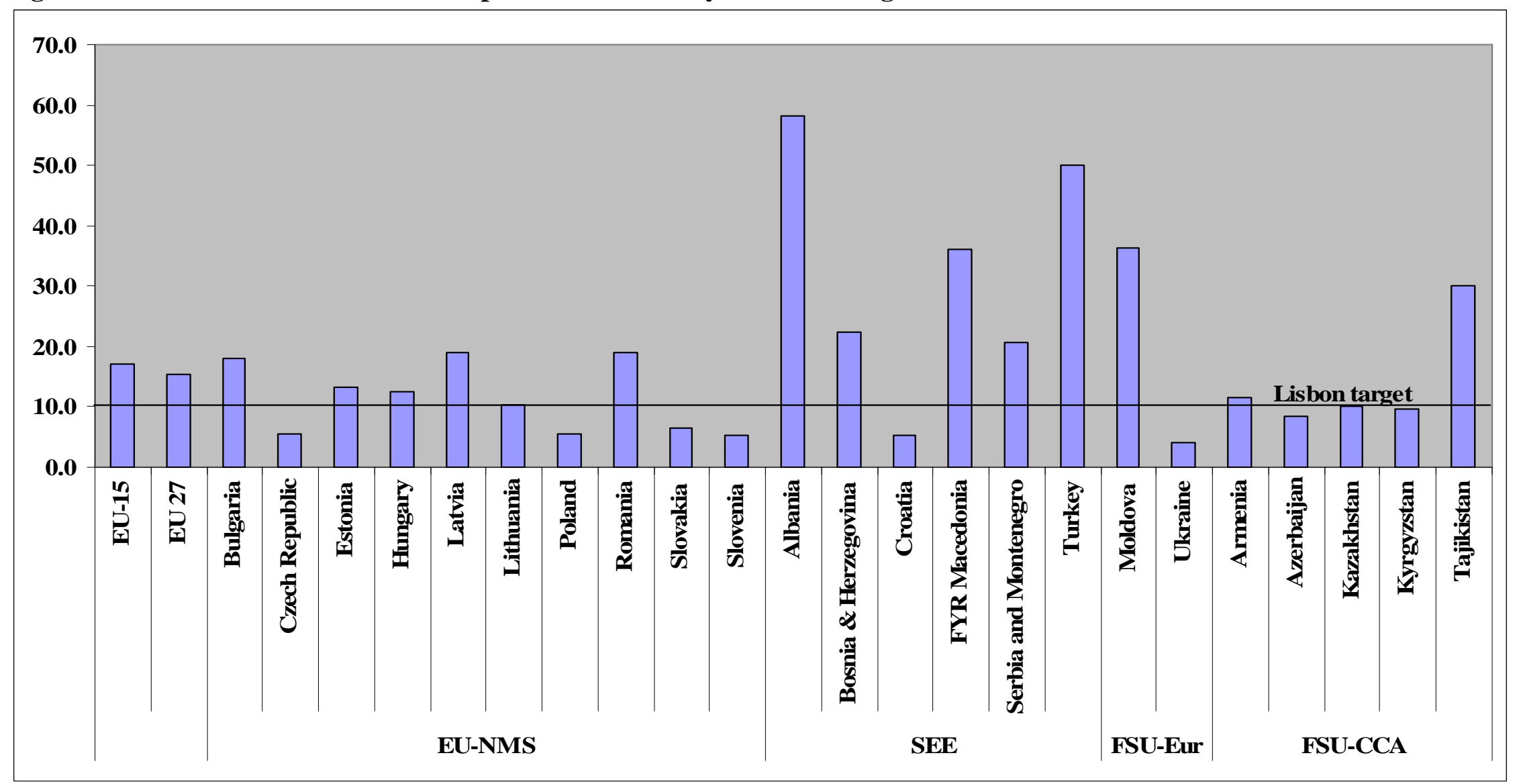

Source: Eurostat (http://epp.eurostat.ec.europa.eu) for EU-15, EU-27, EU-NMS, Croatia and Turkey; Macedonia (ETF 2005); Bosnia \& Herzegovina, own calculations on the 2006 LFS; all other countries, own calculations on the World Bank database of household surveys.

Note: The figure reports the \% of 18-24 year olds who have not completed secondary education and are not in education or training. Data are for 2006 except, Albania, Croatia and Serbia \& Montenegro (2005); Macedonia, Moldova and Tajikistan (2004); and, Armenia, Azerbaijan, Kazakhstan and Kyrgyzstan (2003). 
Figure 12: In most countries, the educational attainment of young women is better than that of young men

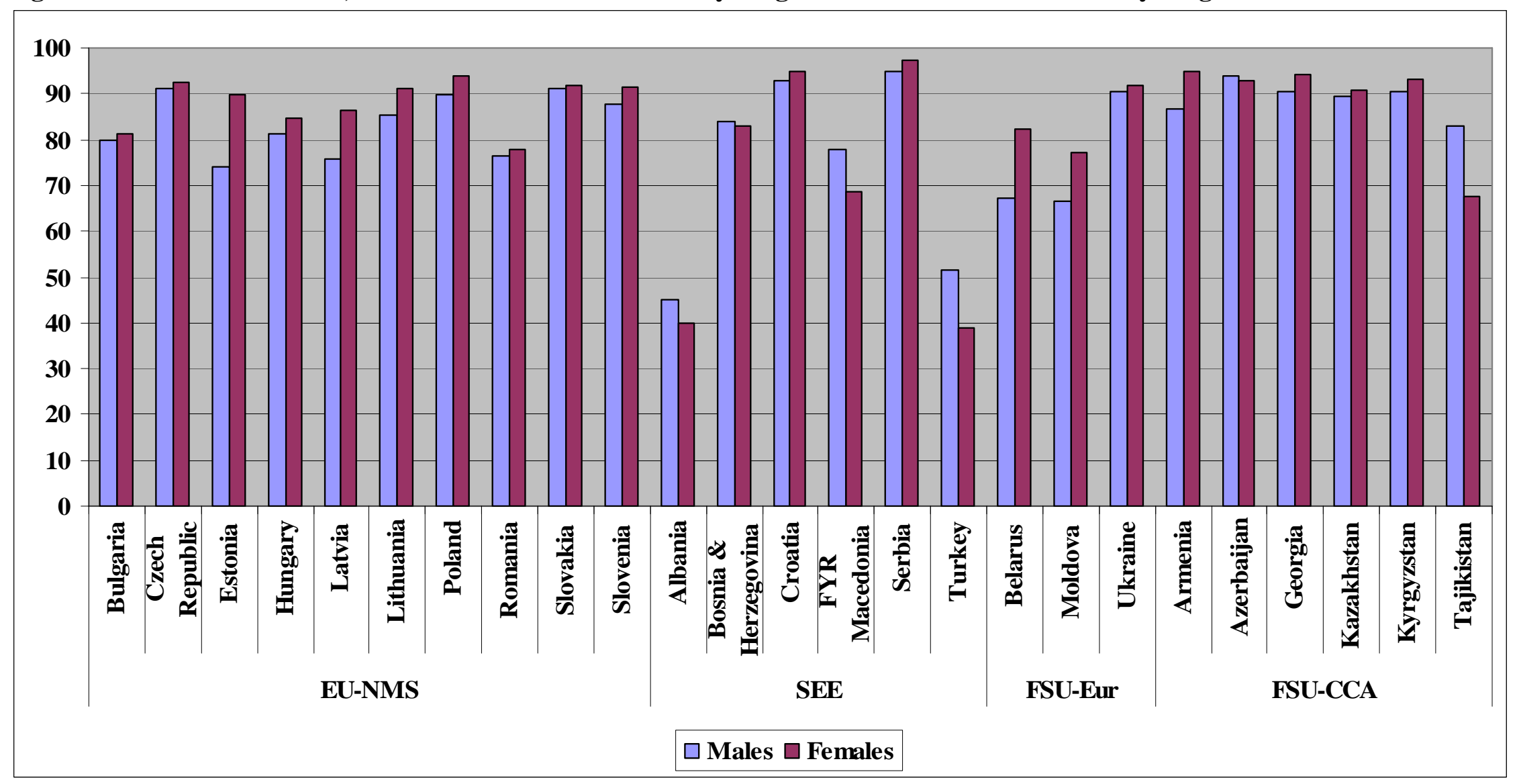

Source: Eurostat (http://epp.eurostat.ec.europa.eu) for EU-15, EU-27, EU-NMS, Croatia and Turkey; Macedonia (ETF 2005); Bosnia \& Herzegovina, own calculations on the 2006 LFS; all other countries, own calculations on the World Bank database of household surveys.

Note: The figure reports the \% of 20-24 year olds who have completed upper secondary education by sex. Data are for 2006 except, Albania, Croatia, Georgia and Serbia (2005); Macedonia, Moldova and Tajikistan (2004); Armenia, Azerbaijan, Kazakhstan and Kyrgyzstan (2003); and Belarus (2002). 
Figure 13: But living in rural areas means also getting a lower level of education - in some cases much lower

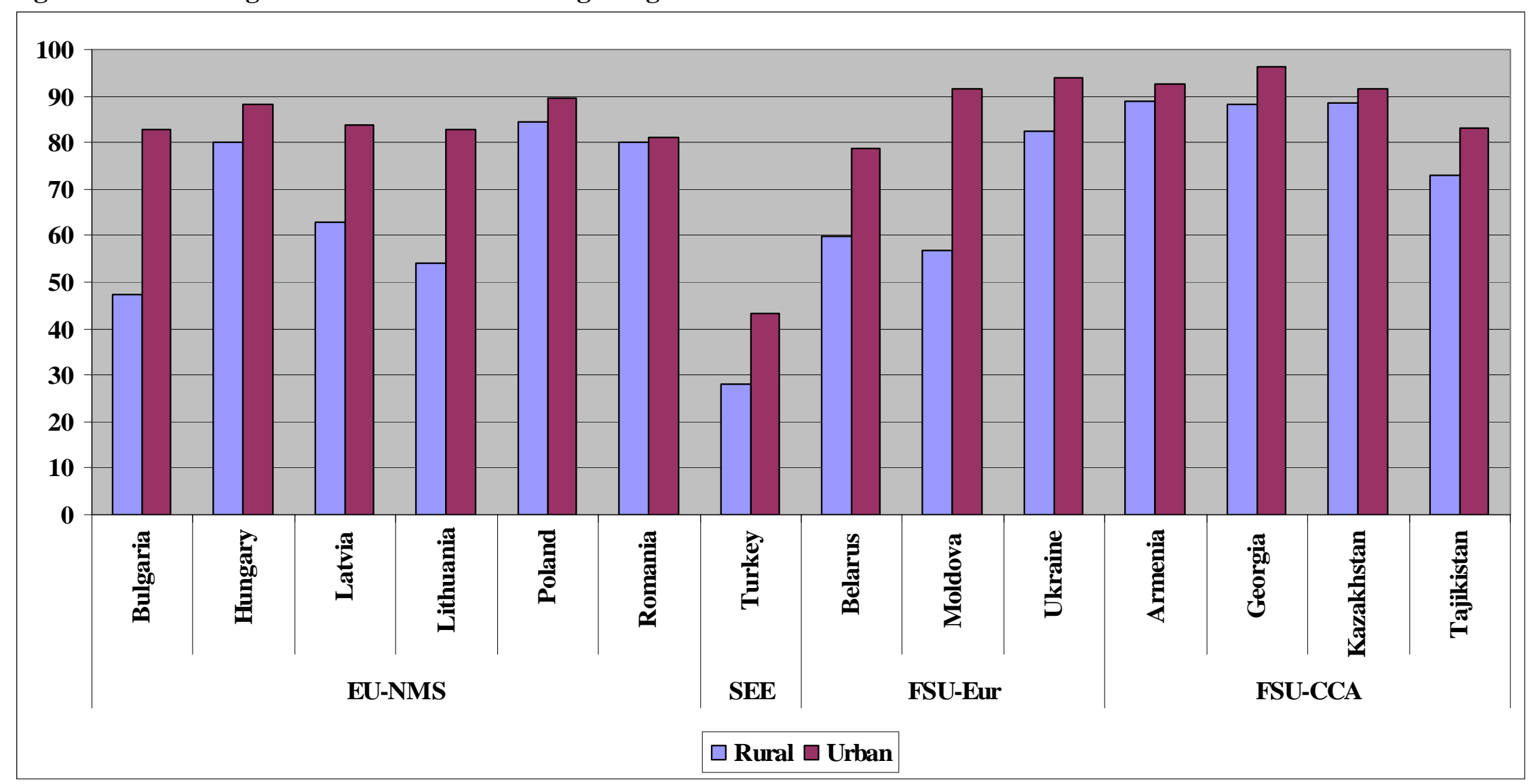

Source: own calculations on the World Bank database of household surveys.

Note: The figure reports the \% of 20-24 year olds who have completed upper secondary education by rural/urban residence. Data are the most recent available in the database which means: Ukraine (2006); Georgia, Poland and Romania (2005); Hungary, Latvia, Lithuania, Moldova and Tajikistan (2004); Armenia, Bulgaria and Kazakhstan (2003); and, Belarus (2002). 
Figure 14: Increasing participation in secondary education in EU-NMS has lead to widening of educational gaps between EU-NMS and the rest of the region
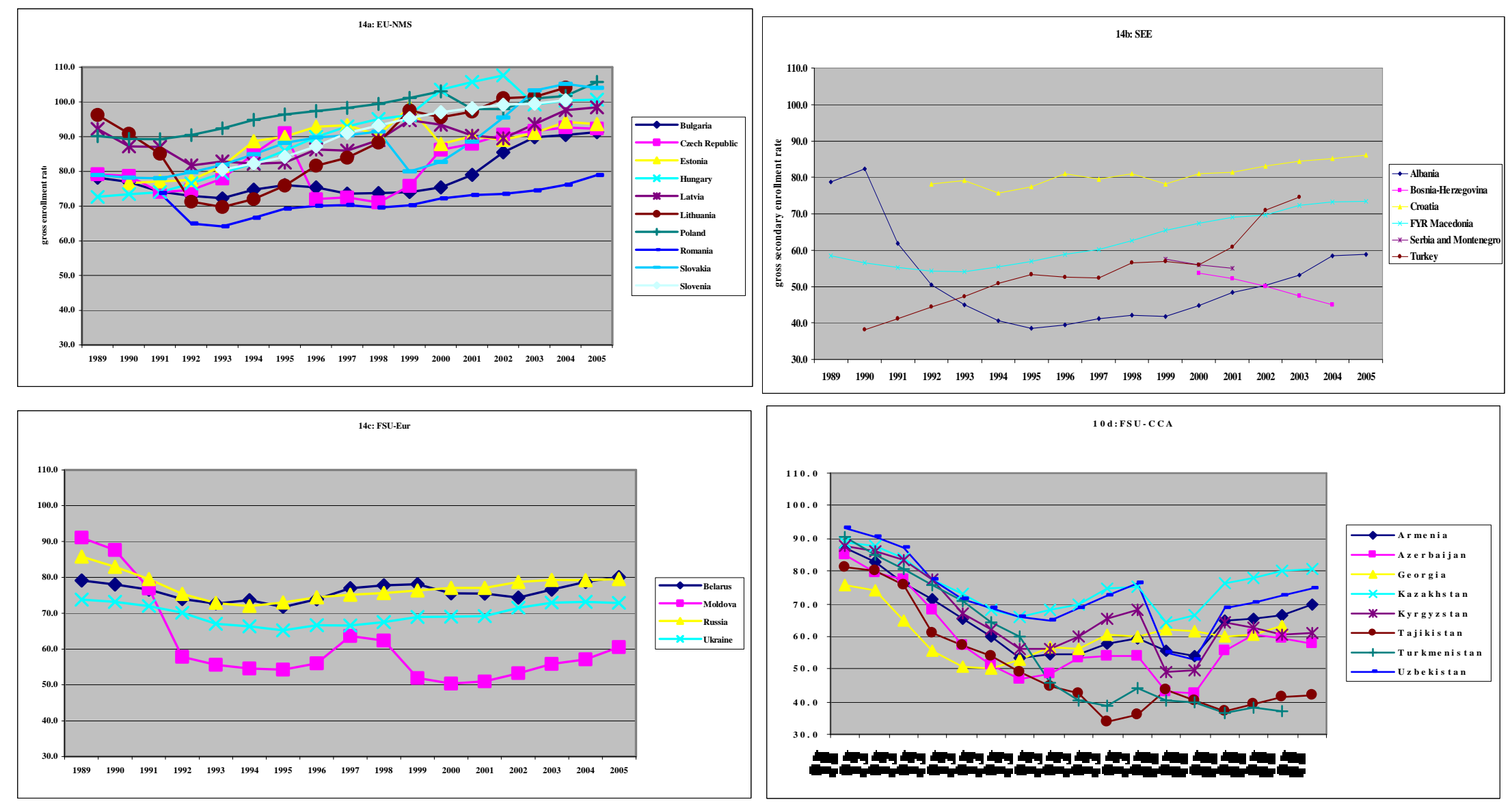

Source: Based on data from the Transmonee 2007 database, UNICEF IRC, Florence (http://www.unicef-icdc.org/resources/) except Turkey which uses data reported in Hoşgör (2004).

Note: the figure reports gross enrollment rates in secondary education, 1989-2005. 
Figure 15: Participation in tertiary education has been increasing throughout the ECA region although much faster in EU-NMS
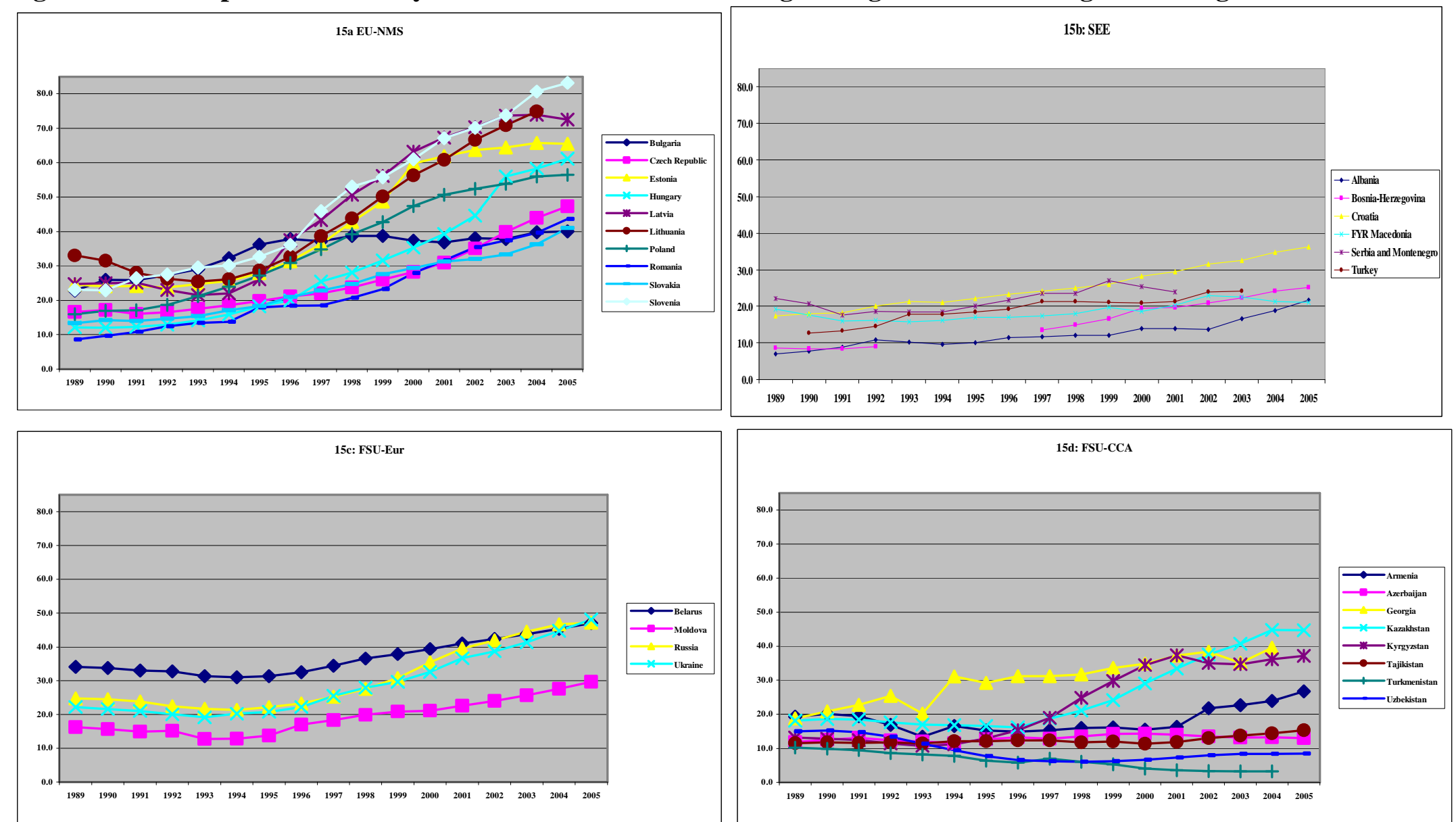

Source: Based on data from the Transmonee 2007 database, UNICEF IRC, Florence (http://www.unicef-icdc.org/resources/) except Turkey which uses data reported in Hoşgör (2004).

Note: the figure reports gross enrollment rates in tertiary education, 1989-2005. 
Figure 16: The incidence of youth unemployment is highest in SEE, but it is also substantial in EU-NMS.
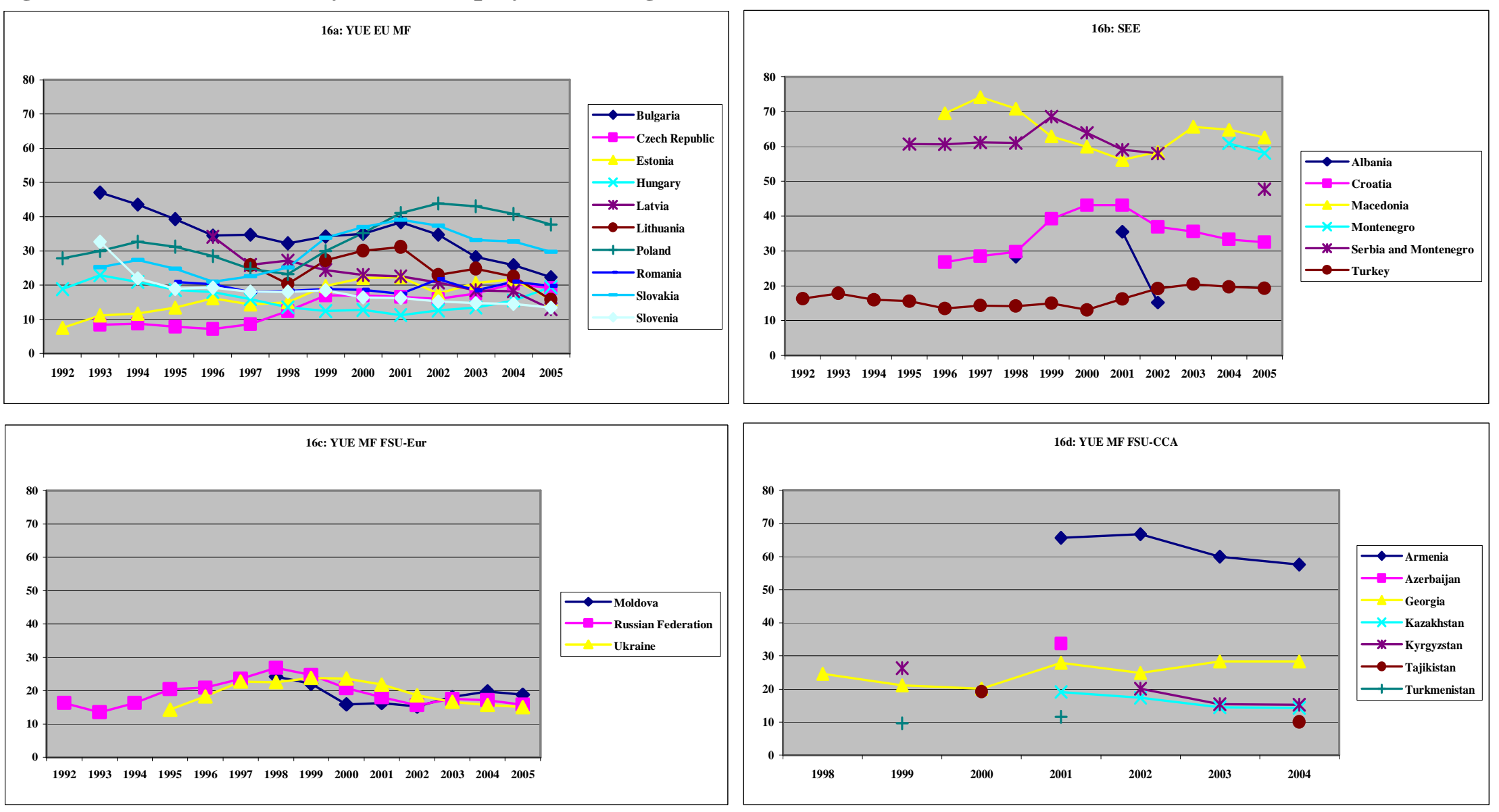

Source: Compiled from ILO-KILM, Transmonee 2007 \& UNECE database - see, previous figures for web addresses.

Note: The figure reports youth unemployment rates, 1992-2005, based on LFS data and ILO definition. 
Figure 17: The ratio of youth to adult unemployment rates bears no relation to the youth unemployment rate per se

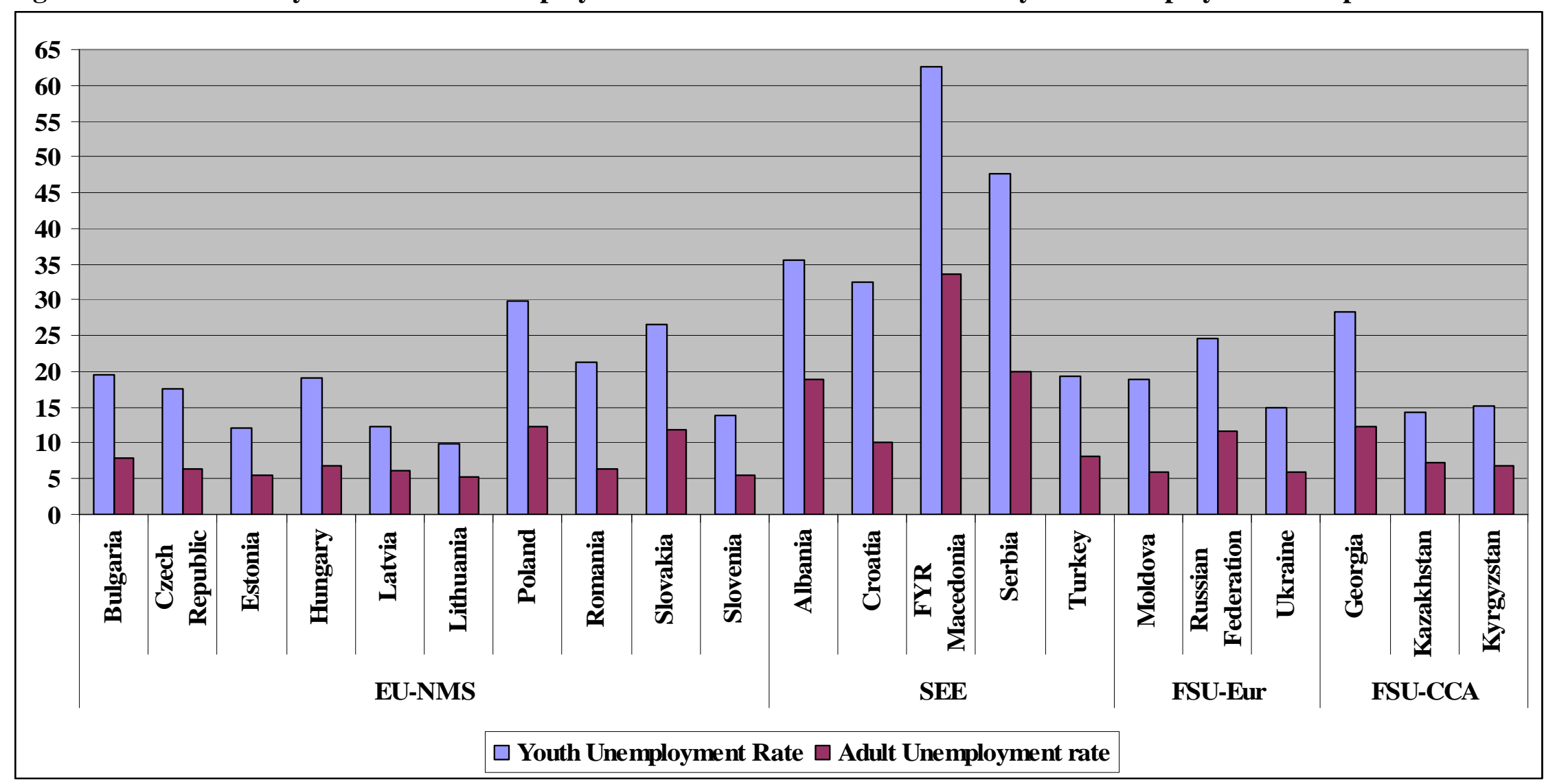

Source: EU-NMS countries - EC(2007b), otherwise ILO-KILM database (http://www.ilo.org/public/english/employment/strat/kilm/index.htm) except for Serbia taken from World Bank (2006b).

Note: The figure reports the Youth (15-24) and Adult unemployment rates. For EU-NMS countries, ratios are for 2006, otherwise 2005 except, Albania (2001), Russian Federation (1999), Kazakhstan and Kyrgyzstan (2004). For EU-NMS countries \& Serbia, 'adults' are defined as 25-54 year olds. In other countries they cover the age groups 25-72, 25-74 or 25+. On the basis of the EC (2007b) paper which reports the ratio for both types of 'adult' definition, one may assert that the difference in 'adult' age groups makes very little difference in the reported ratio between youth and adult rates. 
Figure 18: But the ratio is high and in many countries is getting worse

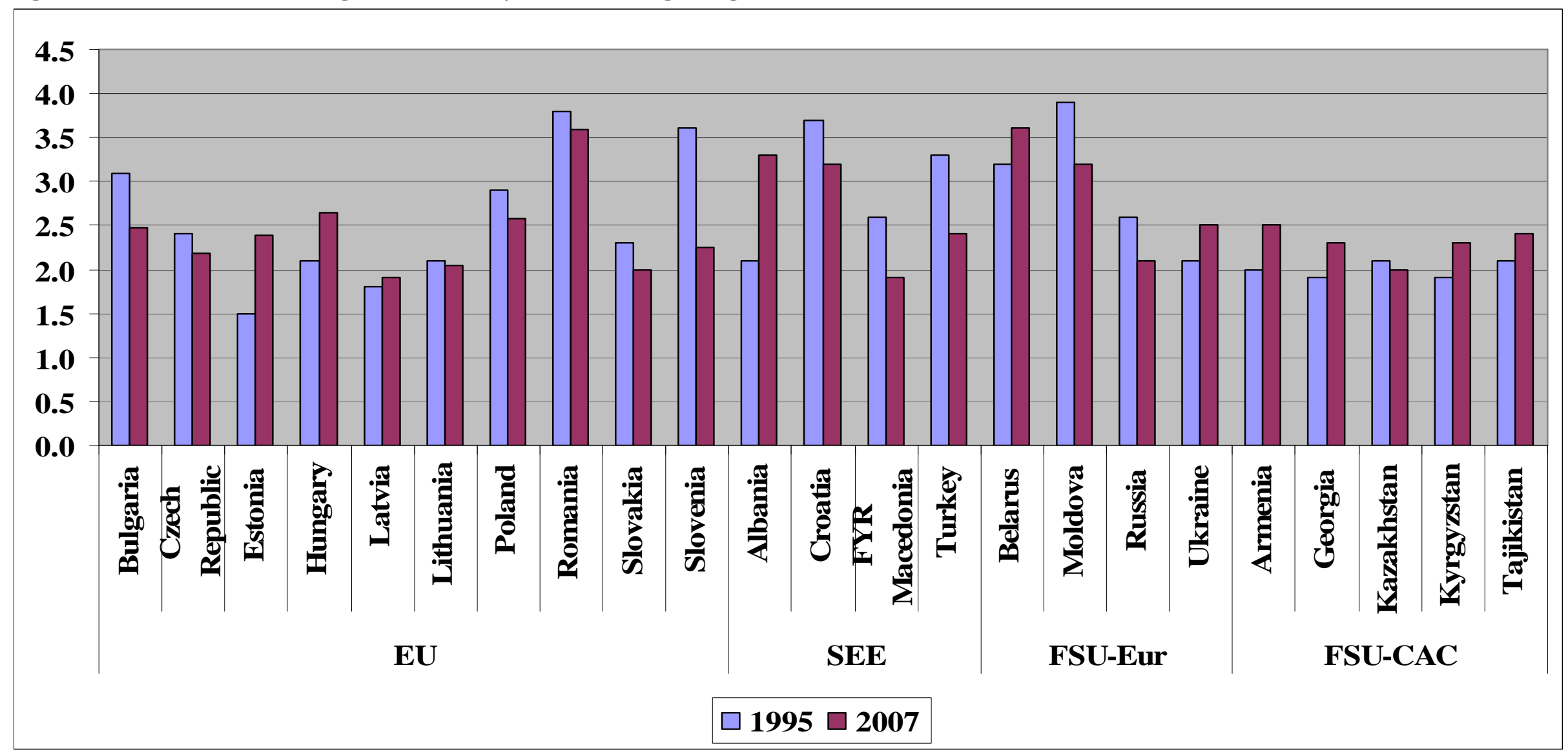

Source: EU-NMS countries - author calculations on ILO-KILM database, EC(2008) and World Bank database of household surveys.

Note: The figure reports the ratio of Youth (15-24) to Adult unemployment rates. The base year employed is 1995 except: Latvia (1996), Lithuania (1997), Belarus,

Croatia \& FRY Macedonia (1998), Armenia, Georgia \& Tajikistan (1999), Albania \& Kazakhstan (2001), Ukraine \& Kyrgyzstan (2002). The most recent year employed is

2007 except: Russia (1999), Belarus (2002), Armenia (2003), Kazakhstan \& Kyrgyzstan (2004) and Albania, Croatia, FRY Macedonia, Turkey, Moldova, Ukraine \& Georgia (2005). 
Figure 19: Youth jobless rates provide a rather different picture to youth unemployment rates.

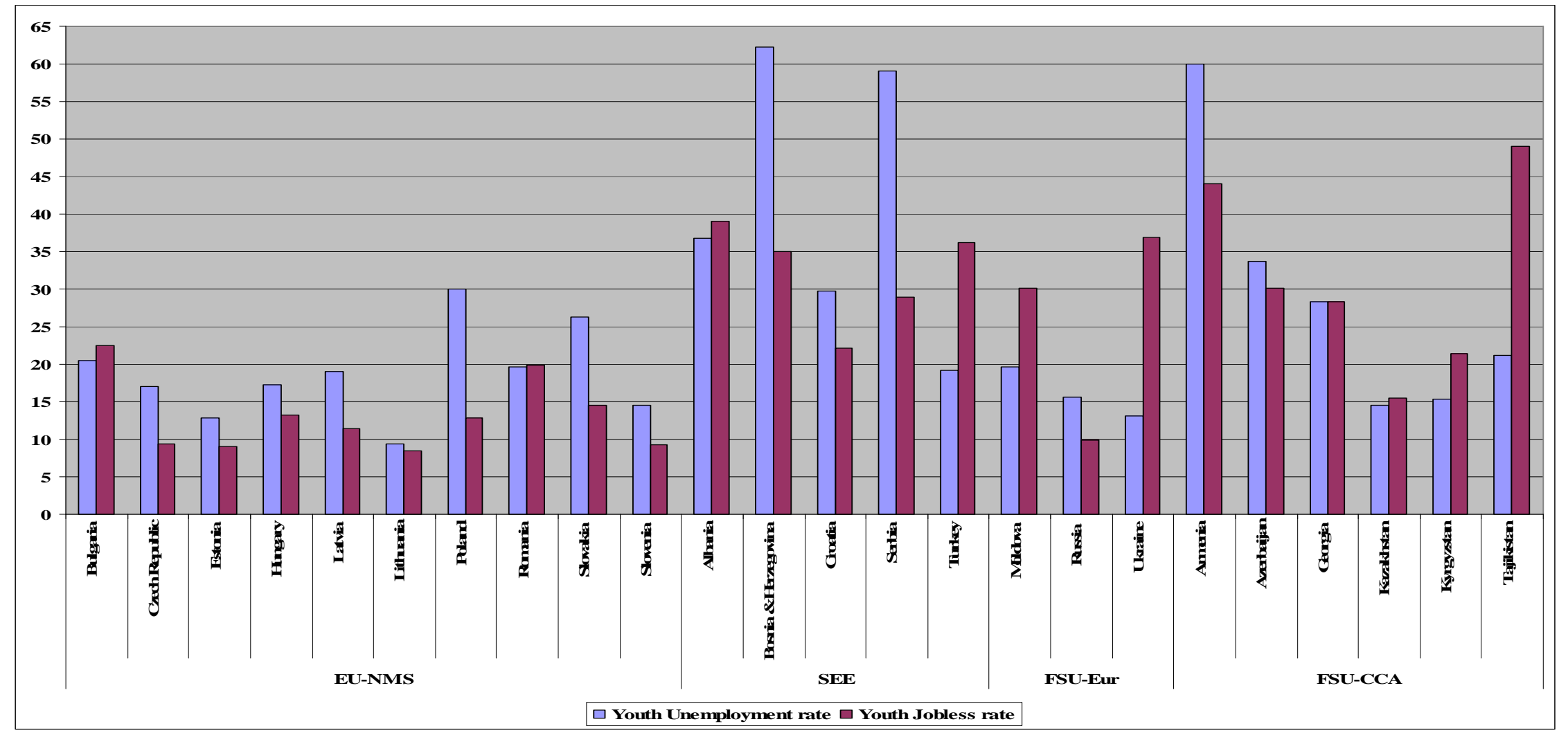

Source: Youth unemployment: EU-NMS - EC (2007a), Bosnia \& Herzegovina, own calculations on the basis of the 2006 LFS, otherwise as figure 16; Youth joblessness EU-NMS - EC (2007b), for other countries - Own calculations on World Bank database of Household Surveys apart from Bosnia \& Herzegovina, own calculations on the basis of the 2006 LFS

Note: The figure reports Youth unemployment and Jobless Rates for ECA. The youth (or adult) jobless rate is calculated as number of young people (adults) who are neither in employment or education as a percentage of the youth (adult) population. Data (for both unemployment and joblessness) are for 2006 except, Albania, Croatia, Georgia and Serbia (2005); Macedonia, Moldova and Tajikistan (2004); Armenia, Azerbaijan, Kazakhstan and Kyrgyzstan (2003); and Russia (1999). 
Figure 20: High youth joblessness is closely related to poor educational attainment in countries, although the relation is weaker in FSUCCA countries.

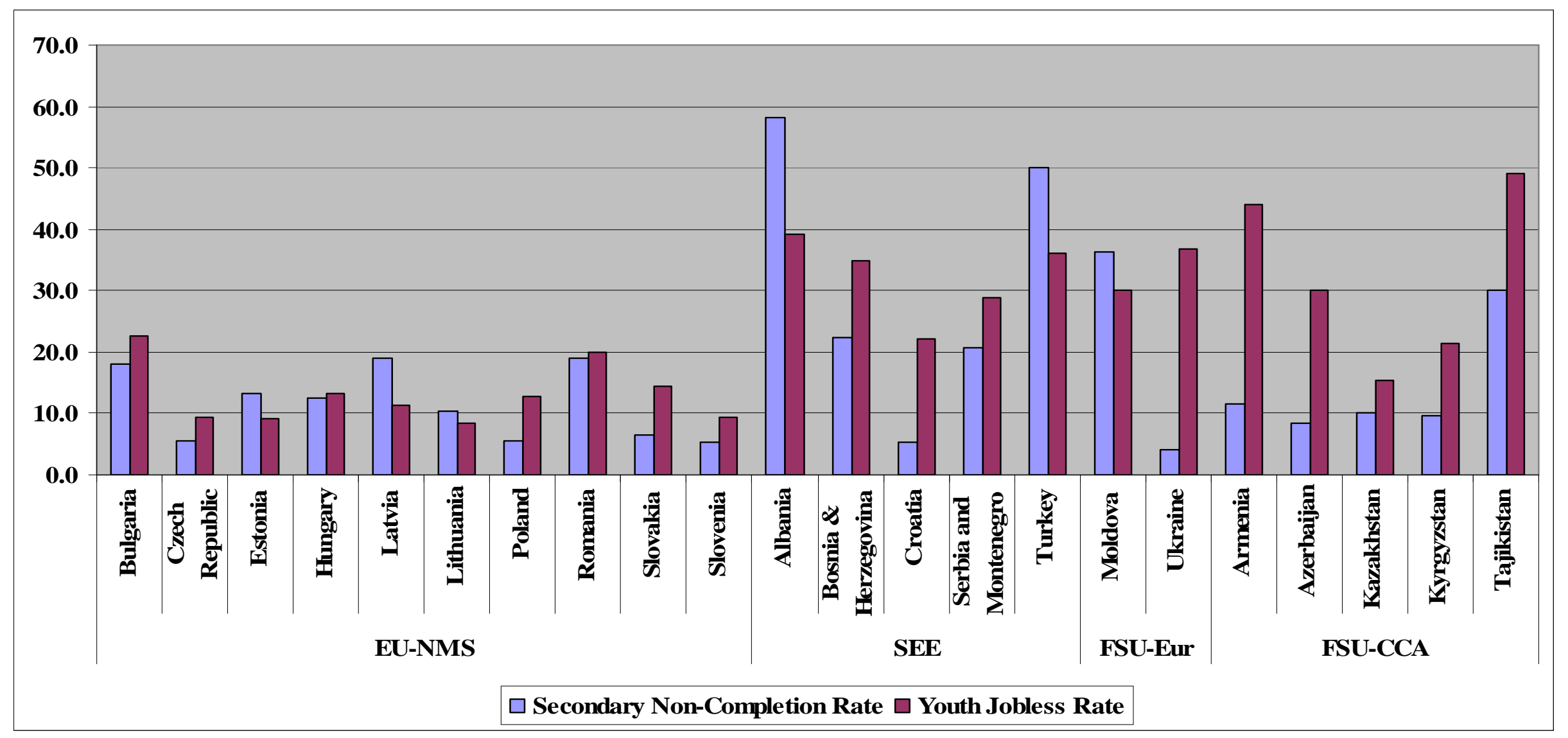

Source: Secondary non-completion - as figure 11; Youth jobless rate - as figure 18.

Note: The figure reports rates of non-completion of secondary education and youth joblessness as defined in figures 11 and 18 respectively. 
Figure 21: There appears to be a positive relation between the size of the informal sector and the extent of youth joblessness

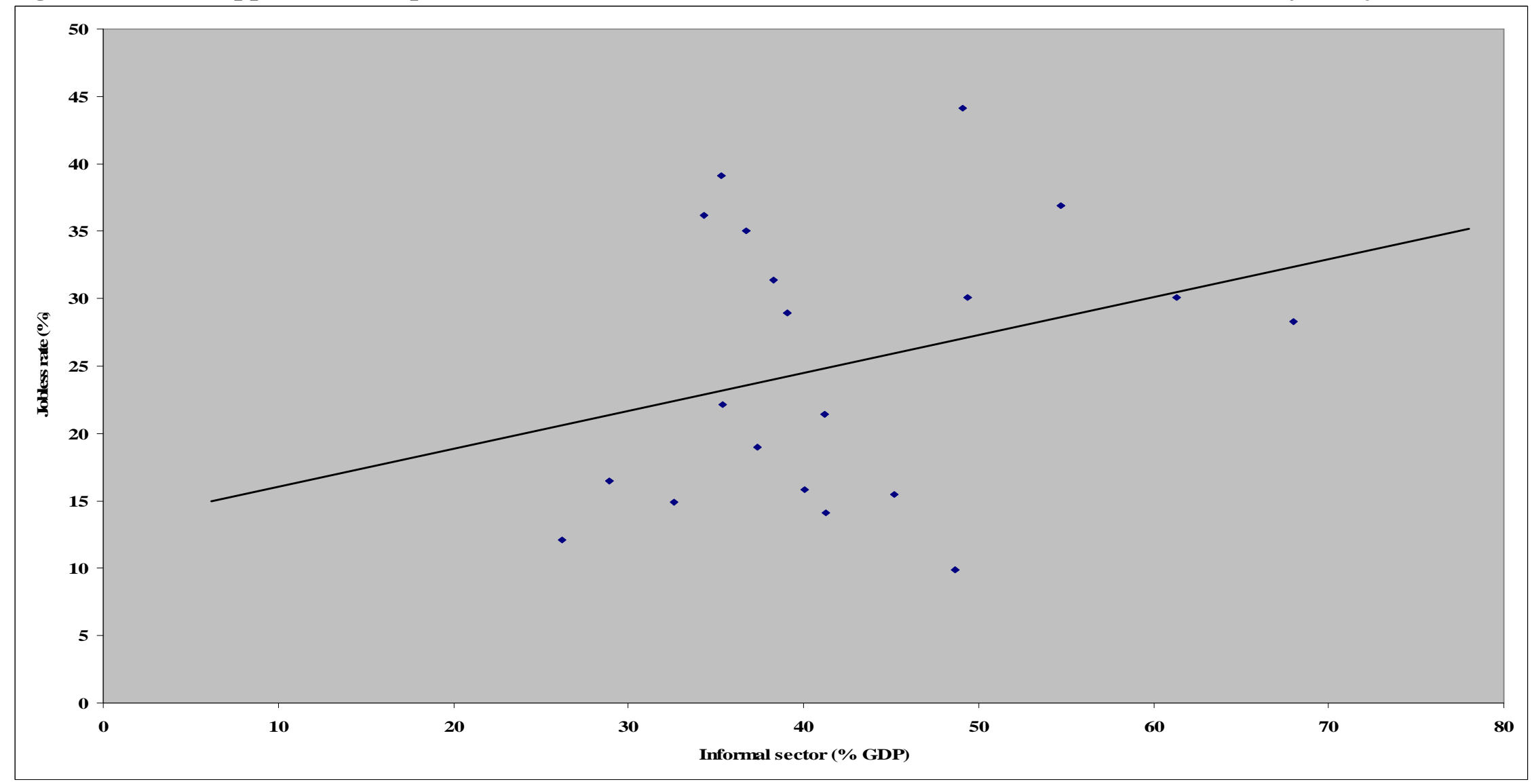

Source: Youth Joblessness - Own calculations on World Bank database of Household Surveys (2005) apart from Bosnia \& Herzegovina, own calculations on the basis of the 2006 LFS; Informal sector - Schneider (2006).

Note: The figure plots the rate of youth joblessness against the size of the informal sector (as a \% of GDP). Data for the informal sector are for 2003/4. For the jobless rates, the closest available dates to $2002 / 3$ are used. 
Figure 22: In most countries joblessness is more prevalent amongst young women

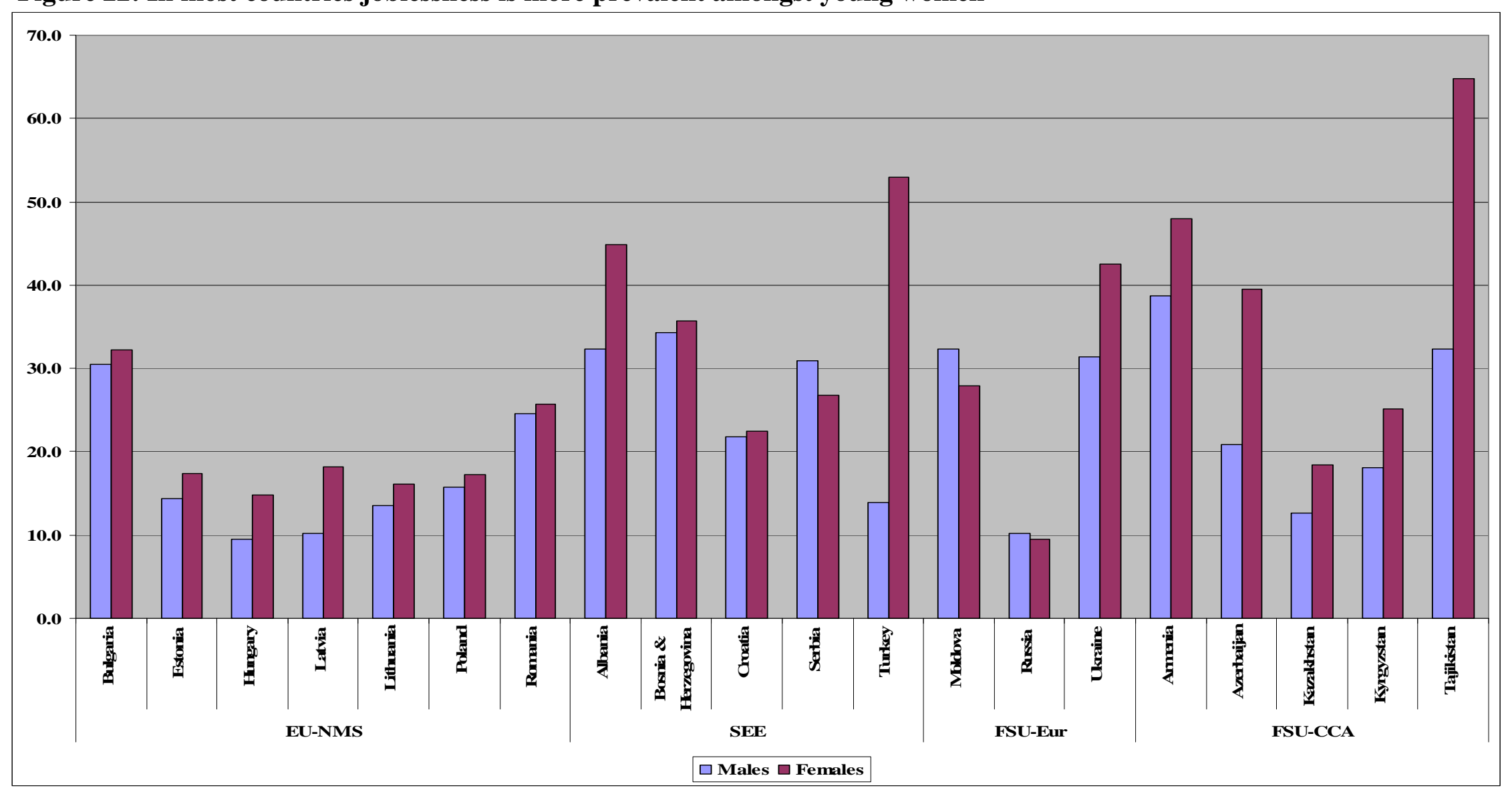

Source: Author calculations on the basis of World Bank database of household surveys and Bosnia \& Herzegovina Labour Market Survey 2006. Note: The figure reports male and female youth jobless rates for the most recent year available. 
Figure 23: and the youth jobless rate is usually higher in rural areas

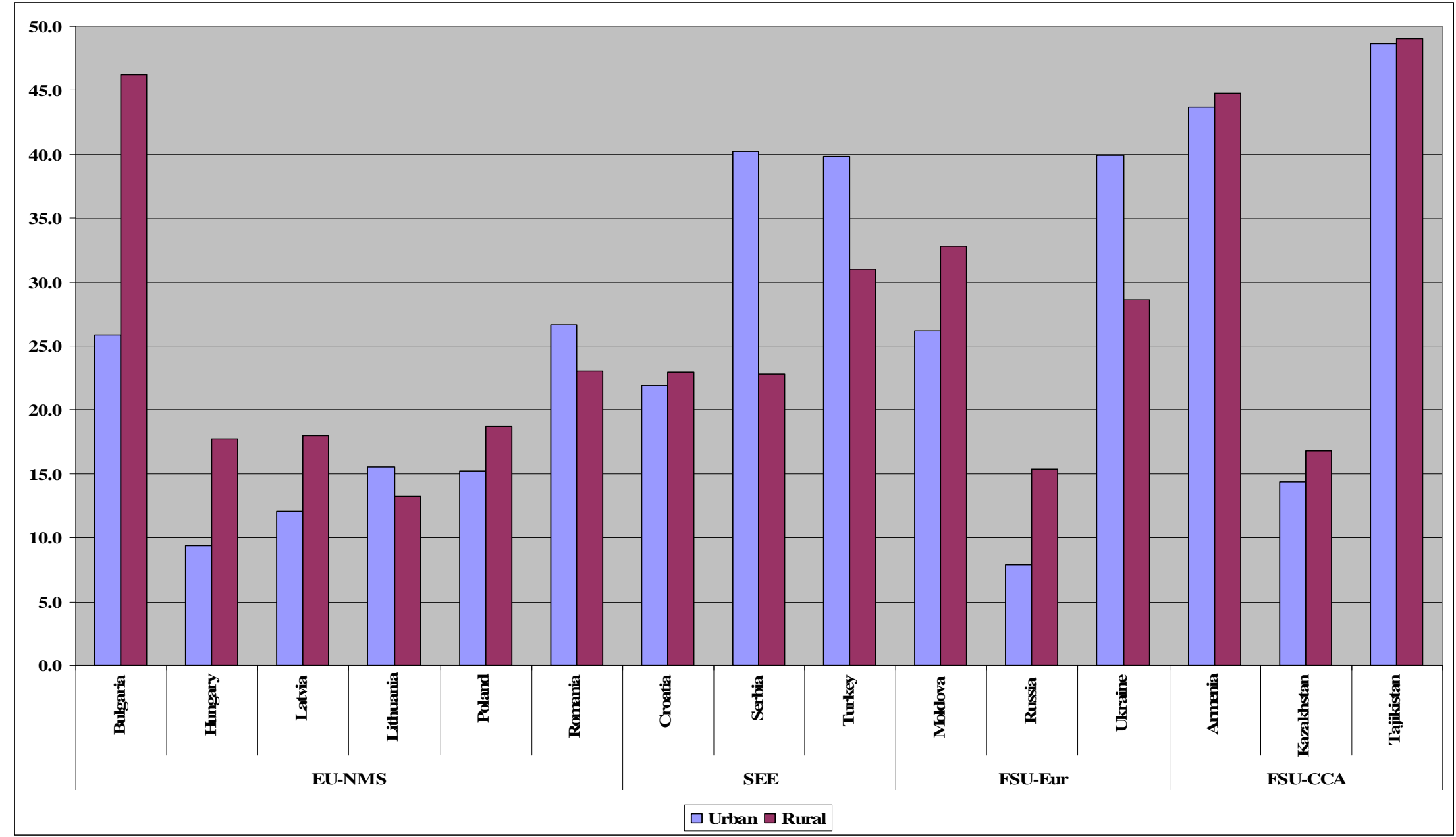

Source: Author calculations on the basis of World Bank database of household surveys.

Note: The figure reports urban and rural youth jobless rates for the most recent year available. 
Figure 24: Higher levels of education are clearly associated with lower rates of joblessness amongst young(ish) people

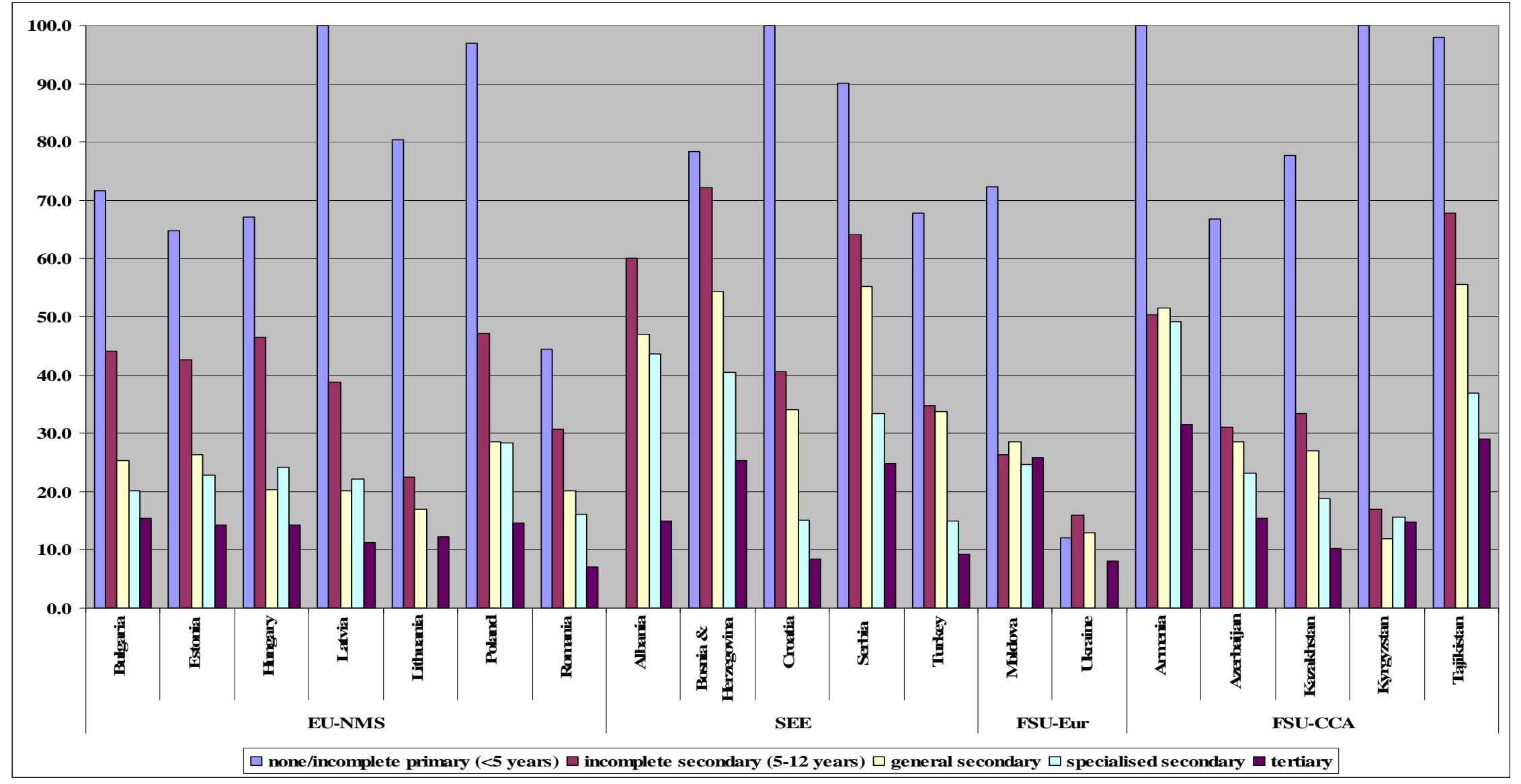

Source: Author calculations on the basis of World Bank database of household surveys.

Note: The figure reports the jobless rates by standardized level of education of young adults aged 25-34 for the most recent year available. The classification of educational level in Serbia is slightly different from other countries ( $1=$ none; $2=$ incomplete elementary; $3=$ elementary; $4=$ secondary; and, $5=$ tertiary). 
Figure 25: a similar picture emerges also for unemployment rates by education

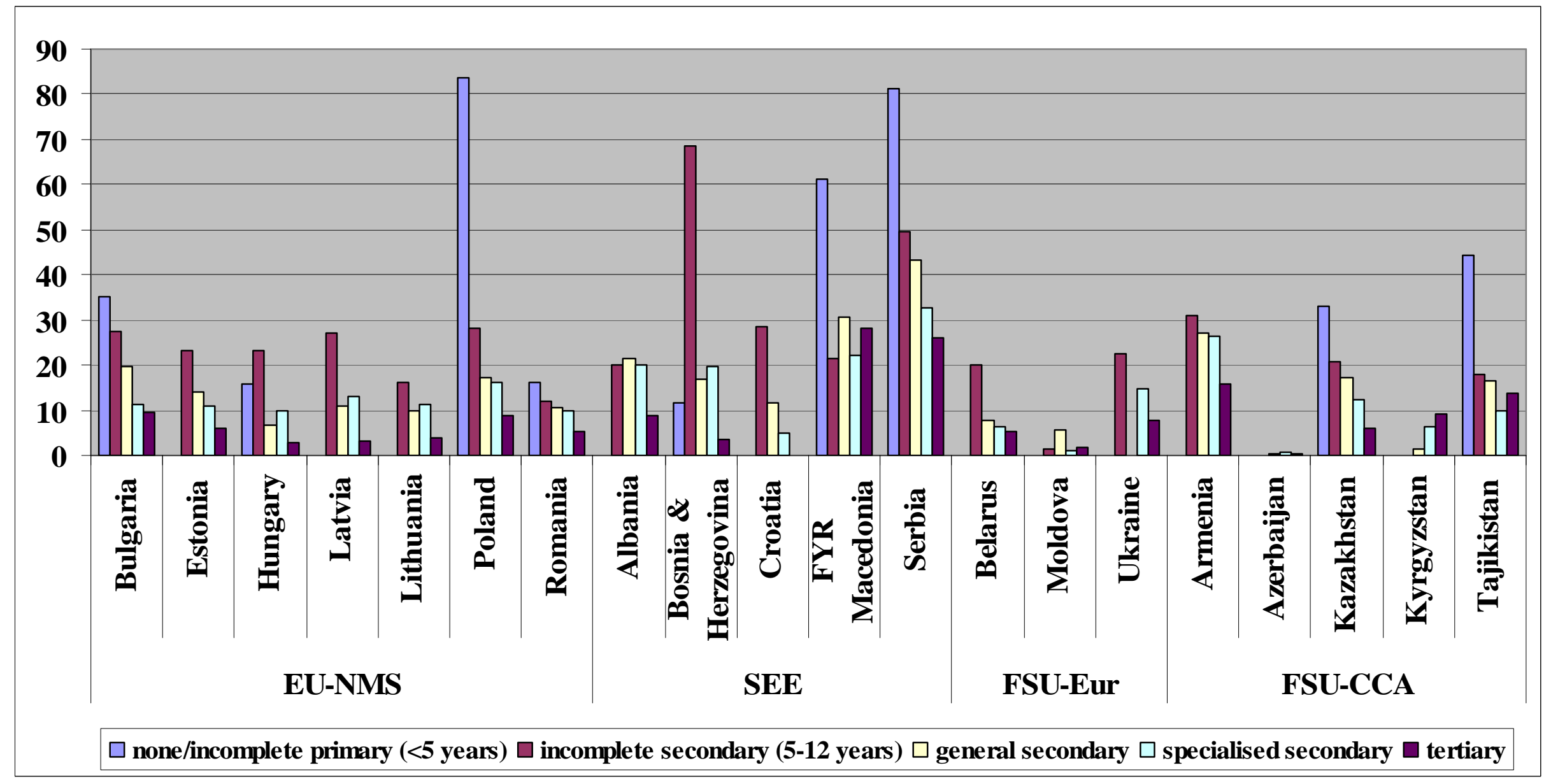

Source: Author calculations on the basis of World Bank database of household surveys.

Note: The figure reports the jobless rates by standardized level of education of young adults aged 25-34 for the most recent year available. The classification of educational level in Serbia is slightly different from other countries $(1=$ none; 2 = incomplete elementary; $3=$ elementary; $4=$ secondary; and, $5=$ tertiary $)$. 
Figure 26: The informal sector is substantial and growing throughout the region

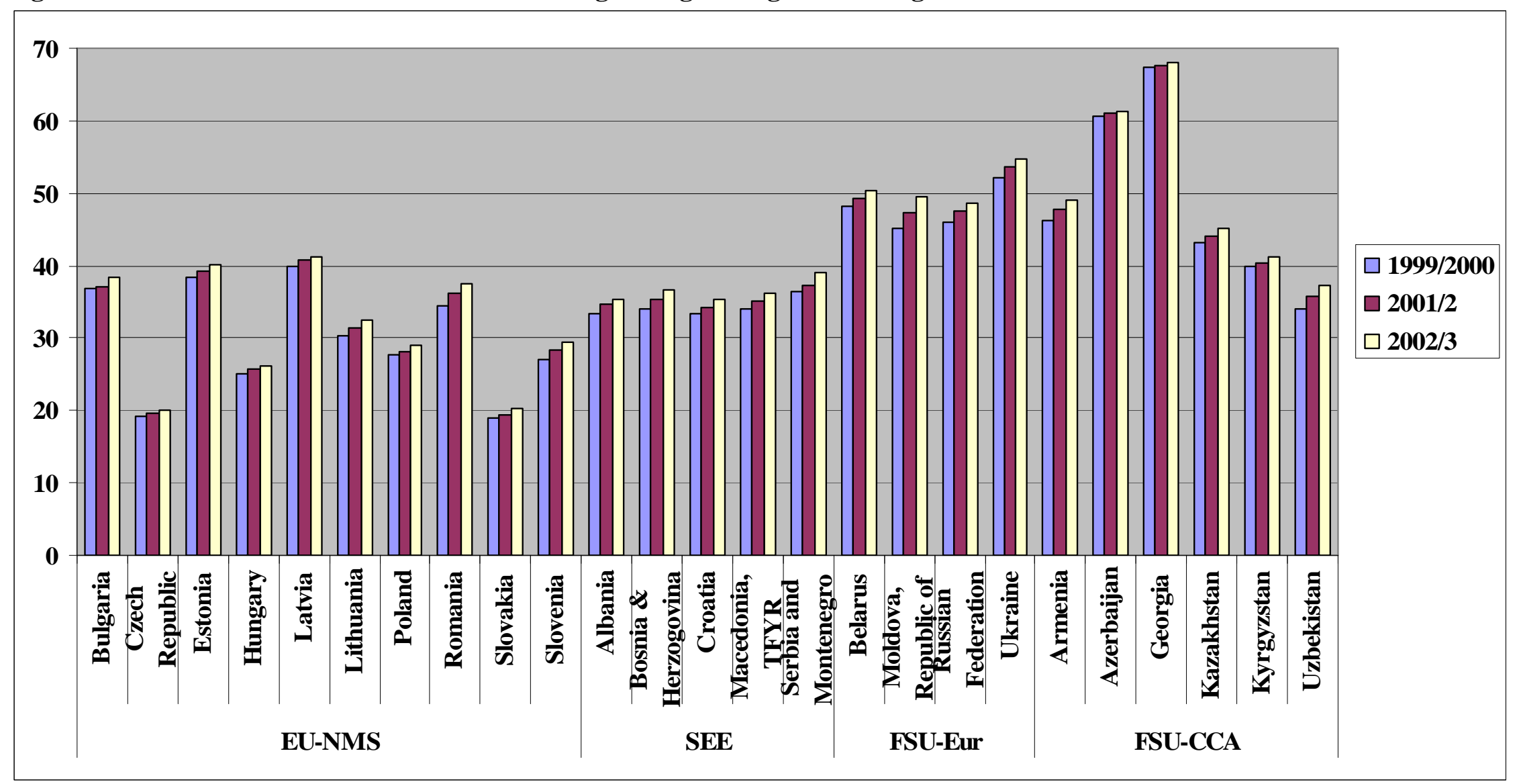

Source: data from Schneider (2006).

Note: The figure reports estimates of the size of the informal sector as a percentage of GDP 1999-2003. 